\title{
Enwheeled: Two Centuries of Wheelchair Design, from Furniture to Film
}

\author{
Penny Lynne Wolfson \\ Submitted in partial fulfillment of the \\ Requirements for the degree \\ Master of Arts in the History of the Decorative Arts and Design \\ MA Program in the History of the Decorative Arts and Design \\ Cooper-Hewitt, National Design Museum, Smithsonian Institution \\ and Parsons The New School for Design \\ 2014
}


(C) 2014

Penny Lynne Wolfson

All Rights Reserved 


\section{ENWHEELED: TWO CENTURIES OF WHEELCHAIR DESIGN, FROM FURNITURE TO FILM}

\section{TABLE OF CONTENTS}

LIST OF ILLUSTRATIONS

ACKNOWLEDGEMENTS

PREFACE

INTRODUCTION 1

CHAPTER 1. Wheelchair and User in the Nineteenth Century 31

CHAPTER 2. Twentieth-Century Wheelchair History 48

CHAPTER 3. The Wheelchair in Early Film 69

CHAPTER 4. The Wheelchair in Mid-Century Films 84

CHAPTER 5. The Later Movies: Wheelchair as Self 102

$\begin{array}{ll}\text { CONCLUSION } & 130\end{array}$

$\begin{array}{ll}\text { BIBLIOGRAPHY } & 135\end{array}$

$\begin{array}{ll}\text { FILMOGRAPHY } & 142\end{array}$

$\begin{array}{ll}\text { APPENDIX } & 144\end{array}$

$\begin{array}{ll}\text { ILLUSTRATIONS } & 150\end{array}$ 


\section{List of Illustrations}

1. Rocking armchair adapted to a wheelchair. 1810-1830. Watervliet, NY

2. Pages from the New Haven Folding Chair Co. catalog, 1879

3. "Dimension/Weight Table, "Premier" Everest and Jennings catalog, April 1972

4. Screen shot, Lucky Star (1929), Janet Gaynor and Charles Farrell

5. Man in a Wheelchair, Leon Kossoff, 1959-62. Oil paint on wood

6. Wheelchairs in history: Sarcophagus, $6^{\text {th }}$ century A.D., China; King Philip of Spain's gout chair, 1595; Stephen Farffler's hand-operated wheelchair, ca. 1655 ; and a Bath chair, England, $18^{\text {th }}$ or $19^{\text {th }}$ century

7. Wheeled invalid chair, 1825-40

8. Patent drawing for invalid locomotive chair, T.S. Minniss, 1853

9. Advertisement for $\mathrm{H}$. Thompson patent chairs, 1869

10. "Invalid couch," in Sigfried's Giedeon's Mechanization Takes Command

11. New Haven Wheelchair Co. Broadside for the 1876 Centennial

12. Rolling Wheelchair at the 1876 Centennial

13. Women in Sanitarium, 1890

14. Armory Square Hospital, Washington, DC, Mathew Brady, 1863-65

15. Two Civil War soldiers in wheelchairs, Jas Armstrong and Hiram Williams

16. Colonel Elijah Parkhurst and wife, ca. 1890, in locomotive chair

17. Nineteenth-century photographs of outdoor wheelchair use: Man on a porch in a wheelchair and photo of man in wheelchair on road

18. Petersburg, VA, Courthouse, late spring 1865

19. Advertisement for Everest and Jennings foldable wheelchair, 1947

20. George Klein in the "electric" wheelchair he designed with the National Research Council, 1953

21. Marilyn Hamilton's Quickie tennis wheelchair, 1983

22. Ad for Colson wheelchair, 1933

23. Advertisement for The Electriquette at the San Diego Exposition, 1915

24. The Rolling Quads, Berkeley, California, mid-1960s

25. Invacare Power Rolls Arrow wheelchair, 1984

26. Everest and Jennings Lightning wheelchair, 1983

27. Wheelchair pictured in Gordon's Invalid Chairs catalog, ca. 1900-1910

28. Screen shots, Charlie Chaplin and Jess Dandy in The Good for Nothing (1929)

29. Publicity still, West of Zanzibar (1928), Lon Chaney, Lionel Barrymore

30. Screen shot, West of Zanzibar (1928), Lon Chaney

31. Screen shot, Lucky Star (1929), Janet Gaynor and Charles Farrell

32. Invalid Rolling Chair, Page from New Haven Folding Chair Co. catalog, 1879

33. Fixed Rolling Chair, Gordons' Invalid Chairs catalog, ca. 1900-1910

34. Screen shots, On Borrowed Time (1939), Lionel Barrymore and Bobs Watson

35. Folding wheelchair, Colson, 1948

36. Cover of Colson catalog, 1948 
37. Poster for Interrupted Melody (1955), Eleanor Parker and Glenn Ford 38. Screen shots from The Men (1950), Marlon Brando, Teresa Wright

39. Screen shot, Whatever Happened to Baby Jane? (1962), Victor Buono, Bette Davis

40. Screen shot, The Men (1950), Marlon Brando

41. Screen shots, Interrupted Melody (1955), Eleanor Parker

42. Screen shots, Rear Window (1954), James Stewart, Grace Kelly

43. Screen shot, Come as You Are (2011), Gilles De Shrijver, Tom Audenaert, and Robrecht Vanden Thoren

44. Photo, Darius Weems (of Darius Goes West, 2007) at the Grand Canyon with friends

45. Screen shot, Aaltra (2004), Gustave de Kevern, Benôit Delépine

46. Screen shot, Murderball (2005), Mark Zupan

47. Screen shot, Born on the Fourth of July (1989), Tom Cruise, Willem Dafoe

48. Screen shot, Come as You Are (2011), Robrecht Vanden Thoren, Karl Vingenhoets $\mathrm{t}$

49. Steve Brown, Paralympian

50. Screen shot, Body of War (2007), Tomas Young and wife

51. Screen shot, Operation Last Patrol (1972), Ron Kovic

52. Screen shot, Born on the Fourth of July (1989), Tom Cruise

53. Photo, Tomas Young and Senator Robert Byrd, Washington, DC 


\section{Preface}

This thesis on wheelchairs grew out of my scholarly work in both disability and design studies. It also grew out of personal experience: As the parent of a disabled child who has become a disabled adult, I have watched with interest over the years as my son Ansel interacted with a variety of these vehicles, both manual and powered; over and over I have been struck by the intimate dance between wheelchair and user. There is no doubt that wheelchairs, especially to the uninitiated, conjure a reservoir of emotion; even a long-time user like the writer and polio survivor Leonard Kriegel regards his chair as an instigator of powerful feelings, as he recalls in his 1992 essay in The Missouri Review: "\{M\}y huge, ungainly, magnificently ugly throne on wheels" is at first an object of great love- "the way home" after a childhood bout with polio-but as Kriegel recovers the chair becomes an object of struggle and anxiety. ${ }^{1}$ I myself remember, after being told that my threeyear-old would need a wheelchair by the age of 12 , looking down the long tunnel of his childhood and seeing not light but a hard, metal prison. Yet, like a feared stranger who initially seemed to invade the household, the wheelchair soon became actual, and eventually prosaic: a treasured, lively, and fairly reliable member of the family. It was neither light nor dark, just a tool, then a necessary part of Ansel's life. Over the years, the chair has become more and more his home; he is dependent on it, yet controls it; when it is being repaired, he is disgruntled and frustrated, even when another chair is made available. With it his movement has a grace and fluency

1 “Wheelchairs," Missouri Review 15, no. 3 (Summer 1992). 
he otherwise lacks. When I see the wheelchair without him, or him without the chair, when he was recently hospitalized, for example, and I spotted it in the hallway, waiting, like a lost puppy, I felt bereft and confused. (It was a marker for him; yet where was he?) If someone touches his chair, he feels his space has been invaded. Besides holding him, the wheelchair is a receptacle for other objects and a place for others, occasionally, to catch a ride. We used to jokingly call it our mobile shopping unit because we'd hang our grocery bags on the handles to carry them home. It is nearly impossible to avoid the chair; it provides mobility but is also an encumbrance. It announces and precedes him. It is his seat in the car and often, at restaurants or the theater. It is a means of self-expression: on the back of one chair he plastered a sticker in the shape of an abstract sea creature that spelled out "gefilte fish." His latest chair, a Permobil that reclines and elevates his seat and leg rests, lets him relax in a way l've not seen before; it is a flashy neon green. It is a machine yet a part of him. It is to him, Ansel—and his indispensable wheelchair-that I dedicate this thesis.

\section{Acknowledgements}


First of all, thank you to my husband, Dr. Joseph Lurio, for putting up with me, for supporting and cajoling me, and for insisting on the completion of this thesis.

Marilyn Cohen, my steadfast and brilliant teacher and thesis advisor, introduced me to film studies and helped me through the tangles of this complex thing; I will be forever grateful to her. Sarah Lichtman has been an insightful second reader for this thesis. Other teachers, including Clive Dilnot, Barry Harwood, and Amy Sande-Friedman, helped me formulate the ideas presented here; Barry, curator of decorative arts at the Brooklyn Museum, also met with me to discuss patent furniture. Sarah Lawrence, my program advisor, has been an important mentor, as has Ethan Robey, assistant director. At the Cooper-Hewitt, National Design Library, thanks go to Elizabeth Broman, Stephen Van Dyk, and Jennifer Cohlman.

Craig Williams, senior historian at the New York State Museum in Albany, helped with Civil War research; Paul McCutcheon, librarian at the National Museum of American History, Smithsonian Institution, with trade catalogs; Douglas Platt of the Disability Museum, and the scholar David Serlin (UC, San Diego), answered questions by email. Ariana Cohen-Halberstam of the Jewish Community Center in New York made it possible for me to re-view the film Come as You Are.

My friend and colleague Tyrel Holston has been essential to the thesiswriting process, as have friends Razel Solow, Barbara Feinberg, and Elizabeth Gold, who critiqued parts of this thesis. Finally, thanks to my children, Ansel, Diana, and Toby, who had to tolerate their mother during this long, sometimes painful process. 


\section{Introduction}

In the realm of objects, chairs are, literally, king. Mihaly Csikszentmihalyi and Eugene Rochberg-Halton note the chair's special status in The Meaning of Things: Domestic Objects and the Self, first pointing to the blurring of identity of human and chair-"with its worn velvet fabric, musty smell, creaking springs, and warm support" - and going on to reiterate the strong relationship of the chair with human power: "It is difficult to imagine a king without a throne, a judge without a bench or a distinguished professor without a chair."2

Jules Prown, too, in "Style as Evidence," notes that "chairs are particularly revealing of cultural values because they so easily become human surrogates.... We use such analogies as feet, legs, back, and seat...\{I\}t is not unreasonable to speculate that aspects of an object that seem to echo the human anatomy may reflect in abstract terms the ways in which individuals...perceive themselves." ${ }^{3}$ And recently, biologists have shown that the microbial environment found on chairs is more similar to the human ecosystem than that found on any other object. ${ }^{4}$ In so many ways, humans and chairs are bound.

\footnotetext{
2 Mihaly Csikszentmihalyi and Eugene Rochberg-Halton, The Meaning of Things: Domestic Objects and the Self (Cambridge, UK: Cambridge University Press, 1981), 15.

3 Jules David Prown, "Style as Evidence," Winterthur Portfolio 15 no. 3 (Autumn 1980): 199.

${ }^{4}$ Jessica Green, director of the Biology and the Built Environment (BioBE) Center at the University of Oregon, interview with Leonard Lopate, The Leonard Lopate Show, WNYC, New York, "Please Explain: The Microbes Inside," Nov. 9. 2012.
} 
One might call wheelchairs the chairiest of chairs. For many users they are not just comfortable places to sit but are transportation, shelter, and identity. Many wheelchairists (as one writer has taken to calling them) spend the greater part of their lives in their chairs, breaking only to shower, toilet, or sleep. ${ }^{5}$ They are so dependent on their chairs that without them they cannot work, travel within or outside their homes, attend school, visit others, shop-or, in other words, engage in the myriad of activities most of us take for granted. For many if not all, their sense of self and/or identity includes their wheelchair; they may perceive the chair as their environment or personal space, as an extension of themselves or a means of selfexpression; for some, the wheelchair is completely incorporated into their body image.

The evolution of the wheelchair - from comfortable furniture for invalids to iron or steel mobility devices for war-injured veterans to high-performance vehicles for athletes--also gives expression to historical trends and events in the nineteenth and twentieth century, as well as to concepts of disability. Through the wheelchair we can trace not just our military conflicts but also the development of stronger, lighter-weight materials, the introduction of antibiotics and other life-extending therapies, the growing importance of the automobile, and cultural trends including disability activism.

Although the last few decades have seen a surfeit of literature on disability, little scholarly work has in fact been done on the wheelchair as a designed object. Herman Kamenetz's 1969 book on the wheelchair, which included a historical

${ }^{5}$ Rory Cooper estimates 16 hours a day, almost 365 days a year, in Wheelchair Selection and Configuration (New York: Demos, 1998), xiii. 
chapter, stood for several decades as the only work documenting this object's development over the centuries. ${ }^{6}$ It is now quite dated. Recently, the British researchers Nick Watson and Brian Woods have made valuable contributions with their report on the historical sociology of the wheelchair (2003), in which they emphasized the impact of disability activism on new technology: people with disabilities who demanded better chairs or simply came up with their own innovative designs. This, in turn, has bettered the lives of disabled people. Several articles stemming from that report have added to our understanding of wheelchair history, though their work is biased toward British sources. ${ }^{7}$

The life writing of physically disabled people is less rare, but surprisingly little focuses on the wheelchair itself. Much more has been written about what has been called "the illness narrative": the tale of woe and adjustment that at times attends the disability experience. ${ }^{8}$ The few who have written about their relationship with their chairs include the afore-mentioned Leonard Kreigel, the journalist and radio commentator John Hockenberry, the disability activist Simi Linton—who named her wheelchair "Rufus," anthropologist/blogger William Peace, and the wheelchair dancer Alice Sheppard. ${ }^{9}$ Their work informs this thesis. The

\footnotetext{
${ }^{6}$ Herman Kamenetz, The Wheelchair Book: Mobility for the Disabled (Springfield, IL: Charles C. Thomas, 1969).

${ }^{7}$ See list of relevant Watson and Woods publications in Bibliography.

${ }^{8}$ Arthur Kleinman is generally thought to have coined the phrase in his 1988 book The Illness Narratives: Suffering, Healing, and the Human Condition (New York: Basic Books, 1988).

${ }^{9}$ John Hockenberry, Moving Violations (New York: Hyperion, 1995); Simi Linton, My Body Politic: A Memoir (Ann Arbor: University of Michigan Press, 2007); William Peace, Bad Cripple blog, http://badcripple.blogspot.com; Alice Sheppard, "Showing
} 
engineer and wheelchair user Rory Cooper has written two helpful books about wheelchairs, but they are quite technical and have poorly reproduced illustrations. ${ }^{10}$ Gary Karp's simpler and informative books, such as Choosing a Wheelchair (1998) and Life on Wheels (2008), are geared toward the practical side of wheelchair use. ${ }^{11}$ In terms of a more metaphysical treatment, and utilizing film as a means to examine the wheelchair, Martin Norden's work on wheelchairs in the movies, including his 1993 chapter "Reel Wheels" and his masterful book The Cinema of Isolation, certainly paves the way for the second half of my thesis, on the twentieth century. But as we shall see, his primary interest is in the depiction of disability.

None of these works has used the lens of the design historian to explore what I have in this thesis: the close personal relationship between the wheelchair and its occupant, the subtle interplay between disabled human and necessary object. Exactly what is the transaction between this specialized machine and the person who uses it? Does it function as a tool, an instrument, an extension, or a part of the body? How does the user impact the chair, and vice versa? Is the wheelchair master, imprisoning its user, as implied in the phrase "wheelchair-bound"? (As Brian Woods and Nick Watson note, “Terms such as 'confined to a wheelchair'.... reinforce the

Spine," unpublished paper, presented at Center for the Study of Social Difference, Columbia University, February 9, 2012.

10 Rory Cooper, Rehabilitation Engineering Applied to Mobility and Manipulation (New York: Taylor and Francis, 1995), and Wheelchair Selection and Configuration (New York: Demos, 1998.)

${ }^{11}$ Karp's books include Choosing a Wheelchair (Sebastopol, CA: O'Reilly Media (1998); and Life on Wheels (New York: Demos Health, 2008). 
perception that wheelchair users are imprisoned by their machines"12) Or is it, as a 1970s Everest and Jennings catalog puts it, touting their improved power chair, the user's slave, able to propel him anywhere-to do his bidding-with the touch of the joystick $?^{13}$

Along with the movement away from furniture-like chairs toward more machine-like vehicles over the course of two centuries, two trends in the history of wheelchairs are particularly relevant to this study. One is the naissance of the individual chair. Previous to the invention of the Everest and Jennings foldable chair in the 1930s, many chairs were shared, like the early-nineteenth-century Shaker "community" wheelchair noted in chapter 1 (fig. 1) or those utilized by entire hospital wards rather than awarded to an individual (see chapter 2, pages 53-55). During the Second World War and after, it became standard practice to give veterans and other disabled individuals their own chairs. Secondly, wheelchairs have become more and more customized over time: We see this in the elaborate seating systems that have been developed for power chairs, and in the manufacture of lightweight athletic chairs, which are tailored to the specifications of particular sports and fit the body as closely as a shoe or glove. While it is true that in the late nineteenth century one could order several different models from the available catalogs (see, for example, pages from the New Haven Folding Chair Company, 1879 (fig.2), wheelchairs are now essentially bespoke items: in the twentieth century

12 Brian Woods and Nick Watson, "No Wheelchairs Beyond This Point," Social Policy and Society 1:4 (2005): 98.

13 "Whether it's a trip around the house or outside around the block, an amazing Power-Drive chair is its owner's slave." "Premier" catalog, Everest and Jennings, April 1972, 42. 
fitting a wheelchair to any client has become a complex undertaking. (See the chart in a 1972 Everest and Jennings catalog, fig. 3). These factors no doubt have contributed towards a new body/machine awareness. A user may well feel more of a connection to a chair literally made just for him.

\section{Defining the Wheelchair as Prosthetic}

Wheelchairs are not generally classed as prostheses; they fall into the category of orthopedic or assistive appliances, closer to worn than attached object, according to most classifications-like those of the bioethicists Courtney Campbell and her colleagues. They divide such devices into five categories: worn, attached, penetrating, implanted, and transbodied. They do not actually mention wheelchairs, but refer to worn objects as things squarely outside the corporeal body: "The least intrusive technology can be donned and doffed at will. Eyeglasses, hearing aids, false teeth, limb braces, and other assistive technologies possess a quality of easy reversibility...."14 Yet in the user's often profound dependence on the chair, and in the chair's adaptation to the user's needs and idiosyncrasies, to his actual shape and hand or eye movements, he and it are inextricably connected. The wheelchair and person have to adjust to one another, as the disability researcher Myriam Winance has said, and in the process, become one: "[T\}he aid becomes part of the body and the person.... [I\}t modifies the way the person perceives, moves, and relates to the

\footnotetext{
14 Courtney Campbell, Lauren A. Clark, David Loy, James F. Keenan, Kathleen Matthews, Terry Winograd, and Laurie Zoloth. "The Bodily Incorporation of Mechanical Devices: Ethical and Religious Issues (Part I)," Cambridge Quarterly of Healthcare Ethics 16 (2007): 229. doi:10.1017/S0963180107070259.
} 
world." 15 Wheelchair and person are linked through a common and continuous circuitry; the chair becomes literally a vehicle through which emotions and actions are carried out. ${ }^{16}$ This is how the disability scholar and paraplegic wheelchair dancer Alice Sheppard expressed it in a talk she gave at Columbia University in 2012: “Once your spine is ‘broken' you don't just freeze in two halves, one functioning, the other not. You acquire instead a new spinal anatomy. Disabled people who use assistive technologies like crutches, canes, and wheelchairs often speak of this equipment as part of our bodies. We are describing both the emotional connection and the feeling of metal, wood, and plastics becoming an essential part of the body."17

In research on patients with spinal cord injuries, Italian psychologist Mariella Pazzaglia and colleagues have also noted the seeming dissolution of the chair/human boundary. In one study they concluded: "Among all patients the regular use of a wheelchair induced the perception that the body's edges are not fixed, but are instead plastic and flexible to include the wheelchair." While a few of the paraplegics and quadriplegics they studied did view the wheelchair as simply an artificial device, many others voiced the sense of being "enwheeled," of having the corporeal boundary between the person and the machine disappear, in the process

15 Myriam Winance, "Trying Out the Wheelchair: The Mutual Shaping of People and Devices through Adjustment." Science, Technology and Human Values 31, no. 1 (January 2006): 52-72.

${ }^{16}$ The tool as part and parcel of human circuitry is Gregory Bateson's notion, as put forward in a 1971 article, "The Cybernetics of Self": A Theory of Alcoholism. Steps to an Ecology of Mind," Psychiatry 34, no. 1 (1971): 1-18.

17 "Showing Spine," (lecture, Institute for Research on Women, Gender, and Social Difference, Columbia University, New York, Feb. 9, 2012, unpublished text), 11. 
radically revising their body schema. "18 In this sense, the wheelchair is even more than a prosthetic replacing a lost or no-longer-functional body part; here one can no longer distinguish between body and appliance. ${ }^{19}$

Since I often rely in this study on the language of prosthetics, I would be remiss if I did not pause here to refer to what has become a vast body of literature on the subject. Prostheses-manufactured "replacements" for lost limbs or other body parts—have a long and complex history. ${ }^{20}$ "Prosthetic" is originally a grammatical term, meaning an addition of a letter or syllable to the beginning of a word, but by the nineteenth century was used to describe the numerous artificial devices humans had used for centuries to make themselves whole. In the twentieth century the word has taken on a much larger meaning, which often has nothing to do with the physical, replacement body parts to which "prostheses" traditionally referred. Instead the term is used metaphorically, as a trope, as in Marshall McLuhan's idea of technology as prosthesis, or even more inclusively, as any tool, as Freud would have it in Civilization and Its Discontents: "With every tool man is

18 Mariella Pazzaglia, Giulia Galli, Giorgio Scivoletto, and Marco Molinari, "A Functionally Relevant Tool for the Body Following Spinal Cord Injury," PLOS ONE 8, no. 3 (March 2013): 1. doi:10.1371/journal.pone.0058312, Pazzaglia and colleagues see this dissolution as a therapeutic opportunity. "The ability to embody new essential objects extends the potentiality of physically impaired persons and can be used for their rehabilitation." They also note a difference in the body schema of those who have upper as opposed to lower spinal cord injuries.

${ }^{19} \mathrm{Of}$ course the user of a prosthetic arm or leg may experience this as well. See Vivian Sobchack's essay "A Leg to Stand On," chapter 2, in Marquard Smith and Joanne Morra, The Prosthetic Impulse: From a Posthuman Present to a Biocultural Future (Cambridge, MA: MIT Press, 2007), 17-43.

${ }^{20}$ See Katherine Ott's introduction in Katherine Ott, Stephen Mihm, and David Serlin, ed. Artificial Parts, Practical Lives: Modern History of Prosthetics (New York: New York University Press, 2002). Kindle edition, "Introduction." 
perfecting his own organs.... Man has, as it were, become a kind of prosthetic God."21 As Marquard Smith and Joanne Morra explain in their introduction to the essay collection The Prosthetic Impulse, "Pointing to an addition, a replacement, an extension, augmentation, and an enhancement, prosthesis has become a staple in the armory of metaphors or tropes utilized by intellectuals, scholars, students, and practitioners." 22

In Freud's vision a tool or prosthetic is an enhancement through which imperfect man becomes more and more godlike, not a replacement for something missing--which may also provoke a discourse on what the normative body is, and open the door to bionic humans, cyborgs, and the endless ability to transform or better ourselves through technology; in that world biodeficient and bionic become merely points along a continuum..$^{23}$ The performance-enhancing drugs of Major League ballplayers or the Cheetah legs of the amputee Oscar Pistorius co-exist, and everyone can reimagine and reinvent himself or herself using technology.

Yet while actual prosthetic devices have been examined in the context of "prosthetic theory"-in, for example, the work of Vivian Sobchack ("A Leg to Stand

\footnotetext{
${ }^{21}$ Sigmund Freud, Civilization and Its Discontents. Standard edition, trans. and ed. James Strachey, (New York: Norton, 1961), 43.

${ }^{22}$ Marquard Smith and Joanne Morra, ed. The Prosthetic Impulse: From Posthuman Present to a Biocultural Future (Cambridge, MA: MIT Press, 2006), 2.

${ }^{23}$ See Donna Haraway's essay "A Cyborg Manifesto: Science, Technology, and Socialist-Feminism in the Late Twentieth Century," in Simians, Cyborgs and Women: The Reinvention of Nature (New York; Routledge, 1991), 149-81. Haraway ironically uses the concept of the cyborg, "a condensed image of both imagination and material reality " to expand the possibilities of feminism. The terms "biodeficient" and "bionic" were mentioned in the sense I've indicated by a Columbia Ph.D. student, Zoe Wool, during a discussion at the Future of Disabilities Studies workshop session at Barnard College, October 25, 2013.
} 
On") and Sarah Jain, or in the 2002 collection Artificial Parts, Practical Lives (edited by Katherine Ott, Stephen Mihm, and David Serlin), wheelchairs have not. ${ }^{24}$ One of the things I seek to do here is to situate wheelchairs between literal prostheses and the much larger landscape in which practically anything can be seen as prosthetic. Like Ott and Mihm, as well as Sobchack and Jain, I don't want to throw out the baby with the bathwater; metaphoric thinking is essential to this exploration. But I do want to claim the wheelchair's physical and undeniable place in this continuum, which has not previously been widely considered. While prosthetic devices like artificial arms and legs have had their day and their portion of the scholarly landscape, wheelchairs and other "appliances" have not.

\section{Methodology and Resources: Nineteenth and Twentieth Centuries}

This thesis, then, is about the special relationship of the "wheelchairist" and his/her instrument, the transaction or set of transactions that occur, as Mihaly Csikszentmihalyi might say, between object and user; or, even, as described in Mimi Hellman's “Furniture, Sociability, and the Work of Leisure in Eighteenth-Century France," their shared performance. ${ }^{25}$ For Hellman, furniture influences the bodily positions of sitters as much as the sitters influence the furniture. (See my footnote page 18.)

To study this interface, I began by looking at wheelchairs and related

24 "The Prosthetic Imagination: Enabling and Disabling the Prosthesis Trope." Science, Technology, \& Human Values 24, no. 1 (Winter 1999): 31-54. http://www.jstor.org/stable/690238.

${ }^{25}$ As described in Csikszentmihalyi and Rochberg-Halton, The Meaning of Things, chap. 7; Mimi Hellman, "Furniture, Sociability, and the Work of Leisure in Eighteenth-Century France, Eighteenth-Century Studies 32, no. 4 (1999): 415-45. 
ephemera from the early nineteenth century, soon after they first were manufactured and sold in this country. ${ }^{26}$ In the era before photography and film, the evidence of chairs consists mostly of records of trade fairs, patent drawings and descriptions, print advertising and trade cards, hospital inventories, newspaper and magazine articles, books, and wheelchair companies' catalog pictures and text. Photographs of wheelchairs begin to appear during the Civil War, and these greatly enrich our knowledge of late-nineteenth-century chairs. All of these have been consulted here to investigate how a wheelchair user might relate to his chair; how he might sit or act; what he might expect or might be expected of him by manufacturers, merchants, and the society at large; and how he actually used the chair in the built environment. Facts of materials and construction, user testimonials, sickroom instructions, and patentees' designs reveal a fount of information about the chairs, their users' or makers' thinking, and concepts of disability.

But if photographs were helpful in revealing new information about wheelchairs, movies, which came into being in the 1890s, were revolutionary. And it is on film that I focus in the second half of this thesis, because film gave new life to our understanding of objects. No one can argue with the cineastes Paul Loukides and Linda K. Fuller, writing in volume 3 of Beyond the Stars (1993), that "\{motion pictures\} offer us a unique opportunity to study the visual record of our culture and

${ }^{26}$ See Nancy Goyne Evans, Windsor Chairs: Specialized Seating, 90. 
reflect on the world caught on film." 27 In their volume on material culture, everything from weapons to automobiles to furniture and clothing is used to look at our changing culture.

In this sense wheelchairs are like other objects. We can trace their life in movies over the century and come to conclusions about our culture and its participants in different ages. As design historians, we may note the details of the iron-and-cane chairs used in early-century silent movies, the foldable chairs of The Men (1954), and the sleek sports chairs of Murderball (2004). We may examine their upholstery, their technology, and their use, which I do in the pages ahead. From these we may deduce aspects of the culture: for example, the need for a folding wheelchair in the age of the automobile, the flexibility that allowed war-time materials—steel aircraft tubing — for peacetime use in the Everest and Jennings chair; the desire for and emphasis on speed, which gave way to nimble power chairs in mid-twentieth century.

We can also sense more complex ideas, value systems, aspirations, and beliefs, some transmitted unconsciously: "American films often tell more about their times than their filmmakers consciously intended," says the film historian Peter Rollins in Hollywood as Historian. ${ }^{28}$ Wheelchairs may be particularly useful, powerfully revealing the culture's prejudices, aspirations, and beliefs about, for instance, disability, patriotism, manhood, and sexuality.

27 Paul Loukides and Linda K. Fuller, ed. The Material World in American Popular Film, vol. 3 of Beyond the Stars: Studies in American Popular Film (Bowling Green, OH, Bowling Green State University Popular Press, 1993), 2. ${ }^{28}$ Peter Rollins, Hollywood as Historian, rev. ed. (Lexington: University Press of Kentucky, 1998), Kindle edition, "Introduction." 
Martin Norden, the foremost chronicler of disability in the movies, has described how filmmakers over the twentieth century have transmitted both conscious and unconscious cultural ideas to create stereotypes of disabled characters. According to Norden, wheelchairs are rarely inconsequential players; rather, they are often used as symbolic items that telegraph societal prejudices, aspirations, and fears. In his 1994 essay "Reel Wheels: The Role of Wheelchairs in American Movies," Norden says, "Moviemakers have ascribed a wide range of qualities and functions to wheelchairs over the years, including humor, evil, helplessness, confinement, deception, heroism and dehumanization.“29 Thus, filmmakers often used wheelchairs to denote evil or comedy, pity or trickery.

In examining a series of films I have divided by era-early, mid- and late twentieth/early twenty-first-century—I have not completely sidestepped these issues. But I have turned my own camera slightly aslant: Is it possible, while keeping in mind the powerful associations of wheelchairs, that we can train our lens even more tightly on the relationship between chair and user on screen? Norden comes closest to this in "Reel Wheels" when he touches on the movie The Deer Hunter (1978):

Stevie is $\}$ is a young man who lost both legs and an arm after falling from a helicopter. A key moment in the film occurs when his hometown pal Mike (Robert de Niro) visits him in the V.A. hospital and Stevie declares that he does not want to go home. What ensues is a power struggle with the wheelchair as its object: Mike tries to push the chair while Stevie tries to anchor himself to his surroundings and

${ }^{29}$ Martin T. Norden, "Reel Wheels: The Role of Wheelchairs in American Movies," in Loukides and Fuller, Material World, 187. 
shove Mike away. Mike wins the clash of wills by the sheer strength of able-bodied force..... ${ }^{30}$

This type of interaction, where the chair becomes a fulcrum of action or emotion between characters, is of primary concern to me in this study. However, Norden's own intentions in examining this scene, revealed immediately after this passage, are slightly different from my own: He goes on to quote an article about wounded veterans by Leonard Quart and Albert Auster, in which they point out that the Stevie character in this scene is "nothing but a helpless, dependent victim." 31 In this way, Norden and other disability scholars, such as Rosemarie Garland Thompson or Cynthia Barounis, are concerned primarily with the depiction of disabled characters in movies, what Sally Chivers and Nicole Markotic have called the "projection of the problem body," an essential subject but not the subject of my thesis. ${ }^{32}$ My subject is the closeness of the wheelchair user to his machine. My own discussion about the scene I've described in the Deerhunter would not focus on who wins the battle of wills and what that presumes about the characters and how the culture perceives and depicts them. Instead I would discuss the relationship of the characters to each other vis-à-vis the wheelchair; I would not be interested in "the

\footnotetext{
30 Norden, "Reel Wheels," 197-98.

31 Norden, "Reel Wheels," 198.

32 See, for example, Rosemarie Garland Thompson, "Shape Structures Story: Fresh and Feisty Stories about Disability," Narrative 15, no. 1 (January 2007): 113-23; and Cynthia Barounis, "Cripping Heterosexuality, Queering Able-Bodiedness: Murderball, Brokeback Mountain and the Contested Masculine Body," Journal of Visual Culture 8, no. 1 (April 2009): 54-75. doi:10.1177/1470412908091938; Sally Chivers and Nicole Markotic, The Problem Body: Projecting Disability on Film (Columbus: Ohio State University Press, 2010).
} 
connotation of victimization," that Norden puts forth. ${ }^{33}$ (See, for example, my discussion in chapter 5 of the struggle between Ron Kovic and his father in Born on the Fourth of July on page 113). I am concerned with the wheelchair as the mediator of feelings, as an agent in the process. In my examination, through his interaction with the chair, the wheelchairist is not a victim; he is simply a man-or a womanand his machine is an extension of his personhood. ${ }^{34}$

I have said that film is a particularly good medium for looking at wheelchairs because it provides the opportunity to observe moving objects. But all objects can be seen anew when depicted in art; there the object can have a power it does not possess in real life. Art narrates and elucidates design not only because it documents history, but because it frames and focuses the object. Thus the pearl earring of Vermeer or the Torah scroll of Chagall are weighted, visually and emotionally, by being framed, focused, set apart. This is even truer in film, where magnification and repetition play a large part. "One of the recurring fascinations within early film theory was cinema's unique ability to animate and enliven the...material objects of our everyday world, to reveal their 'personalities' and 'faces,' even to grant them a kind of mute 'voice,"' says the blogger brookhenkel on a

${ }^{33}$ Norden, "Reel Wheels," 198.

${ }^{34}$ This does not mean I consider this thesis outside the realm of disability studies. While the thesis does not possess the expressed political or advocacy purpose of most scholarship in that field, it does articulate the experiences of disabled individuals and chronicles a history of technology used by and for people with disabilities. Thus this thesis can and should be included in "disability studies." As I stated in the preface, this work springs from my background in both disability studies and design history/material culture studies. 
website about thing theory. "In doing so, film was understood to transform the relationship between people and inanimate objects...."35

The film scholar Tom Gunning has spoken of what he calls the cinema of attraction. ${ }^{36}$ In Gunning's view, silent films did not simply or inevitably lead to talking narrative film in some sort of natural evolution; the silents were substantially different, closer to the variety and exhibitionism, implicit or explicit, of vaudeville and Coney Island amusements than to the linear stories that most later films became. Their purpose, no less sophisticated than talking narrative pictures, and possibly more-was to show. We see this in the lingering shots of people and objects in early film, even when, as in Lucky Star (1929), the film tells a story and is ostensibly a talkie. ${ }^{37}$ In that film the director frames, in the backdrop of an open doorway, the picture of his two stars facing one another, one in a wheelchair, the other in a chair of similar height; he holds the spectator's attention for an extended moment (fig. 4). And the thing-that is, the wheelchair-and the two people are all equally on show.

"Film is a medium that makes things visible," says the media historian Judith Keilbach in an article about the loss of objects during the Holocaust. "It is eminently

\footnotetext{
35 Brook Henkel, “Cine-Things: 1924," thingtheory blog, posted June 29, 2009, accessed April 2, 2014, http://thingtheory2009.wordpress.com/author/brookhenkel/.
}

36 Tom Gunning, "The Cinema of Attraction: Early Film, Its Spectators, and the Avant-Garde," Wide Angle 8, nos. 3-4 (1986): 63-70.

${ }^{37}$ Lucky Star (directed by Frank Borzage, Fox Film, 1929) had a complicated release history and was originally seen as a talkie in the U.S. but in Europe as a silent. The only remaining print, recently found in Amsterdam, is a silent film. 
suited to depict the connection between objects and emotions...." 38 She cites Bela Balazs, the Hungarian critic, who states in his classic work, Early Film Theory, that "film lends a different kind of meaning to visible objects because any difference of degree between persons and objects is minimized by pictorial representation."39 (Paintings can do this, too, in a different way, since boundaries can be blurred by tint and brushstroke. See for example, Leon Kossoff's painting Man in a Wheelchair (1959-62) (fig. 5) where wheelchair and occupant seem of one flesh.)

Wheelchairs are not just objects that can take on life; they are naturally performative objects, thus perfectly suited to examination through film. While earlier evidence provides us with valuable information about wheelchairs, film is a medium that shows physically as well as emotionally "moving"' images of the ways in which various wheelchairs have been utilized by a variety of fictional and nonfictional characters with different impairments. Since wheelchairs are mechanical objects primarily used for mobility, it is especially instructive to see them in action. We can repeatedly watch how the chairs are operated; we can witness the expression of fear, anger, hesitance, cowardice, joy, love, and alarm through the agency of the wheel or joystick; we can watch as both users and others often unconsciously accept the assimilation of the wheelchair into the corporeal

\footnotetext{
38 Judith Keilbach, "Houses, Vases, Bicycles, and Rocking Horses: 'Aryanized' Objects in the Documentaries Die Akte Joel and Marianne Heimkehr," trans. Gabriele Rahaman, Leo Baeck Institute Yearbook 57, no. 1 (2012), 295, doi: 10.1093/leobaeck/ybs014.

${ }^{39}$ Keilbach, "Vases, Bicycles," 296, Keilbach cites Belazs from Early Film Theory: Visible Man and the Spirit of Film (New York: Berghahn Books, 2010), 23, from the series Film Europa: German Cinema in an International Context.
} 
body. When this doesn't happen, on the other hand, when the wheelchair encounters the harsh reality of a curb or inaccessible environment, or when a chair breaks down, we see disjunction: machines and humans at odds.

As Hellman has demonstrated using eighteenth-century furniture, though objects are manmade, aspects of these objects force humans to perform or behave, to sit or stand, in certain ways. ${ }^{40}$ Actors playing characters in wheelchairs are as bound by this phenomenon as anyone else. Scientists have shown that when humans use tools, our brains immediately accommodate; using the tool alters the body image or "schema" — so that as soon as you use a grabber, say, your arm itself is experienced as actually being longer. ${ }^{41}$ It may be that long-term use further alters this schema, but even an actor playing the part of a wheelchaired character will almost immediately have an altered schema, a kind of self re-embodiment that he uses in maneuvering the wheelchair.

Actors in wheelchaired roles use and have used the same wheelchairs available to other wheelchairists from their eras, and many, like their real-life

\footnotetext{
${ }^{40}$ Hellman, "Furniture and Sociability," 434: It should be clear by now that objects not only provided the tools for performances of leisured sociability, but also required individuals to exercise the attributes of polite conduct that I have just summarized. Tables that were tiny, unstable, or intricately structured could only be negotiated through physical restraint and light, delicate movements.... The shapes of desk chairs, day beds, and voyeuses produced bodily positions that appeared relaxed and natural."

${ }^{41}$ Cardinali, Lucilla, Francesca Frassinetti, Claudio Brozzoli, Christian Urquizar, Alice $\mathrm{C}$ Roy, and Alessandro Farnè, "Tool Use Induces Morphological Updating of the Body Schema," Current Biology 19, no. 12 (June 23, 2009): R478, doi: 10.1016/j.cub.2009.06.048. "Using a mechanical grabber that physically extends the arm...alters[s\} the kinematics of subsequent free-hand grasping movements...."
} 
counterparts, have spent numerous hours learning to use and adapt to the chair. ${ }^{42}$ (In many cases we see this occur onscreen, as so many of the characters go through therapy and rehabilitation after an injury or illness.) In addition, several of the fictional movies (notably, The Men, filmed at a veterans hospital) utilize numerous "extras" who are genuinely disabled and can also be observed. The documentariesand there are several in chapter 5-speak for themselves, although these also reflect the biases, slants, and agendas of their makers. The documentarian is as much an artist as the maker of fictional films, designing and framing experience. ${ }^{43}$ However, documentary films reinforce the "realities" or "truths" of the fictional films that I have selected.

I have made it a point to include in this thesis, when possible, documentary footage that is similar in nature to the fictional films so that there may be a basis for comparison. I was able to view, for example, both Born on the Fourth of July (1989) as well as a documentary about Vietnam Veterans Against the War, Operation Last Patrol (1972), which includes several scenes with Ron Kovic, the character Tom Cruise depicts in Born on the Fourth of July. Come as You Are (also known as Hasta la

42 Marlon Brando, for example, spent several weeks in a veterans' hospital observing other wheelchair users and practicing his own maneuvers for his part in The Men; Joan Crawford describes spending many weekends in the chair for her role in Whatever Happened to Baby Jane?. Tom Cruise worked on and off over a period of a year to perfect his skills in Born on the Fourth of July. Peter Manso, Brando: A Biography (New York: Hyperion, 1994), 287; Joan Crawford, interview by Philip Jenkinson, BBC Movie Star Interview, Part 3 of 4, 1966. Accessed April 1, 2014, https://www.youtube.com/watch?v=xqLdB7hiHE0. Martin Norden, The Cinema of Isolation, Kindle edition, "The Road to Rehabilitation."

${ }^{43}$ Thanks to Adriana Kertzer, who made this evident to me in her e-book Favelization. (New York: Cooper-Hewitt, National Design Museum, New York: Smithsonian Institution, 2014). 
Vista, 2011), was based on a BBC documentary about the quadriplegic Asta Philpot; here, too, footage is available (although Philpot does not appear to have exactly the same disability as the character in the film.) Philpot has said in an interview that he admires the movie and finds it quite realistic. ${ }^{44}$ The (nondisabled) actors are convincing enough in their parts to have fooled officials at a Canadian film festival, who apologized because the restaurant they'd chosen wasn't wheelchairaccessible. ${ }^{45}$ In other cases, I have noted similarities between scenes or actions in fictional and documentary films.

One caveat: This is clearly not a scientific study. These are but a few selected movies from over the course of a century chosen to demonstrate one aspect of my thesis. I have tried to be representative and, as far as possible, to show what I considered to be "authentic" portrayals. "Authenticity" is of course subjective: For example, my disabled son thought that Aaltra (2004), which one might consider the least realistic and most farcical of the feature films, was the best movie he had seen about people in wheelchairs. He also identified Murderball (2004) as an important film, both personally and historically. Many of the better-known films treated here came to me by way of suggestion from others, including Rear Window (1954), Born on the Fourth of July (1989) and Whatever Happened to Baby Jane? (1962). Norden's book The Cinema of Isolation was a source for others, such as The Men (1950), which

${ }^{44}$ Asta Philpot, interview by Robert Nelson, Come as You Are BBC Premiere, June 6, 2013. http://www.youtube.com/watch?v=Pd7ITOV7E8w.

45"Robrecht Vanden Thoren and Tom Audenaert Talk to The Fan Carpet's Stefan Pape About Their New Film Come As You Are." June 7, 2013. http://www.youtube.com/watch?v=h0Ce0WPMPhM. 
included actual military veterans who were disabled, and West of Zanzibar (1928), which starred the extraordinary Lon Chaney, in a role that I thought so well acted that it defied its own strangeness and stereotyping. I looked to Norden, too, for the other silent films, though I selected some of those given accessibility. ${ }^{46}$ In including two foreign films, both Belgian, I have acknowledged the increasingly international nature of the film industry. Come As You Are (2011), for instance, which takes place in Spain, France, and Belgium, is actually based on the story of Asta Philpot, a British man who lives in Florida. I viewed it at an American film festival in New York.

One of the more striking things in studying these films is the scarcity of both women and older characters. The latter is probably true of movies in general, but it is especially noticeable in stories about wheelchairs, presumably used by larger numbers of elderly people. Lionel Barrymore was the only older character in the feature films. ${ }^{47}$ The imbalance of male to female characters is particularly noteworthy. According to the filmography compiled by Norden at the end of his "Reel Wheels" article, approximately 50 films have featured characters in wheelchairs, and perhaps only six of these featured women; published in 1993, the article doesn't include most of my "later" films. ${ }^{48}$

${ }^{46}$ Lucky Star, for example, was available on youtube, and the Fatty Arbuckle and Charlie Chaplin movies were available online as well.

47 The Intouchables, which I eliminated for other reasons-I thought the actor's relationship with the chair was completely impersonal and inauthentic-does feature an older man, by whom I mean in his forties or fifties. He does not seem to be elderly. In Rolling, both men are middle-aged.

${ }^{48}$ Although the 2011 film Musical Chairs and the TV show Push Girls first broadcast in 2013, focus on female characters-and use some disabled actors--it is too early to tell how quickly these tendencies may be changing. 
I suspect there are at least two reasons for the dearth of female characters in films with wheelchairs. First of all, the veteran with disabled war injuries is a consistent story line from Lucky Star (1929) to The Men (1950) to Born on the Fourth of July (1989) to Body of War (2007). Until recently, American women did not see combat; thus, few, if any films have been made about women soldiers and war. Perhaps this will change to reflect the new reality of women with war disablement. Second of all-and this is a more complex reason which needs more study-it may reflect a personal and societal anxiety over male sexual organs, impotence, and castration, not felt to be entirely transferable to women, in whom sexuality is perceived as a more complex phenomenon. This may also be because men have controlled the film industry; for whatever reason, the sexuality/loss of sexuality by women seems to be a much less discussed topic in mainstream film and literature.

\section{Evolution and Structure of Thesis}

This thesis had its start as a term paper for a film class taught by Marilyn Cohen in the spring of 2011; asked to write about any aspect of design and film, I chose as my subject the wheelchair as material object, and focused on four midtwentieth-century movies: The Men (1950), Whatever Happened to Baby Jane? (1962), Interrupted Melody (1955), and Rear Window (1954). I had read the work of Csikszentmihalyi and Halton-Rochberg many years before, but was reintroduced to The Meaning of Things in that class. Their ideas, which utilize object-relations theory as well as sociological methods to understand our transactions with things, are significant in this thesis, as is my understanding of actor-network theory (ANT), which I first came across in the work of Myriam Winance. In ANT, "actants," objects 
and people equally, engage in a constant process of making and doing. ${ }^{49} \mathrm{In}$ "Thinking the Poetics of Things," a class taught by Clive Dilnot in the spring of 2012, I had the liberty to further explore some of the observations I had made about wheelchairs and users. Some of this material, particularly about prosthetic theory, is presented in the introductory chapter, but informs much of the thesis in more invisible ways. In Amy Sande-Friedman's class on material culture, I was influenced by readings from the French Annales school, particularly Marc Bloch, and utilized various methodologies, including those of Csikszentmihalyi, Hellman, and Ruth Schwartz Cowan, for my final paper on American wheelchair history. It was then I began to construct what is now my first chapter on the nineteenth-century wheelchair. In reading about early film, I came across "thing theory," which gives primacy to objects, exploring how the material environment affects people. Thing theory is described by its inventor Bill Brown thus: "[T\}he inanimate object world helps to form and transform human beings alike.... How does our material environment shape us?"50 Some of these ideas became important to me in looking at the wheelchair in film.

In her book History and Material Culture, Karen Harvey discusses the distinction Bernard Herman makes between object-centered and object-driven studies. "Object-centered" is further broken down into two parts, the second being Prown's art historical method of description/deduction/and speculation where,

\footnotetext{
${ }^{49}$ See Bruno Latour, Reassembling the Social: An Introduction to Actor-Network Theory, New York: University Press, 2005) http://dss-edit.com/plu/Latour_Reassembling.pdf.

${ }^{50}$ From the video "The Nature of Things," Big Think, posted March 30, 2010, accessed February 3, 2014. http://bigthink.com/videos/the-nature-of-things.
} 
Harvey notes, "the focus moves from the object to what we might regard as the emotional or psychological dimensions of material culture." My own research has been necessarily more object-driven than object-centered; I was not, for example, able to personally interact with the vast majority of the wheelchairs to observe their nuanced shapes, to feel how they moved-which a strictly Prownian approach would necessitate. Nevertheless, Prown has been important in shaping many of my ideas about material culture. As Harvey observes, though Prown's approach is object-centered, it sits at the junction between the two concepts: His "method edges towards what Herman calls an object-directed approach," says Harvey, which "regard $\{\mathrm{s}\}$ objects as evidence of other complex social relationships. ${ }^{51}$ I think Prown's influence shows in my thesis, particularly, in chapter 1 , in my discussion of nineteenth-century chairs. There, basing my ideas on the construction of and the improvements in wheelchairs - their new, self-propelling mechanisms, for example, their new, steel elliptical springs-I speculate about the interaction of chairs and users and on the possible cultural implications. I hope I have used the "creative imaginings" that he encourages. ${ }^{52}$ What may be more important than dividing this territory is material culture's general acknowledgement, as Harvey notes, of the active quality of objects. As she says, in differentiating things from most of the other resources used by historians, "objects are actual and autonomous, not reflective."53 This attention to the specialness of objects has been important to this thesis.

\footnotetext{
${ }^{51}$ Karen Harvey, History and Material Culture: A Student's Guide to Approaching Alternative Sources (New York and London: Routledge, 2009), 18.

52 Cited in Harvey, History and Material Culture, 18.

53 Harvey, History and Material Culture, 19.
} 


\section{Films and Chairs}

I have extended my earlier study of film and wheelchairs to include five early films, from 1914 to the 1930s, and six others, from the 1980s to the present. I watched many others, including Rolling, a documentary aired on PBS, in which three wheelchair users train a camera on their daily lives, and Musical Chairs, a 2011 feature film about wheelchair dancing. I included these two because they show women in wheelchairs, a group not often depicted. (Because of this, and because wheelchair terminology already complicates syntax, I made the decision to generally use "he"' and "him" and "man" in this thesis.) Although I focus on feature films, my research encompassed a variety of other material, including selected video, newsreels, government training films, and television sources. I occasionally refer to these in the text when they are relevant. They are all documented in a filmography at the end.

Initially, I thought of wheelchairs as a single class of objects. But as I began to study their history, especially the differentiation that occurred in the twentieth century, I saw that the human/machine interaction, though undoubtedly existing in each iteration, differed according to type of chair: manual, power, or lightweight athletic. The early chairs shown in the silent films were generally of one type, such as that seen in the Chaplin film The Good for Nothing (1914): rigid-frame chairs with a tall back, often made of rattan or cane, with oversized spoked front wheels and a single caster wheel in back (see fig. 27). These do differ slightly as far as width and height, but in construction they seem similar. They might have been made or distributed by any number of companies at the time, including Gendron, Colson, or 
Gordon. In all the mid-twentieth century movies in chapter 4-The Men (1954) Interrupted Melody (1955), Whatever Happened to Baby Jane? (1962), and Rear Window (1954)—characters use what seem to be foldable manual chairs, most probably made by Everest and Jennings, which at the time had a near-monopoly of such chairs in the United States. (See fig. 19.) These self-propelling chairs of steel tubing are of a simple construction, consisting of a seat, two large rear wheels, two small front casters, and two footrests. A cross brace lines up when folded and forms an X when open. (In the case of Rear Window, it is possible that Stewart's chair does not fold and is simply a "depot chair," the type used in an institution, since he is only temporarily impaired; he doesn't tend to propel himself, and his broken leg is supported by one raised, split foot rest.)

The chairs seen in the later films reflect the changes in technology since the 1950s, and vary widely in composition and construction. They include folding and rigid-frame chairs, sportschairs, power chairs, and one scooter. This was a period of much innovation in wheelchair design and materials, and the films represent a broad swath, appearing as they do over a period of more than sixty years. It is not possible to identify the make, model, or manufacturer of these chairs in most cases. Some characters, like "l'employé" in Aaltra (2004)—Benoît Delépine is the actorutilize both manual and power vehicles over the course of the film..$^{54}$ Darius Weems (in Darius Goes West, 2007) uses a power chair and, when that breaks down, a manual chair pushed by others. Other movies feature several characters, each of whom use different chairs, like Lars (manual folding) and Philip (power) in Come as

${ }^{54}$ In Aaltra the two characters are dubbed simply "l'employé" and "l'ouvrier agricole." 
You Are. In Born on the Fourth of July Tom Cruise uses a manual, foldable chair-it is the exception, being labeled and easily identifiable as an Everest and Jennings chair-and in Murderball the chairs are highly specialized rigid-frame manual machines specifically made for "quad" rugby.

I expected when I began this work to simply include a brief history of wheelchairs, drawn largely from secondary sources, but it became apparent quickly that no such comprehensive narrative existed about the wheelchair in America. In addition, it became clear that the relationship of wheelchair to user in the twentieth century could not be understood without understanding the nineteenth. The section on the nineteenth century, therefore, was expanded, and includes material I gleaned from archives, museum exhibitions, trade catalogs, magazines, advertising, and literature of the various periods. ${ }^{55}$

Chapter 1 of this thesis, therefore, is a history of the wheelchair in nineteenth-century America, telling the story of the wheelchair from trade fairs to patent furniture makers to post-Civil War manufacturers, from the development of "locomotive" chairs, through the "comfort seating" of mid-century, the needs of the countless wounded veterans following the War Between the States, and finally, to the sanitariums of J. H. Kellogg and others. It includes a discussion of do-it-yourself

55 The portion covering the nineteenth century was delivered, in somewhat revised form, as a talk at Design and Mobility: The Twenty-Second Annual Parsons/CooperHewitt Graduate Student Symposium, April 27, 2013; at the Future of Disability Studies working group, Center for Social Difference, Columbia University, October 25, 2013; and as part of a panel of graduate students at the Victorian Society, New York, February 11, 2014. A response to the talk at Columbia from the wheelchair user/inventor, anthropologist, and blogger William Peace is included in the Appendix of this thesis. 
versions and written accolades from wheelchair users who ordered their chairs from the leading commercial makers. ${ }^{56}$ In this chapter I address the user/wheelchair interface as far as possible. I made use of collections at the Smithsonian's National Museum of American History in Washington, DC, the New York Public Library, the Thomas J. Watson Library at the Metropolitan Museum of Art, the Otis Historical Archives of the National Museum of Health and Medicine; the New York State Library and Museum in Albany; Columbia University's Health Sciences and Avery libraries, the library of the New York Academy of Medicine; and such online sources as the Disability History Museum and archive.org.

In chapter 2, I have included an introduction on twentieth-century chairs, divided, in a rough chronology, into three principal types: folding manual chairs, as developed by Everest and Jennings in the 1930s; motorized chairs, as pioneered by the Canadian scientist George Klein at the end of World War II; and the ultralightweight, rigid frame chairs such as the Quickie, inspired by the paraplegic athlete Marilyn Hamilton in the late 1970s. I have put the rigid frames in one section but in reality rigid-frame chairs have become two overlapping categories: highperformance athletic chairs and chairs for everyday use, as I will explain. Many other types of chairs exist, like scooters, standing chairs, chairs that climb steps, beach chairs, and walker-type conveyances, but I have left these aside for the time being.

56 Most of this comes from the catalogs of the New Haven Chair Co., established 1863. It is possible these were written solely as promotional material, generated by the companies. I have chosen to take these at face value, as actual comments from consumers. At any rate, they show a forward-looking view of wheelchair users as independent, mobile people. 
In chapter 3, 4, and 5, I concentrate on wheelchairs in film. Aside from watching numerous commercial movies on DVD and on Netflix, I obtained and viewed videos on and public television; tapes made for the Independent Living Center, available online and at the Bancroft Library at the University of California, Berkeley; government footage from a number of federal agencies and vintage newsreels from the Motion Pictures section of the National Archives and Records Administration at College Park, MD. ${ }^{57}$ But at least a century of American wheelchairs precedes the advent of film, and it is there I begin, in the early years of the nineteenth century.

57 The Jewish Community Center on the upper West Side of New York also allowed me to re-view the movie Come As You Are, which I had originally seen as part of their Reelabilities Film Festival. 


\section{Chapter 1. Wheelchair and User in the Nineteenth Century}

"Alexander Stephens...is one of the most powerful figures in the United States Senate, and when the wheeled chair and its occupant are missed from the accustomed place, among the first questions asked is 'Where is Stephens?'”

'The Exercises of the Evening High School," Brooklyn Eagle, Feb. 21, 1880

In his 1969 The Wheelchair Book: Mobility for the Disabled, Herman Kamenetz recounts the history of the wheelchair: a sarcophagus engraving from sixth-century China, King Philip of Spain's gout chair from the 1590s, the German paraplegic Stephen Farffler's ingenious vehicle of the seventeenth century, and the Bath chairs of the English spa town. (See fig. 6.) He dates the beginning of the wheelchair in America to the War Between the States: "[T\}here is no report of the use of wheelchairs before the time of the Civil War, when they appeared for sick and wounded soldiers." ${ }^{58}$ But in fact we have evidence that a variety of wheelchairs were manufactured and retailed in America at least a half-century before the Civil War.

As Nancy Goyne Evans writes in her 1996 volume Windsor Chairs: Specialized Seating, wheelchairs were known in this country at least from the late 1700s; and by the first quarter of the next century cabinetmakers like Abraham McDonough of Philadelphia and J.C. Hubbard of Boston produced wheeled invalid chairs. ${ }^{59} \mathrm{~A}$

\footnotetext{
${ }^{58}$ Springfield, IL: Charles C. Thomas, 30. Many blogs and web sites take this as a given. See for example, the "Civil War RX," http://civilwarrx.blogspot.com/2013/04/civil-war-wheelchairs.html: "The Civil War is the first recorded instance of wheelchair use in America."
} 
Windsor wheelchair, pictured in her book (fig. 7), is displayed at the Pennsylvania Farm Museum in Lancaster, and is from about 1840. High-backed, with the requisite slats, it seems to be adapted from a household chair-note that it has all four legs. It is painted mustard yellow with black penciling, and its single wooden wheels are rimmed with iron. The tacks in the arms show they were once stuffed, Evans notes, and its rather large, slanted footboard was once attached by straps. Another chair from the period, dated 1825-40 (fig. 1), is a maple-wood "community" wheelchair, with a caned seat and oval finials, exhibited at the Shaker village in Watervliet, New York; it is the group's adaptation of a ladder-back rocking chair, its rockers still in place. Several chairs with wheels are mentioned at trade fairs of the 1830s and 40s: In 1834, at the Seventh Annual Fair of the American Institute at Niblo's Garden in New York, a J. C. Jenekes showed a "carriage chair for an invalid," described as "a very ingenious contrivance by which sick persons are able to move themselves around from room to room, and also alter their position of sitting." 60

Another conveyance, by James Grey of Brooklyn, at the First Annual Fair of the New York Mechanics Institute, was a "mahogany chair of compact size....[WITH A ] mechanism by which the person moves it with either hand."61 And at the exhibitions and fairs of the Massachusetts Charitable Mechanic Association in 1839 and 1847, I. C. Hubbard and Charles Howe, respectively, displayed "locomotive

${ }^{59}$ Nancy Goyne Evans, Windsor Chairs: Specialized Seating (New York: Hudson Hills, 1997, 90-92.

60 "Seventh Annual Fair of the American Institute Held at Niblo's Garden," in Mechanics Magazine 4, no. 4 (October 1834): 245.

61 "Fair of the American Institute," Mechanics Magazine and Journal of the Mechanics Institute, vol. 6, no. 5 (Jan. 1, 1835). 
invalid chairs." 62

None of these was patented, but in 1853 a chair invented by Thomas Minniss, of Meadville, Pa, was (fig. 8). Minniss showed his locomotive chair at New York's Crystal Palace the same year and received this review in Horace Greeley's Art and Industry in the Exhibition: “\{The) locomotive chair... is a model machine.... With a slight effort of one hand, the poor invalid can propel himself in doors and out, turning the shortest corners with ease, going back or forward, upon smooth surfaces, absolutely without labor. Then in one minute he can change it from a selfpropeller to a little wagon, to be drawn by an assistant."63

Also on display at the exhibition were the wares of the furniture maker M W King \& Sons. Matthew King, who established his business on lower Broadway in Manhattan in 1833, had patented a swivel chair and sold a number of other types of seating, including a wheeled invalid chair. In an 1857 text advertisement in the Rockland County Courier, King \& Sons "invite an examination of their great variety and superior assortment of CHAIRS, manufactured at their own establishment, including Pivot Revolving Chairs, Self-Acting Extension Recumbent Chairs, Improved Invalid Wheel Chairs... for the luxury of the Sick, the Aged, the Infirm, the Lame, and Lazy."64

Manufacturers often took the design for a patented reclining chair and just

62 "Second Exhibition of the Massachusetts Charitable Mechanics Association at Quincy Hall in the City of Boston" (Sept. 23, 1839):18; and "Fifth Exhibition, at Faneuil and Quincy Hall" (Sept. 1847):129.

${ }^{63}$ Horace Greeley, Art and Industry of the Crystal Palace (New York: Redfield, 1853), 314.

${ }^{64}$ Rockland County Journal, no.52 (April 25, 1857): 1, news.hrvh.org. 
added wheels, as $\mathrm{H}$. Thompson apparently did for its recumbent chair, using one of the designs inherited from King, from whom they took over the business in the 1860s or 70s. An advertisement shows both nearly identical chairs (fig. 9).

The fact that wheelchairs were largely the province of patent furniture makers may seem odd. 65 But the mid-nineteenth century was an age that prized comfort, adaptability, and mobility; it was also, as Sigfried Giedeon puts it in his classic Mechanization Takes Command, a time when the furniture maker took his cues from the "technics of the engineer."66 Moreover, Giedeon notes, the posture of the nineteenth century—halfway between lying and sitting—was derived directly from sickroom furniture. ${ }^{67}$ Invalid couches and sofas invented in Europe evolved into the American "variety couch" or invalid chair (fig. 10), capable of elevating head or feet or maintaining a number of positions. Reclining furniture, like that of George Wilson or the Marks Adjustable Folding Chair Co. popular through the 1890s, often had castors or wheels for portability; both companies also manufactured wheelchairs per se, with large wheels for transport. Indeed, so closely associated were patent and invalid chairs that, in a 2008 article in the Journal of Design History,

65 "Patent furniture" was the nineteenth-century term for seating, tables, beds, etc., that was newly invented and patented because of novel or innovative technology. Popular in Victorian-age America, such furniture was based on notions of health, posture, comfort, and mobility and often involved adjustments made by the user.

${ }^{66}$ Sigfried Giedeon, Mechanization Takes Command (New York: Oxford University Press), 1948, 420, caption.

${ }^{67}$ See especially "The Constituent Furniture of the Nineteenth Century," 389-422, in Giedeon, Mechanization. 
Jennifer Pynt and Joy Higgs even go so far to say that "patent seating fell into disfavor with the public because of its connotation of infirmity."68

One of the most important wheelchair makers in the U.S. was the New Haven Chair Co., which started life in 1863 as the New Haven Folding Chair Co. and initially made only a rather elegant range of collapsible seats. But by 1871 New Haven also showed one model of rolling chair; and it is interesting to see, in a broadside from the 1876 centennial displaying the company's stock, how the wheelchair, with its slightly reclining high back and up-slanting footboard, blends in (fig. 11). ${ }^{69}$ In 1878, Isaac Dann and Dan Kelsey patented an improved wheelchair, which New Haven manufactured. ${ }^{70}$ The object of the invention was "to provide.... springs as well as to make the adjustment of the chair more convenient for the occupant." By the 1890s, advertisement for the New Haven Chair Co. highlighted its "invalid furniture": " an 1895 ad in the Century Illustrated magazine mentions reclining chairs, but also bidets and commodes, which seems to indicate a permanent change in direction. ${ }^{71}$ An 1890 New Haven catalog shows 22 models of wheelchair as well as two reclining couches with wheels. ${ }^{72}$

${ }^{68}$ Jennifer Pynt and Joy Griggs, "Nineteenth-Century Patent Seating: Too Comfortable to be Moral?" Journal of Design History 21, no. 3 (September 1, 2008): 285.

${ }^{69}$ New Haven Folding Chair Co., 1876, Connecticut History Online, Broadsides, http://www.cthistoryonline.org/cdm/singleitem/collection/cho/id/726/rec/1.

${ }^{70}$ Isaac Dann and Dan Kelsey, "Improvement in Chairs," U.S. Patent 205,059, June 18, 1878.

${ }^{71}$ The Century 49, nos. 1-6 (Nov. 1894-April 1895): 1085.

72 New Haven, Folding Chair Co., Price List of Invalid Folding Chairs (New Haven, CT: The Company, 1890). http://archive.org/details/pricelistofinval00newh. 
The centennial of 1876 in Philadelphia featured another innovation: special wheeled chairs available for rent, supplied by the Smith Rolling Chair Co. They were utilized not just by fair-goers who didn't wish to walk but also by those who couldn't -like a man disabled by a bad leg (see fig. 12). Herbert Smith was the patentee; after the exposition his company continued to make these rolling chairs, which, unlike earlier ones, had no caster in back but had two small wheels in front, which allowed them to be lifted over curbs. However, they did need to be pushed by another person. Smith's company continued to manufacture and advertise these chairs till at least $1891 .^{73}$

The interest in health foods, hygiene, and fresh air, which led to the opening of invalid hotels and spas mid-century, and later, the emergence of TB sanitariums, supplied a growing market for wheelchairs: In a picture c. 1890, seven women sit in a semicircle in wheelchairs in an outdoor arcade, attendants at the ready despite the fact these are self-propelling chairs with hand rims (fig. 13). As early as 1879 the physician J. H. Kellogg, inventor of breakfast cereal and director of the Battle Creek Sanitarium, wrote to the New Haven Chair Co. expressing his satisfaction with the first wheelchairs his institution had received. ${ }^{74}$ By 1889 Battle Creek had at least thirty wheelchairs from the company and was ordering five more.

Some disabled people and family members have always fashioned their own wheelchairs, and nineteenth-century America was no exception. Home inventors could find any number of suggestions for DIY chairs. The maker of the Crystal Palace

${ }^{73}$ Advertisement in Century Illustrated Magazine 41, no. 5 (March 1891): 36.

${ }^{74}$ New Haven, Price List, 47. 
locomotive chair, Thomas Minniss, proposed making use of "a common chair mounted on its back end with two plain hind wheels $\{$ which $\}$ would afford a cheap and effective perambulator for the affected poor, who will perhaps oftener need assistance...."75 In her 1865 Domestic Receipt Book, Catherine Beecher proposes jury-rigging a rocking chair to create an invalid chair; she describes

a contrivance for securing exercise in the open air for invalids,... Such an article can easily be made of the broken toy of a child, called a velocipede, or the back wheels of a child's wagon. Nothing but shafts are needed, and a common rocking-chair, with a foot-board nailed across...." 76

A Scientific American article discusses an 1883 patent for a wheelchair by M. J. Koenig of Jersey Shore, Pennsylvania: His "improved attachment for chairs will convert an ordinary chair into an invalid chair which can easily be moved about. ${ }^{77}$

Writing in 1865, Beecher may have been directing her ideas at a new audience: the families of wounded Civil War veterans. At least half a million Confederate and Union men were wounded, and nearly 60,000 amputations were performed by surgeons of both armies; about a third were amputations of the leg. ${ }^{78}$ The majority of these men survived, and some of them may have used wheelchairs. As we have seen, there were wheelchairs available. Yet there is little direct proof of their use. I have found only three photos of single soldiers in wheelchairs during the

${ }^{75}$ T.S. Minniss, “Invalid Locomotive Chair,” U. S. Patent 9708, May 10, 1853.

${ }^{76}$ Catherine Beecher, Domestic Receipt Book (New York: Harper, 1850, 1846), 216.

77 Scientific American 48, no. 20. (May 19, 1883): 312.

78 Statistics from "Maimed Men," U.S. National Library of Medicine. History of Medicine, accessed October 11, 2013. http://www.nlm.nih.gov/exhibition/lifeandlimb/maimedmen.html. 
conflict - this after combing web sites, museums, and libraries-and one was the often-replicated picture by Mathew Brady of Armory Hospital, Washington, DC, from 1865 (fig. 14). The two others (fig. 15) appear among those taken by the army surgeon R. B. Bontecou at Harewood Hospital, Washington, DC, some of which were part of a 2013 exhibition at the Metropolitan Museum of Art in New York. ${ }^{79}$

Hiram Williams was injured at the battle of Appomattox Courthouse, and is shown awaiting an artificial limb. The other soldier, the Confederate Jas Armstrong of South Carolina, suffered a gunshot wound to the right leg, at Petersburg, VA. The two chairs they use look similar but may not be identical; they seem to be made from Windsor chairs and may have been cobbled together on-site; they have large carriage-type wheels and a large footboard.

There are also photographs from the decades after the war of two highly decorated officers seated in wheelchairs. One is General Daniel Sickles. At Gettysburg Sickles was wounded, and his right leg was amputated-he apparently visited the amputated leg once a year thereafter — and he used a wheelchair or crutches to get around. Two of these chairs seem to be the type seen at the centennial, with two front wheels, and a handle in back pushed by an attendant, without hand rims (fig. 12). They resemble any number of reed, willow, or rattan

79 From the collection of Dr. Stanley Burns. Reed Bontecou was an army surgeon who documented and memorialized, through hundreds of photos, men with newly amputated limbs and other war injuries. According to the introduction to Shooting Soldiers (New York: Burns Archive Press, 2011) a collection of his work, "he was responsible for pioneering and taking the largest number of photographs of wounded soldiers during the war...., 6; "Photography and the American Civil War," Metropolitan Museum of Art, New York, NY, April 2-September 2, 2013. 
examples from catalogs of the 1870s on. He was also photographed in a selfpropelling chair.

Colonel Elijah Parkhurst, pictured with his wife in an undated photo c. 1890 (fig.16) was wounded at Lynnville, Tennessee, during his second term of service; his left leg was hit by cannon fire and later amputated, as was, eventually, his other leg, due to blood poisoning. Parkhurst's chair, which was of a later vintage, probably the 1890s, was self-propelled, a "locomotive" chair with hand cranks which had more in common with the bicycle than with either patent furniture or medical appliances. In fact, in 1890 Peter Gendron of Toledo invented a wire wheel which he originally used for bicycles, wagons, and baby carriages, but which he also applied to invalid chairs; later his company switched entirely over to wheelchair manufacture. Gendron is now the oldest continuously operated wheelchair company in the United States.

One of the few mentions of soldiers in wheelchairs during the war comes from a New York Times article dated June 26, 1864. Titled "Our Military Hospitals," the piece seems to point toward a distinction between regular soldiers, who "hobble about with cane and crutch," and officers: At the Armory Square Hospital in Washington, DC, the anonymous author says, "Lieutenants, Captains, Majors, and others, who have shed their blood and lost their limbs in the service of their country, may be seen on their snow-white beds, and in wheeled chairs, or at their tables reading and writing, killing time-all that is left for them to kill, since the war is 
ended. “80 It doesn’t say so explicitly, but this might mean that only officers were granted wheelchairs as a special privilege, or that their own families had provided them.

Wheelchairs may not be mentioned often, but artificial limbs are, for good reason. ${ }^{81}$ Both the Union and the Confederacy issued prostheses of all kinds to wounded and disfigured men — noses and ears as well as limbs-yet, as far as I can tell, never similarly gave out wheelchairs. Why this privileging of artificial limbs over wheelchairs by the government?

David Serlin, an expert on prostheses and co-author of Artificial Parts, Practical Lives, proposed in an email that "limbs, especially by makers like Hanger \{founded by the Confederate James Hanger, whose leg had been amputated $\}$ and $\{$ A. A.\} Marks \{of New York\} were pretty state-of-the-art technologies in the 1870s. While wheelchairs could be made by any number of artisans--coach makers, furniture makers, blacksmiths, etc.-and could be purchased second hand or even handmade at home," Serlin continues, "the art of the prosthetist and limb maker were such that the government might have recognized the rarity of those devices over the relative ease with which one could purchase or even build a wheelchair."

${ }^{80}$ New York Times, “Our Military Hospitals," June 26, 1864. http://www.nytimes.com/1865/07/02/news/our-military-hospitals-a-glance-attheir-organization-and-work.html.

${ }^{81}$ Other than a list of supplies from the Bath (New York) Home for Soldiers in 1902, which listed four wheelchairs for a population of 250, I have uncovered little else about wheelchairs even tangentially relating to the Civil War. Part of this may be the difficulty of the research itself: Several layers of hospitals and other institutions were created for soldiers during and after the war; combing through records of the U.S. Sanitary Commission, plus federal and state homes from both the union and the confederacy, is a complex and titanic undertaking, of which, I fear, I have only scratched the surface. 
This may have seemed, he remarks, like a more respectful or committed response to veterans. ${ }^{82}$

Other reasons proposed by the British researchers Nick Watson and Brian Woods, as well as the French philosopher and historian Henri-Jacques Stiker, reflect contemporary attitudes towards disability, which in some ways, as others have said, paralleled the idea of patching up the union of states after the war. ${ }^{83}$ "The nineteenth century discourse of rehabilitation situated disability as a lack to be filled by medical correction and technology," Stiker writes in his 1997 History of Disability. ${ }^{84}$ As Woods and Watson note in their 2008 article "The Social and Technological History of the Wheelchair," there was "the assumption that with a prosthesis you could replace or augment what had been lost." 85 On the other hand, they continue, wheelchairs "denoted failure and ran counter to a wider ideology which deemed it the duty of disabled people to adjust themselves to society." 86 Since soldiers had to buy their own wheelchairs, cost was almost certainly a consideration. In 1863, a fully disabled Union soldier's pension was only $\$ 8$ a month—officers got as much as $\$ 30$--and although pensions rose through the

82 Personal communication, April 4, 2013.

${ }^{83}$ See, for example, Lennard Davis, in "Stumped by Genes: Lingua Gataca, DNA and Prosthesis" in Smith and Morra, The Prosthetic Impulse.

${ }^{84}$ Henry-Jacques Stiker, trans. William Sayers, $A$ History of Disability (Ann Arbor: University of Michigan Press, 1999), xii.

85 Brian Woods and Nick Watson, "The Social and Technological History of Wheelchairs," International Journal of Therapy and Rehabilitation 11, no. 9 (September 2004): 407.

86 Woods and Watson, "Social and Technological History," 407-08. 
following decades, by 1900 the average disabled Union veteran still might receive only $\$ 12$ or $\$ 13$ a month. Confederate veterans received far less, just $\$ 3$ or $\$ 4$ a month. ${ }^{87}$ The cheapest, most basic wheelchair in the New Haven Folding Chair Co. catalog of 1879-the first year for which I have figures—made completely of oak, including wheels, with no hand rims and incapable of reclining, cost $\$ 16$, and most were far more expensive. ${ }^{88} \mathrm{An}$ upholstered chair with hand rims and caned back and seat cost between $\$ 34$ and $\$ 42$; if made of black walnut, $\$ 45$. But these seem to be on the low end. An 1873 piece in Scribner's - which may have had a relatively wealthy readership—prices a chair at $\$ 50$ to $\$ 150$ for "ordinary styles." Their recommended chair cost $\$ 125$, and prices went up to $\$ 350$ for one made-to-order. ${ }^{89}$

Can we assume that this was a century that moved invalids and "cripples" as some nineteenth century Americans might have said-towards greater independence and mobility, from the sick room into the street? Certainly it was a century that prized movement, from the locomotive to the barber's chair to the velocipede. But did this extend to ill and/or disabled people? Aspects of the chairs themselves-hand rims, springs, and cranks, and the improvements in wheels, from all wood to iron-rimmed to bicycle-style rubber-would certainly have us think so. The copy in advertising and catalogs also promotes or takes for granted the self-

${ }^{87}$ From Peter Blanck and Chan Song, "Never Forget What They Did Here: Civil War Pensions for Gettysburg Army Veterans and Disability in Nineteenth-Century America," William and Mary Law Review 44, no. 3. http://scholarship.law.wm.edu/wmlr/vol44/iss3/5.

${ }^{88}$ New Haven Folding Chair Co., Seventeenth Annual Illustrated Catalogue and Price List (New Haven: The Company, 1879).

89 "Furniture for the Sick Room," Scribner's Monthly 5, no. 4 (February 1873), 510. 
sufficiency of wheelchair users, from changing their own position to changing their scenery. The attitude of these texts is relentlessly optimistic and forward-looking. And there were role models: Several important figures, including Civil War bigwigs as well as politicians-like the former Confederate vice-president, congressman, and governor of Georgia Alexander Stephens; General Dan Sickles; and Colonel Elijah Parkhurst—appeared in public in wheelchairs, some self-propelling. And rolling chairs made a splash at the Centennial, blurring boundaries between the able-bodied and the disabled.

Twentieth-century scholars have their doubts—“\{The wheelchair’s) primary function of mobility was limited, even under the best conditions," says Nancy Goyne Evans-but the wheelchair companies of the day seemed at pains to assure patrons of a smoother, easier ride and of their own independence. ${ }^{90}$ Drawings show dignified-looking, well-dressed ladies and gentlemen in both indoor and outdoor clothing, comporting themselves in private and public. The Sharp and Smith Catalog of Surgical Instruments and Deformity Apparatus of 1889 makes the modest claim that its self-propelling invalid chair, a locomotive-style vehicle, "will work comparatively well on a sandy or rough road (and) when ascending a moderate incline" and advertises that its chairs are made with connections of malleable iron, steel axles, and "welded oval tires." 91 The earlier, 1879, Seventeenth Annual New Haven catalog is even more confident: "The Invalid Rolling Chair has added Steel

90 Evans, Windsor Chairs, 90.

${ }^{91}$ Sharp and Smith Catalog of Surgical Instruments and Deformity Apparatus (Chicago, IL: Blakely Printing Co., 1889), 793, 794. 
Elliptic Springs placed between the seat and gear, thus preventing the jar caused by rolling over uneven ground and making it very desirable for outdoor use."92

Certainly the testimonials in the New Haven catalog of both 1879 and 1890 underline the idea that disabled wheelchair occupants were using them indoors and out, for work, pleasure, and travel. As early as 1877 the company was apparently in receipt of a letter from a George Tyrrell of New Haven who stated: "I have used no other chair for the past two years, and am able to roll myself around in all parts of the city, without assistance." ${ }^{93}$ Mr. H. E. Jackson writes colorfully from Walpole, Massachusetts: "With the aid of the Chair I can go around and take care of forty hens, and raise 100 chickens each season; can also run from my house to the postoffice, which is one half-mile. Without the Chair I would be confined to my room."94 Another, a John Tate from Louisville, Kentucky, asked "to know the price of a pair of wheels for \{the $\# 24$ chair. I have been using one for almost eight years and find it as you recommend. I travel over two miles in it every day." ${ }^{95}$ Others speak of foreign or domestic travel, getting around Chicago, New York, and Cleveland.

Yet Woods and Watson insist that "few wheelchairs facilitated independent mobility outdoors.... \{T\}he...assumption was that the user would be housebound or institutionalized. Nearly all occupant-propelled wheelchairs...had the propelling wheels...at the front and the castor/s at the rear, best suited for indoor use," they point out. "Once outdoors... front-propelling wheels were useless. The rear castor/s

\footnotetext{
${ }^{92}$ New Haven, Seventeenth Annual, "Invalid Reclining Rolling Chair," 4.
}

93 New Haven, Seventeenth Annual, 16.

94 New Haven, Price List, 48.

${ }^{95}$ New Haven, Price List, 47. 
made it impossible to tip and balance these types of wheelchair, which prevented progress up kerbs [sic] or up/down steps." ${ }^{96}$

Still, nineteenth-century photos do record outdoor use, including a man on his ramped porch, and another who is taking a ride on a country road. (See fig. 17). Advertising and catalog testimonials are only that, projected wishes and possibly invented stories. But it is worth considering that present-day scholars may be looking at this issue through a modern lens. In the post-Civil War age people rode in carriages, often not on paved streets; they were not used to the cushioned automobile rides we now enjoy. A somewhat rough ride in a wheelchair may not have been different from a ride in another type of transport—jarring and uncomfortable, perhaps, but not unexpected.

As for the difficulty of getting and up and down curbs: This is still a problem for wheelchairs users in many locales, who nevertheless negotiate their chairs outdoors and in. It may in fact have been easier in the nineteenth century, as a Civil War photograph of Petersburg, VA, seems to demonstrate (fig.18): As you can see, the pavement slopes down toward the street at corners and the distance between sidewalk and street in general is quite small. The writer on a web site (http://jeanhuets.com/"Leaves of Grass") displaying the photos says that "the crossing, made of granite slabs, and the ramped transition from sidewalk to street are not to accommodate the handicapped, but rather for handcarts and

${ }^{96}$ Woods and Watson, A Historical Sociology of the Wheelchair: Full Report, 13. 
wheelbarrows." ${ }^{\prime 97}$ In that nineteenth-century world, where such wheeled conveyances were often used, and where the bumps and jolts of sandy and stony roads were the norm, it may have been easier to use a wheelchair outdoors than it is now.

The development of the wheelchair in the nineteenth century was not as event-driven as we may have thought; the Civil War may not have played as direct a role as implied by previous histories. The patent furniture movement, the centennial, the growth of sanitariums and hospitals, and the development of the bicycle all played their parts. While many did not have their own conveyances and relied on the few wheelchairs kept by institutions, others made or bought their own from the many new companies like New Haven or Smith. Whether moving themselves or being moved by others, they all forged relationships with these machines. Pynt and Griggs have observed that in the nineteenth century, "interaction with furniture were not considered to be refined"; we can only guess at the intimacies thus implied between a person and a wheelchair, which demands constant touch and adjustment. ${ }^{98}$ As we shall see in the chapters to come, in the twentieth century and the era of film, this close relationship of person and chair becomes more apparent.

${ }^{97}$ Jean Huets, Leaves of Grass, posted April 27, 2012, accessed April 2, 2014, http://jeanhuets.com/19th-century-streetscapes-petersburg-virginia/ 98 Jennifer Pynt and Joy Griggs, A History of Seating, 3000 B.C. to 2000 A.D.: Function Versus Aesthetics (London: Cambria Press, 2010), 201. 


\section{Chapter 2. Twentieth-Century Wheelchair History}

Thus far we have spoken of wheelchairs as an entity, one group of like objects. But in the twentieth century, at least three different types of wheelchairs emerged, each of which created a unique user-machine relationship. ${ }^{99}$ These included the flexible, foldable chair introduced by Everest and Jennings in 1933 (fig.19); the motorized chair with joystick pioneered by George Klein and the

${ }^{99}$ For a more detailed history of the wheelchair-albeit with a British slant-see Brian Woods and Nick Watson, "A Historical Sociology of the Wheelchair: ESRC Full Research Report," L218252007. Swindon, UK: ESRC, March 10, 2005), as well as an article based on the report, "The Social and Technological History of Wheelchairs," International Journal of Therapy and Rehabilitation 11, no. 9 (September 2004): 40710. For an article that focuses on motorized chairs, see Watson and Woods, "A Short History of Powered Wheelchairs," Assistive Technology 15, no. 2 (August 2003): 16480. For more on the importance of the Everest and Jennings chair, see Mary Tremblay, "Going Back to Civvy Street: A Historical Account of the Impact of the Everest and Jennings Wheelchair for Canadian World War II Veterans with Spinal Cord Injury," Disability and Society 11, no. 2 (July 1, 2010): 149-70, doi:10.1080/09687599650023209. The article has at least one egregious errorshe confuses the identities of Everest and Jennings-but is otherwise an important contribution. 
Canadian National Research Council in the 1950s (fig. 20); and Marilyn Hamilton's sports wheelchair, the Quickie, from 1979, which heralded a generation of superlightweight athletic chairs (fig. 21). ${ }^{100}$ One might arguably add to this Dean Kamen's end-of-the-century invention, the iBot, a chair that could climb stairs and jump curbs, and raise and lower the user, all based on a sophisticated system of gyroscopes, as well as wheelchairs that are voice- or breath-activated. ${ }^{101}$ But I will keep to the three major groupings outlined above.

\section{The Rise of Everest and Jennings: The Transportable Chair}

By 1899 more than a dozen companies across the country produced wheelchairs, including New Haven Chair in Connecticut, W. D. Allison in Indianapolis, J. S. Ford in Chicago, Milwaukee Chair, and A. A. Marks in New York. 102

${ }^{100}$ Dates vary for the $\mathrm{E}$ and $\mathrm{J}$ chair. The two invented the chair sometime between 1927, when they met, and 1932, the year they established their company. The year 1933 may have been when the first wheelchair rolled off the line. Their first patent was not filed until 1936. For the story of the Klein chair, see Richard I. BourgeoisDoyle, "The First Wheelchairs for Quadriplegics," in George Klein: The Great Inventor, chap.7, 161-84 (Toronto: NRC Research Press, 2004). For a history and discussion of the impact of the Quickie, see "The Screaming Neon Wheelchair," chap. 7 in Joseph Shapiro, No Pity: People with Disabilities Forging a New Civil Rights Movement (New York: Random House, Times Books, 1993).

101 The iBot, manufactured by Johnson and Johnson, was discontinued after six years because of its high price tag-about $\$ 24,000$ - and the decision by the Centers for Medicare and Medicaid Services not to reimburse disabled buyers for the cost. A throat microphone picks up the vibrations of the vocal cords, or a headset microphone can be used. ("Voice Activated Power Wheelchairs and Other Devices for Quadriplegics," www.katavalox.com.) "Sip n' Puff" drive control systems allow users to direct their chairs with their breath. Some severely disabled users have head-control devices ("Power Wheelchair Drive Controls" http://mobilitybasics.ca//wheelchairs/drivecontrols.php), and even thoughtcontrolled wheelchairs are in the works. http://disinfo.com/2011/02/wheelchaircontrolled-by-brain-signals-and-prosthetics-that-feel/. All of these bring up different ideas about the relationship of body to machine. 
Some of these, like New Haven, had begun as furniture companies; others, like Marks, provided a variety of orthopedic apparatus including artificial limbs, crutches, and wheelchairs. Still others, like Gendron in Toledo, Ohio, primarily made baby carriages and bicycles, but also produced rolling chairs, utilizing some of the same materials and parts.

The wheelchairs made by these companies varied, as we have seen in the preceding chapter; many were pushed by attendants, but many others were selfpropelled; some were attractively covered in upholstery or wicker or reed. Some had reclining mechanisms, or articulated leg rests that could accommodate a broken limb. Rubber "cushion" wheels had been added to some, after the pneumatic and then the detachable tire were invented late in the nineteenth century. Some had coil springs, to protect the user from hard knocks or ruts in the road. Some could be propelled by the occupant using levers and cranks. There were both three-wheeled and four-wheeled vehicles. But all were rigid-frame, unwieldy affairs, constructed of wood and/or steel castings, whose manufacturers, by and large, emphasized "comfort, strength, durability, and finish."103 For example, the early-century Gordon's catalog says that “Our chairs...are made by skilled and experienced reed and wood workers, and... are not only artistic in design but perfect in the

102 See Seeger and Guernsey's Cyclopedia of Manufactures and Products of the United States (New York (?): U.S. Industrial Publishing Co., 1899), 141. There may have been considerably more companies making wheelchairs. "Invalid" and "invalid rolling chairs" make up two separate but overlapping lists; but wheelchair manufacturers such as the Gendron company and possibly others classified in other categories were omitted here. Gendron was listed as a maker of wheelbarrows, doll carriages, children's velocipedes, tricycles, and rattan furniture, although the company was producing wheelchairs by the 1890 s.

${ }^{103}$ From an advertisement for the Go-Lightly Rolling Chair Manufactury, The Century 30 (new series), no. 52, May-October 1896, 1000. 
proportion, shape and fit to the body...." It goes on: "All oak chairs are finished in golden oak, rubbed and polished, the finest quality of varnish being used."104 Even after World War I, and into the twenties and thirties, wheelchair companies continued to make similar chairs (See ad for Colson company, 1933, fig.22).

Collapsible, lighter-weight chairs were invented earlier in the century: The first, by Chester Hockney, was patented in 1907.105 Another, reported in Scientific American in 1914, was the joint endeavor of two fathers with disabled daughters. 106 A third was E. B. Green's “folding wheel-chair," patented in 1916.107 But there is no evidence that any of these was ever manufactured beyond a single prototype. It was the Everest and Jennings chair that made history—and it took several decades to make it.

The invention came about as many wheelchairs have: through the creative initiative of a disabled person. Herbert Everest, an engineer, had broken his back in a mining accident in 1918 , and as a result was rendered paraplegic. ${ }^{108}$ Frustrated with the heavy wooden chair he used, he proposed to his friend and fellow engineer

104 Gordon's Invalids' Chairs Catalogue (Toledo, OH: Gordon Manufacturing Co. ca. 1900-1910), 4.

105 Chester L. Hockney, “Wheel-Chair,” U.S. Patent 909411, filed November 25, 1907.

106 I have been unable to find a patent for this chair; the story appeared in the January 17, 1914, issue and was entitled "A Folding Wheel-Chair." According to the author, the chair "rolls up somewhat like a bolt of cloth."

107 Edward B. Green, "Folding Wheel-Chair,” U.S. Patent 1206106, filed February 4, 1916. The invention is described as "a stanch trundle chair, collapsible at will to fold within narrow compass for easy storage in car or closet, as may often times be necessary." It is interesting that the automobile/wheelchair interface is already included.

108 Watson and Woods say 1919 in A Historical Sociology: Full Report, 14. 
Harry Jennings that they invent something better. In 1932, they designed a simpler, easier-to-propel, collapsible chair made of steel aircraft tubing; it had a folding cross brace and a fabric back ${ }^{109}$ (fig. 19). Though the 1936 patent indicates four small wheels of equal size, later versions reverted to large rear wheels "to accommodate the passage...over bumps or depressions in a road or other surface on which the vehicle is used.... One of the objects of this flexible construction is to maintain both driving wheels always in contact with the floor or ground and thus enable the occupant of the chair to propel it."110 Maneuverability, transportability, and the independence of the user were thus paramount. The E and J chair was also about half the weight of earlier folding chairs, about 35 pounds, allowing, say, a paraplegic with upper-body strength to fold and stow the wheelchair himself. ${ }^{111}$ (This in and of itself is a fascinating reversal of independence/dependence of person/object.) $)^{112}$ The two engineers established a small company in Los Angeles, which would, in time, take up three city blocks and come to dominate the market in the United States and Canada for many years.

Like many inventors, Everest and Jennings had to wait for the culture around

${ }^{109}$ Herbert Everest and Harry Jennings, “Wheel Chair," U.S. Patent 2,095,411, filed February 11, 1936.

${ }^{110}$ Herbert Everest and Harry Jennings, U.S. Patent US 2095411 A, October 12, 1937.

111 The chair highlighted in the 1914 Scientific American article weighed 70 pounds- "not any more," the anonymous author remarked," than the noncollapsible article."

${ }^{112} \mathrm{~A}$ friend once told me he had watched an athletic-looking man in a wheelchair approach the stairs to a New York subway station; and then stop, get up out of the chair, load it onto his back, and descend the stairs on his rump. 
them to catch up with their idea. It was only in the aftermath of World War II, which created a large class of veterans with spinal cord injuries, that the E and J chair became indispensable and, eventually, ubiquitous. That was in large part because the Canadian government, and later the U.S. government, became convinced that, with the combination of a car and an easily stowed wheelchair, seriously wounded veterans could once again become independent, capable citizens. Several developments allowed this to come about: the introduction of antibiotics, which allowed many more people with spinal cord injuries to survive, the birth of modern rehabilitative medicine, and the growing popularity of cars. ${ }^{113}$ The automobile was a crucial link in the chain: The U.S. government actually paid for cars with hand controls for wounded American G.I.s, while the Canadians gave preference for the purchase of cars to their veterans. ${ }^{114}$

This gave a whole new energy, so to speak, to the idea of the wheelchair: it was no longer an article of invalid furniture, used to conveniently ensconce an elderly or ill family member at home or to transport institutionalized patients from ward to ward, but, rather, a means of mobility, a vehicle for a heretofore isolated group of people to hold jobs, go to school, access entertainment-to have a life. With this in mind both governments began to issue $\mathrm{E}$ and $\mathrm{J}$ wheelchairs to every veteran with a spinal cord injury in the mid-1940s. The first order, by the Canadians, was

${ }^{113}$ In World War I, over 80 percent of soldiers with spinal cord injuries died within a few weeks as a result of infection. Tremblay, "Going Back," citing Harry Cushing, 151.

114 "By 1946, \{Canadian\} veterans were beginning to purchase automobiles, for which they were given preference during the post-war period, Veterans were not given automobiles as were American veterans in the late 1940," says Tremblay in "Going Back to Civvy Street, 157. 
for 200 chairs; the U.S. government, the Red Cross, and others ordered thousands. ${ }^{115}$

Two aspects of these chairs are particularly relevant to this study. Other scholars have emphasized the independence afforded the user by the E and J chair, which was certainly true-and revolutionary, at that. This was a chair you could take hold of, direct, and propel on your own. The transformative ability of such objects to change the lives of their users should not be lost on us.

But the new chair also promoted the idea of the individual wheelchair. As Tremblay points out, citing interviews with Canadian WW II war veterans, before Everest and Jennings, hospitalized patients did not have their own chairs. Most institutions kept only a few wheelchairs on hand; often, a crowded ward of patients would have only one. Thus you could not form a close relationship with a wheelchair; it wasn't yours, after all. "The first one up got the wheelchair," reminisced Jack Higman, a Canadian veteran interviewed by Tremblay, who spent time in a Toronto hospital in 1944. "You knew darn well you weren't going to get out of bed the rest of the day because if someone got it first they would be gone."116 Many others attest to the prevailing philosophy that still kept paraplegic patients and amputees in bed, assuming they would die or have no life after their injury, in some ways a relic from pre-antibiotic days. Even during and after World War II, wheelchair use was regarded as either impractical or an admission of failure, and the wheelchairs themselves underlined this concept. As Angelo Nicosia, another

115 Bourgeois-Doyle, George J. Klein, The Great Inventor, 167-68. I have not been able to find more accurate numbers.

116Tremblay, “Going Back, “156. 
World War II quadriplegic veteran, remembers:

The type of wheelchair that was commonly used by the military in those days...had a wicker seat and back and sometimes was called a 'cane chair.' It had two large wheels in the front-24-inch wheels, I think-and two casters in the rear. It was extremely difficult even for a strong paraplegic to propel this kind of chair.... 117

In other words, this type of wheelchair was not meant for routine, personal use. And accepting a better wheelchair would be tantamount to accepting one's injuries, as opposed to fighting against them. Struggling nobly to walk with crutches, for example, no matter how difficult, would be seen as better than sitting in a wheelchair. The idea of the wheelchair as failure or defeat was still being debated as late as 1950. For example, the neurosurgeon Donald Munro, in an article appearing in the Paraplegia News in late 1949-which prompted a series of angry letters from veterans-attacked the Paralyzed Veterans Association for advocating the use of wheelchairs. ${ }^{118}$ Gradually, as this ideology was challenged, the resistance to wheelchair use began to change.

When the culture was ready, it pounced on the E and J chair. The Canadian and American veterans became the guinea pigs for this large experiment, for the most part eager to be pioneers and to improve their lot. Nicosia describes the anticipation and joy when he received his new folding chair: "It took 3 months for me to receive my new Everest and Jennings 18-inch-width wheelchair. It was all

117 Lynn Phillips and Angelo Nicosia, "Clinical Perspectives on Wheelchair Selection," Journal of Rehabilitation Research and Development 24, suppl. 2 (1990): 1-7.

118 Paraplegia News, October 1949-April 1950. The discussion began with a letter from neurosurgeon Munro, in which he claimed that the use of a wheelchair was a sign of defeat. For months disabled readers wrote in, challenging and rejecting Munro's ideas. 
shiny and chrome plated, and I felt like someone had given me a new Cadillac convertible. Propelling it was a pleasure compared to that old high back wicker chair that I had used in the hospital."119

In large part because of the lucrative contracts awarded by the U.S. and Canadian governments, and the great popularity of these portable chairs among disabled users, E and J became the most powerful wheelchair company in the world, controlling more than 70 percent of the U.S. market. ${ }^{120}$ In the early 1980s a New York Times article estimated sales at $\$ 145$ million and profits at $\$ 8$ million. At that point the company was producing about 150,000 wheelchairs a year, about half the domestic wheelchair market. ${ }^{121}$ Yet in the 1940s, the Everest and Jennings Company was the great innovator, and the lighter-weight foldable wheelchair was the ultimate in independence. With its use, a population of disabled people with different expectations emerged, users who forged a new kind of relationship with their very own mobile wheelchairs, transformable things that could, significantly, transform their owners.

\section{George Klein and The Power Chair: Customization and User Input}

119 Tremblay, “Going Back, “ 156.

120 James F. Peltz, "Wheelchair Maker Tries to Regain Profits." Los Angeles Times, April 3, 1990, http://articles.latimes.com/1990-04-03/business/fi-

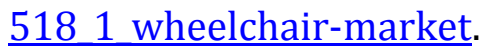

120 Ironically, E and J began to be seen as a monopolistic organization that resisted innovation, and at least two important competitors, Invacare and Sunrise Medical, as well as Sweden's Permobil, were able to eventually capture some of their territory. See N.R. Kleinfield, "Wheelchair Maker vs. Critics," New York Times, February 12, 1981. http://www.nytimes.com/1981/02/12/business/wheelchairmaker-vs-critics.html. See also the appendix to this thesis, in which wheelchair user William Peace criticizes Everest and Jennings. 
The power wheelchair has a rather different history—but one also connected to the automobile. It is in some ways a descendant of the automobile, or perhaps its cousin; it does not really work with it as much as it comes from it. Thus its connection to its occupant is quite different. It may be said to have a less direct connection to his or her physical self because it involves at least one more step in the transfer of energy. The user does not move directly by means of his own hand, but rather by touching a joystick, which then converts power through a battery.

In the early twentieth century a variety of vehicles propelled by electricity or gasoline came on the market, as did, especially in England, the motorized tricycle.122 These were certainly not all meant for a disabled user-many were considered pleasure vehicles-but like some of the earlier, manual wheelchairs they served dual purposes as conveyances for those who couldn't walk and those who didn't want to. A good example was the Osborn Electriquette (fig. 23), produced especially for the 1915 San Diego world's fair and featured in the silent Fatty Arbuckle short Fatty and Mabel at the San Diego Exposition. ${ }^{123}$ (See chapter 3 for a discussion of the film.) The Electriquette was a wicker-covered two-person chair powered by a battery and steered by a movable wand. It rode at a maximum of three-and-half miles per hour, considered walking speed. Some weak or elderly people may have used the vehicle, but those with severe handicaps would have found the Electriquette too difficult to climb into and too open to keep their balance in.

122 "Invalid tricycles" were a sort of three-wheeled, low-maintenance, low-speed motorcar made for disabled users and subsidized by the British and other European governments. They never became popular in the United States.

${ }^{123}$ Fatty and Mabel at the San Diego Exposition, Keystone Films, 1915. http://www.youtube.com/watch?v=l8cebyi-s1k. 
Another was the Custer, a gasoline-powered chair made for one, with more of the profile of a motorbike than a car. (An advertisement from 1933 said The Custer Specialty Co. of Dayton, OH, had been making motor-propelled chairs since 1916.) ${ }^{124}$ Later, similar motorized chairs for one or two were marketed to the disabled, such as the Mitchell chair, which sold for $\$ 395$ and could go six miles an hour, and the Autoette, made by the Blood Sales Co. in Long Beach, California. An advertisement for the chair, which appeared in an October 1950 Paraplegia News claims that "simple hand controls allow even a 90 percent paraplegic to drive with safety anywhere an ordinary car will go." 125

These vehicles were meant for outdoor use; they were far too large and cumbersome for homes and other buildings. They were also impossible for a quadriplegic or other severely disabled person to operate. What was needed was a chair that could transition between in- and out-door, that was maneuverable in tight spaces but powerful and resilient enough to drive around town, a chair that was responsive and supportive enough that it could be used by the most impaired individuals.

Such a chair was not created until mid-century, when Canada's Department of Veterans' Affairs, mindful of the larger number of seriously wounded soldiers who had survived World War II, put aside previous reservations—-they had previously seen such chairs as hazardous and impractical—and asked the country's

\footnotetext{
124“Introducing Our Latest," advertisement, The Polio Chronicle, July 1933, Courtesy of Warm Springs Institute, disabilitymuseum.com. http://www.disabilitymuseum.org/dhm/lib/detail.html?id=1122.

125 Paraplegia News (October 1950): 5.
} 
National Resources Council and the well-known inventor George J. Klein to come up with a power wheelchair for disabled veterans.

The electric wheelchair fashioned by Klein was actually an Everest and Jennings manual chair with a motor that he adapted to his purposes. With input from other engineers and, importantly, from paraplegics and quadriplegics themselves, he came up with a new kind of a controller - a kind of proto-joystick that let users manipulate the chair with as little as a finger touch. (One very disabled veteran who could not use his hands at all but wanted a chair persuaded Klein and his group to come up with a version that he could control with his cheek. This kind of approach was unique at the time and brought about a new field called "rehabilitation engineering." ${ }^{26}$ ) The chair had a 24-volt electrical system and utilized two motors to control the wheel; previous chairs used only one. It had a top speed of 2.5 miles per hour, and a 20 -mile range. ${ }^{127}$ It was easy to operate and maneuver, and was from the start hugely popular with those who tried it.

Canada famously offered this chair to the world, actually gifting one of the Klein chairs to the U.S government in an effort to interest American manufacturers in production, since it was felt that there wasn't a large enough market in Canada. Eventually both the American Wheelchair Company and E and J began to make chairs using the Klein motorized device-the Electromatic and the Powerdrive, respectively.

At least until the 1970s, this type of wheelchair with motor attachment was

126 Bourgeois-Doyle, George J. Klein, The Great Inventor, 183.

127 Watson and Woods, "A Short History of Powered Wheelchairs," 167. 
the standard, offering a new kind of independence to previously homebound individuals-like the "Rolling Quads," a group of disabled college students who, in the mid 1960s, were able to attend classes at Berkeley (fig.24). As Woods and Watson relate, the activism of the Berkeley students would lead not only to more inclusion and better accessibility but also to new and better wheelchair technology.

During the 1960s and early 1970s the Berkeley students and others still had manual chairs augmented by add-on motors. Though these were useful—the Rolling Quads would never have existed without them—and were a great improvement over earlier versions, they nevertheless were not ideal. They often needed repair; they couldn't climb steep gradients, and they were not made for the rough and continuous use of the Berkeley students. Out of necessity, the students finally created their own repair service, where, with constant user input, the technicians came up with alternate solutions and innovations for these wheelchairs. Over time they became authorities in their field, so much so that they began to have an equal if initially contested place at the wheelchair design table.

In 1978, they were invited to the Wheelchair Conference in Miami to present their findings and opinions to representatives from the VA Office of Prosthetic Research, NASA, and others. This turned out to be a watershed event; discussions held there as well as emerging technology spawned a new generation of powered wheelchairs, like the Invacare Rolls Arrow (fig. 25), with a frame factory-built to house the motor, a more sophisticated operating system, multiple speed control, 
more power, better maneuverability, and greater reliability. ${ }^{128}$

In a section on electric-powered wheelchair in the textbook Spinal Cord Medicine, Rory Cooper et al. cite the changes in technology that enabled these new chairs to emerge. ${ }^{129}$ Initially, wheelchair makers used starter motors and batteries from automobiles, later they switched to relays and then transistors, and finally, microprocessors and metal-oxide-semiconductor-field-effect-transistors (MOSFETs); later, programmable computers came into play. Over time, these provided better control and greater efficiency.

Interestingly, just as for a time motors and frames were separate, a new, important trend began to appear in the 1990s, according to Cooper: the separation of seat and frame. Each element could be customized to meet the needs of the user. ${ }^{130}$ The Swedish company Permobil, innovators in seating design, became an important contributor, focusing on systems that could address persistent problems of wheelchair users like pressure sores or poor posture. Frames and seats could be mixed and matched to users' needs, even to the extent of combining manufacturers. People who had limited trunk control, for example, could obtain seating with more upper-body support; features like tilting and reclining, which were beneficial to

128 The Invacare Corporation grew out a long line of wheelchair makers: first the Fay Co., established in the 1870s in Elyria, Ohio, which subsequently became the Worthington Co. and then the Colson Corporation. Colson, renamed Mobilaid, was bought by Boston Capital Group in 1971 and combined with the Invelex company to form Invacare, which was acquired by Johnson and Johnson in 1978.

129 "Electric Powered Wheelchairs," in Lin, ed., Spinal Cord Medicine, http://www.ncbi.nlm.nih.gov/books/NBK8915. Cooper, a well-known expert in the field and a wheelchair-using veteran and athlete, is distinguished professor of engineering at the University of Pittsburgh.

${ }^{130}$ Ibid. 
those with different disabilities, could be built into the chair independent of frame type. The power frame could be customized for indoor or outdoor use, for rough or smooth terrain, for going to class or going to the beach.

One might say that as motorized chairs became more complex, more technologically sophisticated, tougher and more powerful, they once again began to resemble the early automobile-like vehicles such as the Electriquette. But unlike those, often used for pleasure and entertainment, these chairs were and are customized to suit the most disabled individuals, allowing them to fully enter a previously inaccessible world.

\section{The Lightweight Rigid Chair: Quickies and "Super-Crips"}

While the folding chair of the World War II veteran gave him new freedom, it still bore all the signs of the institution and what it connoted: With its muted or somber color and its metallic frame, the chair still gave off a whiff of hardship and the hospital. The Quickie, the first of the ultralights, came on the market in 1979, and said fun, action, color-even sex, especially given the chair's double-entendre moniker. This is in a lot of ways what Marilyn Hamilton meant to do when she persuaded two technologically sophisticated friends to build her a wheelchair she could play tennis in. ${ }^{131}$ Hamilton, an athletic young woman who broke her back in a hang-gliding accident, wasn't about to stop living or doing what she loved best. She wanted a wheelchair that would not only enable her to carry out her lifestyle but

131 The National Museum of American History at the Smithsonian Institution in Washington, DC, exhibits a Quickie wheelchair and acknowledges Hamilton's contribution in its online exhibition "Sport/Breaking Records, Breaking Barriers." In 1983, Hamilton won the Women's Open Wheelchair Tennis Competition. http://amhistory.si.edu/sports/exhibit/removers/wheelchair/index.cfm. 
also to express who she was. With her input, her friends came up with a sleek, skyblue machine that advertised Hamilton's optimistic personality and allowed her to play tennis and other sports. It weighed only twenty-six pounds, about half of what previous rigid chairs weighed, and was more stable than the collapsible, folding chairs.

Her chairs and others like them caught on, both for athletics and for the everyday use of active wheelchairists, who were becoming more vocal and more numerous as the disability rights movement began to blossom. ${ }^{132}$ "Hamilton's brightly colored chairs tapped into \{the\} growing sense that there was no shame in being disabled, " says Joseph Shapiro in "The Screaming Neon Wheelchair" a chapter in his book No Pity: People With Disabilities Forging a New Civil Rights Movement. “Hamilton's stylish product reassuringly said it was okay, it could even be cool to be in a wheelchair."133

Many other similar versions of the Quickie followed. California, particularly, spawned a number of new companies - many of which didn't survive-which were founded by active, liberated users who took saws and welding torches to their conventional chairs to mold them into the vehicles they wanted. Some just wanted an easy, sporty chair to use on an everyday basis, which would be lighter, faster, easier to manipulate, and more forgiving in often-still-inaccessible environments.

132 The University of California, Berkeley, possesses what is probably the best archive of the disability rights movement. Many documents are online, including oral histories; others can be accessed at the Bancroft Library on the university campus. "The Disability Rights and Independent Living Movement," http://bancroft.berkeley.edu/collections/drilm/. 133 Shapiro, No Pity, 213. 
Users had for so long been seen as invalids; the new chairs, with their relentlessly contemporary looks and their speedy profiles, broadcast their users' new idea of themselves in keeping again with the disability rights movement.

Others wanted hard-core athletics, and began to modify their chairs for particular sports, like racing, tennis, basketball, and hockey. As time went on, the everyday ultralights became more and more differentiated, so that, for example, by 1985, "racing wheelchairs no longer had any components in common with everyday wheelchairs." ${ }^{134}$ But many of the ultralight chairs still functioned as cross-overs; the catalog copy for the Everest and Jennings 1983 Lightning chair, for example, touts its suitability for all users: "Lightning responds with amazing ease and agility. And Lightning's stability makes it an excellent chair for everyone from active sportspersons to users who can benefit from the extra advantages of an ultralight chair."135 (See fig 26.)

Wheelchair sports had begun as rehabilitation for World War II veterans in England. Lewis Guttmann, a German-born neurosurgeon, had witnessed the virtual abandonment by hospital staff of soldiers with spinal cord injuries during World War I. When he immigrated to England and became director of a unit for WW II veterans with spinal cord injuries at Stoke Manville Hospital in Aylesbury, he began

134 Rory Cooper, Wheelchair Selection and Configuration (New York: Demos, 1998), 273.

135 Everest and Jennings, "Lightning" catalog (1983). For a discussion of the advantages of rigid versus folding wheelchairs, see Robbie B. Leonard, "To Fold Or Not to Fold?: Rigid vs. Folding Wheelchairs," wheelchairnet.org. TeamRehab Report. March/April 1992: 30-32.

http://www.wheelchairnet.org/wcn_prodserv/Docs/TeamRehab/RR_92/9203art4. PDF. 
a modest sports program, which at first consisted of darts, snooker, archery, and table tennis, but soon expanded to wheelchair polo, basketball, and other sports. In 1948, on the same day the Olympics opened in London, the Stoke Manville Games was held for the first time; sixteen paralyzed veterans competed in archery. ${ }^{136}$ Meanwhile, paralyzed veterans returning from the war began playing wheelchair basketball for recreation at Veterans Administration hospitals in the United States. Soon teams and leagues were formed. The Eastern Paralyzed Veterans Association of New York, with the help of local sports teams like the Nets, pioneered and sponsored many of these teams, but they sprang up all over the country, particularly in California. In 1946 the first competitive wheelchair basketball match was played by the Birmingham, California, team. ${ }^{137}$ The pages of Paraplegic News, a publication devoted to veterans in the post-World War II period, are filled with news of these wheelchair sports tournaments in the early 1950s. By the 1960s, about a dozen sports were played in the United State, but all athletes still played with "depot-style" chairs—that is, the kind of wheelchairs one found in institutions, not customized for use or user. ${ }^{138}$ By the late 1960s, according to Rory

136 It was intentionally held on the same day the Olympics opened in London, and since 1960, the Paralympic Games have taken place in the same year and the same city as the Olympic Games. The Games were initially open only to athletes in wheelchairs; athletes with different disabilities were included for the first time at the 1976 Summer Paralympics. More than 4,000 athletes competed at the 2012 London Paralympics. "The IPC: Who We Are: History of the Movement." http://www.paralympic.org/the-ipc/history-of-the-movement. 137 WNBA web page. History. http://www.nwba.org/index.php?option=com_content\&view=article\&id=34\&Itemi $\mathrm{d}=200$ 
Cooper, wheelchair racers began to modify their own chairs, looking for speed and maneuverability. Greater differentiation of sport and of user led to many modifications over the next decades. As athletes have become more competitive, looking for an edge, specialized wheelchairs for sports have become faster, more streamlined, stripped down to the essentials. And wheelchair athletics has become sexy, turning on its head many people's concept of disability. Such chairs are compared to sports cars: sleek, minimalistic chairs fitted as tight as a glove.139 Much as the popularity of skiing led to the use of synthetic fabrics in clothing, wheelchair sports have also brought new materials to everyday rigid chairs. Aluminum and titanium are routinely used in lightweight chairs, and now carbonfiber materials are being used for the first time by wheelchair companies like Norway's Panthera. The Panthera X, which weighs less than ten pounds, is superlight but very expensive: more than $\$ 10,000$, very steep for a manual chair and certainly for most users. ${ }^{140}$ Most ultralights made of titanium cost in the range of $\$ 2,000-\$ 3,000$.

We have seen how the power chairs of the Berkeley students began a revolution in wheelchairs that brought better chairs and greater accessibility to 138 According to Herman Kamenetz in chapter 14, "Wheelchair Sports," in The Wheelchair Book, 190-97; Cooper, Wheelchair Selection, 272; this also seems obvious from a photo in Kamenetz's book, published in 1969. of a javelin thrower, page 197.

${ }^{139}$ See, for example, the video "BMW Presents Man and Machine with David Weir," Interview with Yann Yonnakis Jones. March 21, 2012. Accessed December 22, 2013. http://www.youtube.com/watch?v=x7NKsiBqZ1U. For a lengthy discussion of athletic wheelchairs, see Rory Cooper, Wheelchair Selection and Configuration (New York: Demos, 1998), 273.

140 Panthera company website: Updated December 18, 2013, accessed Dec. 22, 2013. http://www.panthera.se/panthera_eng/index_eng.htm. 
their users. The ultralights literally propelled the movement forward. In a selfreflexive action, disabled people created new machines, which then re-created the people. Whether they are simply active everymen and everywomen or athletic super stars, these new wheelchair users are on their way to creating new concepts of disability. ${ }^{141}$

Most importantly for this thesis, the ultralight seems to "complete" bodies in a way that other wheelchairs do not entirely. Minimalist and stripped-down, easily disassembled and transportable, these chairs seem in very real ways to be part of the body. This is most true for the sportsmen and sportswomen who play their games with their exquisitely tuned chairs (see chapter 5 , especially the sections on Murderball). But even for those less physically gifted, when the chair/human interaction works, energy flows both ways, and machine and man become one.

To demonstrate this unity in a more dynamic way, I will now move from the history of the wheelchair to its appearance and presentation in film, starting with silent movies in the early years of the twentieth century.

${ }^{141}$ Much of the work of Woods and Watson's "historical sociology" in their report and subsequent articles revolves around this idea. 


\section{Chapter 3. The Wheelchair in Early Film}

In film, "objects burn bright constellations of meaning and crackle tactile effects; things take on life."

Rachel Moore, "Savage Theory: Cinema as Modern Magic"142

According to Martin F. Norden's authoritative book The Cinema of Isolation, physically disabled characters have appeared in the movies since the silent era. ${ }^{143}$ Often portrayed as comic or tragic figures, sometimes as villains or morally corrupt

142 Moore, Rachel Olivia. "Savage Theory: Cinema as Modern Magic." Ph.D. diss., New York University, 1997, 139-40.

143 Martin F. Norden, The Cinema of Isolation (New Brunswick, NJ: Rutgers University Press, 1994). A briefer summary that focuses exclusively on wheelchairs is Norden's essay, "Reel Wheels: The Role of Wheelchairs in American Movies," in Loukides and Fuller, ed., The Material World. 
individuals, these characters displayed a variety of physical handicaps. A number have used wheelchairs, and over the course of the twentieth century, wheel-chaired characters have appeared in dozens of films. To name a few: Lionel Barrymore's Mr. Potter in Frank Capra's 1946 It's a Wonderful Life, Peter Sellers's Dr. Strangelove, from the 1964 movie of the same name; the Tom Cruise portrayal of Viet Nam War activist Ron Kovic in Born on the Fourth of July (1989); and the athletes in the 2005 Murderball, a documentary about the U.S and Canadian wheelchair rugby teams, where quadriplegic men slam their high-tech sports chairs into each other in harrowing physical battles. ${ }^{144}$

One might argue that, of all devices and objects, of all pieces of furniture, the filmed wheelchair is the most expressive. It is the silent centerpiece of many scenes, whether vacant or occupied, in motion or at rest, an emotion-laden repository of meaning. Yet although there is a growing body of literature on the depiction of the disabled in film, little has appeared about the wheelchair-qua-wheelchair, the wheelchair as material object. Recent scholarship only begins to touch on relevant ideas about human-and-machine interfaces, on how characters use their wheelchairs as vehicles of expression, and how the chairs become extensions of the self. Cyborgs and prostheses have occupied thinkers from Sigmund Freud to Le Corbusier to the contemporary architectural historian Anthony Vidler. ${ }^{145}$ In this

\footnotetext{
144 Because of an accident and worsening arthritis, Barrymore actually used a wheelchair. The part of Mr. Potter was tailored to him.

145 I am assuming here that the wheelchair, which substitutes wheels for legs, is a kind of prosthesis, and that humans in wheelchairs are a kind of cyborg. According to its Wikipedia entry, "cyborg," coined in 1960, is short for "cybernetic organism," and often refers to human beings that have enhanced technological abilities
} 
chapter as well as the two following, I hope to examine some of these notions vis-àvis the wheelchair in film.

To explore the early use of wheelchairs in movies, I looked at five films from the teens to the thirties: The Good for Nothing and Fatty and Mabel at the San Diego Exposition (short silents, 1914 and 1915, respectively); West of Zanzibar (1928) and Lucky Star (1929) (silent features), and On Borrowed Time (1939, feature-length "talking picture") In fact, Norden lists only about a dozen films with wheelchairs in the period I would call "early," that is, from 1904 through the late 1930s, and some of these films were difficult to access. (I did view parts of the Dr. Kildare series from the late 1930s, with Lionel Barrymore in a wheelchair, but I found them unrealistic and unremarkable given my project.)

The chairs from the early-film era are typical of what was available in catalogs from the period (fig. 27) rigid-framed wooden and metal structures with high cane or rattan backs, often capable of reclining, wide single footboards, and large, bicycle-style wheels, probably of rubber, with spokes. ${ }^{146}$ All are threewheeled, with a smaller caster wheel at the rear, except for the four-wheeled chairtwo large front, two small rear casters-in On Borrowed Time. The chair back in the Chaplin film is upholstered or at least has had a large cushion placed behind the

http://en.wikipedia.org/wiki/Cyborg. Webster's New World College Dictionary, 4th ed. (Cleveland, OH: Wiley, 2004), 359, gives it a more sinister spin: "a hypothetical human being modified for life in a hostile or alien environment." 146 In "Wheels on Reels" (201) Norden points out that wheelchair choices in film were often random; they took what they had in the stock room. He cites Lauri Klobas, who in her 1988 book Disability Drama in Television and Film (Jefferson, NC: McFarland), says that filmmakers often chose wheelchairs ill-suited to their occupants. 
user. Most have wheel rims for self-propulsion. The Fatty Arbuckle movie showcases what was then a novelty: the battery-powered Electriquette. (See fig. 23.)

Over time, as viewed through these five films, we see an attempt to show wheelchairs and users in a more realistic and more sympathetic way. The Arbuckle film completely ignores the chair's potential as a disability device while the Chaplin movie takes a dim view of disabled people: they are shown as dishonest, cunning, and bad-tempered. But the chair itself is performative, in a way Tom Gunning conceives film "less as a way of telling stories than as a way of presenting a series of views to an audience, fascinating because of their illusory power...and exoticism."147 That is, in these early films we see a number of sketches, almost amounting to a flipbook, in which a mechanical instrument is utilized over and over again to create an effect, an entertainment, irrespective of the story line, such as it is. Who cares what happens to the uncle or the lovers? We just want to see the man/wheelchair perform, in an "act of showing and exhibition."148 West of Zanzibar (1928), with its bizarre premise, could not be called a realistic film; although the character Phroso operates the wheelchair smoothly, the chair and user are also a magical, powerful unit. Lucky Star (1929) may be the first film that offers a more sophisticated approach: a disabled character skilled at using his finely tuned instrument. Still, it retains that silent-film quality that levels object and subject in a way noted by early film critics like Bela Balazs and appreciated by the thing theorists. (See

147 Gunning, "The Cinema of Attraction," 64.

${ }^{148}$ Gunning, "Cinema of Attraction,” 64. 
Introduction.) On Borrowed Time (1939) is unusual in that the wheelchair is not seen as tragic or as all-important; it has a casual presence, and its user, the elderly Gramps (played by the disabled Lionel Barrymore) inhabits it comfortably.

What we often see in the early shorts like The Good for Nothing (also called His New Profession, 1914, a Mack Sennett short with Charlie Chaplin); or Fatty and Mabel at the San Diego Exposition (1915; with Mabel Normand and Fatty Arbuckle, also produced/directed by Mack Sennett), is the chair used as a comic prop, as Norden notes in "Wheels on Reels." 149 There is often a disjunction between chairs and people, and what is comical—or tragic—is that the person and the chair, or the chair and the environment, or a wheelchair occupant and his attendant—do not jibe (see screen shots, fig. 28). This can be due to problematic technology-related to the third, rear, troublesome caster wheel—or to lack of knowledge; the man's injury is temporary, and the Chaplin character has been asked, temporarily, to look after him. Almost immediately, upon giving a little push to what seems like a heavy, difficultto-move chair, Chaplin falls flat; when he attempts to maneuver the chair over a curb, he stumbles and falls backwards several times_almost consciously proclaiming the design flaw of the third wheel about which Woods and Watson complained. (See page 45, chapter 1.) The man in the chair is constantly arguing with the Chaplin character: Take me here! Don't do that! The chair is the crux of this; it is at the center of their transaction. Oddly, although the movies and relationships could not be more different, this type of struggle over the piloting of the chair reappears in two unlikely places in much later films, Born on the Fourth of

${ }^{149}$ Norden, "Wheels on Reels," 187. 
July (1989) and Come As You Are (2011), both in struggles between fathers and sons and both discussed further later on. (See chap. 5.)

Even in a comedy that exploits stereotypes about disability, one can pick up some subtleties of the interaction between chair and man. Just as we will see in the later movies, other people seem to unconsciously use the wheelchair itself as an extension of the disabled person's body, so the Chaplin character, when asking a favor of the "crippled" uncle, leans into the back of the wheelchair, his hand directly on the upholstered lining, bringing him in closer but still some distance away from the man's corporeal body: "Slip me a dime on account," he coaxes the man, but the man simply waves his arms angrily in an effort to get Chaplin moving again.

Although most of the action here is around one wheelchair, a plush version with large self-propelling double wheels, another wheelchair appears briefly in two scenes on the boardwalk. A beggar-he wears a sign that says "Help a Cripple" and has a tin cup for coins - sits there in a more modest wheelchair; this one has single metal or possibly wooden wheels — these were still being made-with a high, caned back, and wooden arms. ${ }^{150}$ Chaplin, ever the opportunist, grabs the sign and cup and places them instead on the now sleeping uncle, and collects the donations to buy himself a drink. The wheelchairs, therefore, serve either as encumbrances or opportunities for the Chaplin character. One of the more striking aspects of the film is how the Tramp does not seem to differentiate between man and object; he leans on the wheelchair back or armrest or wheel and then on the uncle's (broken, casted leg) as if it were a table, and polishes the man's bald head with his handkerchief as

150 For example, the Gordon's Invalids' Chairs catalog, ca. 1900-1910, notes: “When desired, we are prepared to furnish 28-inch wood wheels...." 3. 
though wiping off a counter. Altra (2004) may be the only one of the later movies I have chosen to discuss that echoes Chaplin, though in a more subdued slapstick (see chap. 5). For example, when l'employe steals an unattended motorized wheelchair from an elderly man, or when the two friends are immobilized on a sandy beach in their wheelchairs as the tide steadily rises. One wonders, when sensing the humor/pathos in Aaltra, whether one should be cognizant of the same emotions in these earlier films. Chaplin's characters, after all, not just here but in other filmsthe Tramp, the little flower girl—often make use of an implicit pathos. Their humor is often based on misfortune.

When the chair and uncle cramp his lifestyle too much, the Tramp simply gets rid of them; while flirting with a woman, he carelessly shoves the uncle's wheelchair away with a planted foot; it rests on the dock, just at the water's edge. Both chairs are later used by their inhabitants, who suddenly don't seem very disabled at all, as battering rams that in turn knock over the male lead, the Tramp, and a police officer, who eventually arrests the wheelchaired uncle.

The Fatty and Mabel film is valuable primarily because it features the Electriquette, an open-style, wicker electric vehicle made for two, powered by a half-horsepower motor-the first power wheelchair we see in action. (See chap. 2 and fig. 23.) As previously noted, the vehicle was capable of going three-and-a-half miles per hour. The Electriquette, manufactured specifically for the fair, to "supplant the antiquated push-car and jinrikisha"151 could be steered with a long metal wand set horizontally in front of the driver. What the film displays, though, is how

151 from an advertisement for the Electriquette (Electriquette Motor Chair Company, San Diego Exposition), http://wickercarts.com/wp/historical-info/. 
problematic these chairs would have been for a truly disabled person, and how impersonal: anyone could rent one if they had the money, and there didn't seem to be any way to stabilize an injured or weak body within the vehicle. Fatty and Mabel use the chair as a device for pleasure and play; they leap in and out and through the vehicle and fall in and out the front or sides for comical effect. None of the early photos of the Electriquette or the movie feature people with obvious physical difficulties.

Even in the silents, we do sometimes see a moment of grace between man and machine. In the grim, fantastical West of Zanzibar, where, as Norden has pointed out, the disabled character is demonized, there are moments of astonishing ease and companionship between the wheelchair and the man. ${ }^{152}$ In this 1928 Tod Browning feature starring Lon Chaney, the cuckolded Phroso, a magician, is thrown from a balcony and crippled by his rival, played by Lionel Barrymore. Coming upon his dead wife and a baby that he assumes belongs to the other man, he vows revenge against both father and daughter. The convoluted, Sweeney Todd-like plot takes Phroso to deepest Africa, "West of Zanzibar," where Phroso ensconces himself in his wheelchair as a kind of king among a tribe of cannibalistic natives. Though they have their own chief who arrives by way of a slave-carried palanquin, Phroso outdoes him with his steel-and-woodwork chair, a marker of civilization and a modern means of mobility, as well as with his own magic. His wheelchair thus becomes a sort of throne, which, ironically, he must crawl into; the fact that he always appears in this chair when the natives come by, performing his tricks, like

152 Norden "Reel Wheels," 190. 
his fire eating, seems to impart his magic and majesty to the chair. (Or does the chair, in fact, impart power to Phroso, as a metaphoric "seat of power"?)

The wheelchair is at center stage many times in this film (fig. 29). The most poignant scene comes when Phroso learns that the girl, whom he placed in a brothel years before as a weird sort of payback, is actually his own daughter. Unfortunately he has already set in motion the plan to kill her and her father. When he hears of her identity, he is on the floor, crawling up to his wheelchair, as he often does in the film. Chaney looks up into the camera in horror and pain, and leans backwards, with one hand resting onto the seat of his chair. The chair seat supports him; the two are held together in one long shot, the wheels framing Phroso's shoulders, his head posed squarely in the center of the chair back. (See fig. 30.) His crippling may have been the impetus for his hatred and evil, but in that moment on screen he and the wheelchair become almost equal, living relatives. This harks back—or maybe forward-to Tom Gunning's insistence on the non-narrative showcasing--here, of the wheelchair-man unit—that silent film enables. ${ }^{153}$ Later films, in emphasizing rehabilitation and the courage of the disabled individual, often overlook their wounding, literally and metaphorically. It is only perhaps in the ultimately sad and true story of Tomas in Body of War that we may feel the misery and bitterness that some experience and don't necessarily overcome because of their disability. But I think there is also a link between Phroso and the young warrior Mark Zupan whom we encounter in Murderball (2005) (see chap. 5, and fig. 46), both of whom possess

153 See Tom Gunning, 'The Cinema of Attraction: Early Film, Its Spectators, and the Avant-Garde," Wide Angle 8, nos. 3-4 (1986): 63-70. 
forms of magic - fire eating, tattoos — and both of whom have nearly a mystical connection with their wheelchairs.

The film Lucky Star (1929) has had an interesting history: Born on the cusp of new technology, it was released in the U.S. as a sort of part-talkie, with some sounds included, but in Europe as a silent film. ${ }^{154}$ The American version was lost and the European one only discovered in the Netherlands in the early 1990s. It stars Janet Gaynor as Mary, an unsophisticated farm girl, and Charles Farrell, as a disabled World War I veteran who falls in love with her (fig. 31).

The film's set, ensconced in the misty, shadowy landscape of early film, consists of the two homes of the main characters and the little road between them. As the Times reviewer noted when the film was shown in New York in 1991, the filmmakers had the ingenious idea of using a Dutch door for Tim's house, so that when Mary first approaches she only sees his top half and doesn't realize-neither do we-that he's sitting in a wheelchair. ${ }^{155}$ (It's unclear if she has heard about his injury beforehand). Both the wheelchair and Tim himself seem quite extraordinary: When Tim opens the door the viewer doesn't know what to expect, but we are immediately treated to the sight of a young disabled man able to do every chore imaginable in his household by a variety of clever moves and contraptions. He lives alone, apparently, and is able to very deftly cook, mend broken objects, and generally keep house. Later he shows his ability to operate machinery-he appears

154 Janet Maslin, "Naiveté, and Sophistication Join in a 1929 Silent," New York Times, Nov. 1, 1991; http://www.nytimes.com/1991/11/01/movies/review-film-naiveteand-sophistication-join-in-a-1929-silent.html; and IMDb, "Lucky Star," http://www.imdb.com/title/tt0020122/trivia?ref_=tt_trv_trv.

155 Maslin, "Naiveté and Sophistication." 
to be generating electricity-and to go fishing off his back porch. At Mary's entrance, Tim seamlessly backs his chair into the kitchen, lifts up and adroitly pulls out a chair for her, rolls out his little wheeled table, and brings her tea. He also amuses her by performing tricks in his wheelchair, spinning and twirling around multiple times with a sort of delirious joy, which seems to be connected to his feelings for Mary. “How gran'!” she pronounces in her rough speech. The filmmaker often frames the seated Mary and Tim and the wheelchair in the outline of the double door, seemingly to emphasize their symmetry and unity. (See fig. 4.)

Some of Tim's agility seems related to the chair itself, which, unlike previous versions seen in the shorts or in West of Zanzibar, is more compact and lower to the ground and has a more circular, human-shaped profile. Chairs with a similar look were available as far back as the 1870s (see fig 32), although one doubts they operated as smoothly. (See fig. 33 for a picture of a similar chair from a contemporary catalog.) In Lucky Star (1929), Farrell has mastered the movement of this chair in a way that conjures up much later films like The Men (1950) or even Murderball (2005); the man and the chair show a fluid unity that seems almost shocking for the time.

The story line works against the character's ease and skill. Mary's mother is dead set against her marrying a "cripple," and oddly, Tim, so perfectly capable in his house, never seems to venture outside his own yard. When he does, finally, it is during a snowstorm; planning to ask Mary's mother if he can marry her, he is racing to beat out her other suitor. The chair's wheels are defeated immediately, spinning around despite Tim's frantic arm movements. The mired wheels reflect Tim's 
powerless state of mind, and he quickly retires inside. But the film has an improbable ending which allows a newly able-bodied Tim to marry Mary. In speeding toward Mary's departing train, Tim first is able to rise from his wheelchair and use crutches, very ably, to pursue Mary through the snow. At the last moment, he casts off the crutches and embraces Mary, a fully erect man. One can compare this to scenes in the 1950 film The Men (see chap. 4) in which the paralyzed veteran Bud Wilocek trains madly in the weeks before his wedding so that he can stand up, not sit in his chair, at the ceremony. In each case it seems the man must appear fully erect to marry.

One of the few actually disabled actors to play the roles of disabled people in early film was Lionel Barrymore. Barrymore had been an actor for several decades when worsening arthritis got the better of him and he began using a wheelchair on film. ${ }^{156}$ He starred in the "Dr. Kildare" series of movies, in which he played the older, disabled Dr. Gillespie, and later took the memorable role of the stingy, wheelchairusing Mr. Potter in the classic It's a Wonderful Life (1946). In On Borrowed Time (1939), he is Julian Northrup, “Gramps,” an elderly man raising his grandson Pud, who is orphaned at the start of the film. Despite the loss of his parents, Pud seems to be a carefree boy who adores his grandfather, whom he accompanies everywhere. Both he and Gramps have a casual, affectionate relationship with the wheelchair. Pud leaps on and off the back apparatus, touching the wheels and backrest often when communicating with his grandfather. (See screen shots, fig. 34). The only other later film in which we see a similar relationship is Darius Goes West (2007).

${ }^{156}$ Norden, Cinema of Isolation, Kindle edition, "The Road to Rehabilitation.” 
Near the start of that film, as Darius races through the hallways of his camp program, a child jumps on his lap to cadge a ride on the motorized chair. This kind of casualness and intimacy is emphasized later in the film, too, when the friends/advocates/filmmakers who accompany Darius on his journey pile on and off the back of his chair, sometimes to help, sometimes just to joke around. In Rear Window (1954), a different kind of comfort exists, as I note later, a nest-like coziness shared by the (temporarily) wheelchair-using character and his lover.

Barrymore/Gramps has what seems like a supremely comfortable relationship with the chair. In a way unlike that any of the nondisabled actors, he leans in one direction, towards his dominant hand, when sitting in the chair, and he seems genuinely to be making a physical effort when he pushes along the doublerimmed wheels. In the first scene his suit jacket is draped through the chair's back seat, in a kind of intimate way, and he has a little shelf on the back of the chair where he stows books and other items. His cane is stowed up front; the tip rests on the footboard. We see him carry out minute actions like setting or releasing the brake, and those around him, including his wife, don't have any particular reverence for the chair: For example, in an early scene she grumbles when he tracks mud into the kitchen via the chair's wheels. It is the kind of remark a character would only make in a film where the wheelchair is simply an ordinary object, the opposite of Phroso's magical throne. The movie revolves around two themes: Death, with a capital “D," and the desire of Pud's Aunt Demetria to take over the care of her orphaned nephew. She implies that Gramps is not a suitable caretaker, but despite his infirmity he seems young and capable. "I feel spry as a cricket," says Gramps, in one 
of his wonderfully old-fashioned pronouncements. As far as Pud is concerned, he loves Grandpa most of anyone in the world-so he says-and the wheelchair is just part of the package.

The wheelchair itself is a four-wheeled vehicle with two large self-propelling wheels up front and two much smaller ones in back. ${ }^{157}$ Though its caned back is relatively low, it has a more stretched-out profile than the one used in Lucky Star (1929); that is, the chair is lengthier, with space for a shelf and a rider on the back. Presumably the fourth wheel makes this a more stable vehicle. The house or the set is designed so that the entrance is on a slight incline, and Gramps never has to go upstairs. Thus, there are no encumbrances. Although Gramps and Pud take a trip into town, and we see them on the street, they never encounter a curb, and so we don't see how this wheelchair might behave in such a circumstance. Certainly Barrymore would have needed assistance in his four-wheeled back-castor chair, but this is not shown in the film, perhaps because it would counter the idea of the character's independence, which either the director or Barrymore might be loath to question.

Early films give us a unique window for examining wheelchairs, both historically - it is the first record we have of wheelchairs in action-and as framed objects. In early shorts like The Good for Nothing (1914), we see both disjunction between people and technology, as well as the blurring of distinctions between objects and people noted by early-film theorists like Bela Balazs; in Lucky Star (1929), the framing of object and person — the wheelchair and the character(s)—in

157 He may have used more than one wheelchair as evidenced by a careful reviewing of the film. One chair may have had three, not four, wheels. 
extended camera shots make us consider this dyad in, literally, a new light. Also, Tim's fluidity in his more compact, better-designed wheelchair signals a future direction in which man and machine operate as one: a harbinger of the modern wheelchair as prosthetic device. In On Borrowed Time, there is a matter-of-factness and acceptance of the chair, an assumption that the space of human and wheelchair are one complete sphere. While some early films demonstrate dated and disturbing images of disability in Norden's readings, if we look at them through the lens of Gunning or Keilbach, we can read more closely how the chair and user are symbiotic and related: powerful demonstrations. Viewed as a "cinema of attraction," objects are enlivened; we sense their creative potential as partners to humans. In understanding the potent and nearly magical quality of things, early filmmakers may have shown us the unity of chair and person in their purest form. And they provide many of the situations and much of the scaffolding for movies and characters that would come later in the century and beyond.

\section{Chapter 4. The Wheelchair in Mid-Century Films}

"Film is a medium that makes things visible.... It is eminently suited to depict the connection between objects and emotions...."

Judith Keilbach, Houses, Vases, Bicycles, and Rocking Horses ${ }^{158}$

158 Judith Keilbach, Houses, Vases, Bicycles, and Rocking Horses, 295. 
To explore the use of the wheelchair in mid-century movies, I chose four commercial features from the fifties and early sixties: The Men (1950), Interrupted Melody (1955), Rear Window (1954), and Whatever Happened to Baby Jane? (1962). Following a brief introduction to each film, the chapter is divided thematically, "The Wheelchair, Empty and Occupied," "The Wheelchair in Motion and Emotion," "The Wheelchair as Impediment," “The Wheelchair as Shelter" and "The Wheelchair as Machine."

The Men (1954) was Marlon Brando's screen debut, and features a paraplegic World War II veteran named Ken Wilocek (nicknamed "Bud"), who is first shown briefly on the battlefield as he is wounded and then in a hospital in the States, where he and his other disabled compatriots set out on the problematic road to rehabilitation. The film has a quasi-documentary feel; Fred Zinnemann, the director, and producer Stanley Kramer used "Forty-Five of the Men from Birmingham Veterans Administration Hospital" to supplement their cast, and much of the dialogue and incidents were taken from the lives of the vets. Some of the characters were based directly on real people. Made after World War II but released during the first months of the Korean War, the film garnered several Oscar nominations and good reviews, but didn't do well at the box office, perhaps because audiences didn't want to see what might become of their boys, or perhaps because of its frankness and rather didactic tone. ${ }^{159}$

159 Peter Manso, Brando: A Biography (New York: Hyperion, 1994), 287. 
In Interrupted Melody (1955) based on the real-life story of the Australian opera star Marjorie Lawrence, the singer is felled by polio, suffering permanent damage and weakness to her legs, forcing her to become wheelchair-dependent. Both her depression and her eventual comeback are charted here; they include a suicide attempt and her emotional rehabilitation through singing-wouldn't you know it—to disabled veterans. Eleanor Parker and Glenn Ford starred; the screenplay won an Oscar for the writers.

Rear Window (1954), one of Alfred Hitchcock's best-known films, starred James Stewart, portraying L.B. “Jeff” Jeffries, a temporarily disabled news photographer who has broken his leg but is used to leading an adventurous life and traveling all over the world. Now he spends his days and nights at his window, training his high-power lens on the occupants of the other apartments around the courtyard. A nurse (Thelma Ritter) shows up daily to take his temperature and give him massages; his girlfriend Lisa, played by Grace Kelly, shows up often, bringing love and food. One day he thinks he has witnessed a murder from his window. He ropes Lisa into helping him solve the murder mystery, which eventually endangers both of them. According to Norden, Hitchcock saw the Jeffries character as "an immobilized man"; but he is at once trapped and cosseted by his circumstances. 160 At the end of the film, nearing his recovery, he falls while investigating the murder, and is once more relegated to the chair.

Last, I chose Whatever Happened to Baby Jane? (1962), the creepy classic with Joan Crawford and Bette Davis, directed by Robert Aldrich. Crawford and Davis

160 Norden, “Reel Wheels," 192. 
play two former-celebrity sisters, Jane and Blanche Hudson, aging together in an old mansion. "Baby Jane" was a famous child star; Blanche was a promising actress whose career was cut short by a car accident, which the viewer is meant to presume is the fault of her younger sister. She is now dependent on a wheelchair and seems to be confined to her second-floor bedroom. When Blanche decides to sell the house, the hatred between the sisters, which began in childhood, reaches terrifying proportions. Jane begins to torment and then torture her sister, shutting her up in her bedroom and starving her to near-death. She herself becomes crazier and crazier, lapsing into an imaginary world where she is once again "Baby Jane." The wheelchair is used to stunning effect.

I have not been able to find information on the actual wheelchairs in these films, but it seems likely that they all used manual, foldable wheelchairs similar to those patented by Everest and Jennings in the 1930s and hardly changed in the many years that followed. The frames were made of tubular steel, the seats of plastic leather, and they had large back wheels and small casters in front, steel plate footrests, armrests, and short, coated handles for pushing. (See fig. 35, taken from the 1948 Colson catalog.)

It is worth noting, especially as it concerns the films examined here, that this new style of chair had nothing of the warmth and hominess of earlier wicker or rattan chairs, and that its shape and profile were—and are—hard, cold, and resolutely institutional. Perhaps this is why the Colson company, in advertising their product on the cover of their catalog (fig. 36) used half-tone illustrations rather than photographs, blurring the distinctions between the wheelchair and other types of 
home furnishings. In the illustration, the family sits in a little isolated cloud, all turned toward the wheel-chaired father, one boy with his hand on the armrest. (Notice how this touching of the chair connotes intimacy.) They all blend with the chair and with each other. But in many of the films, and in real life, the tubular-steel wheelchair, for so long associated with hospitals, seems more like an intrusive presence. We will see later that the infusion of humanness-the chair's relationship with its inhabitant—may be more significant in this regard than materials. Consistent use may soften the wheelchair's profile.

In these films, as in the earlier films, the chairs are nearly always powered by the disabled character, not pushed by someone else. Thus, in general, we can assume that the chairs express aspects of their occupants.

\section{The Wheelchair, Empty and Occupied}

In each of these films, the wheelchair is a kind of shorthand that, depending on its placement, speaks volumes. In Baby Jane, for example, the wheelchair embodies all the rage and jealousy of these two aging once-famous sisters; it reminds us, always, of the accident that damaged Blanche permanently, and of her vulnerability. This is made explicit in a famous scene where Blanche remarks, "You wouldn't be able to do these terrible things to me if I wasn't in this chair." Whereupon the Baby Jane character says mockingly, “But y'are, Blanche. Y'are in that chair."

The wheelchair is a signifier: It can say war, loss of career, emasculation, or patriotism. It can say "easy mark," as Norm, the Jack Webb character in The Men, a wheelchair-using vet, discovers when his girlfriend takes him for $\$ 900$ and leaves 
the country. It can telegraph the loss of femininity or sexuality, as in the publicity illustration for Interrupted Melody (fig. 37). Here the actress Eleanor Parkerplaying the real-life opera star Marjorie Lawrence-is pictured twice: on the top right, erect, sporting a skimpy, spangled costume, aware of her powers; and on the bottom left, where, now in the wheelchair, she is hunched over, wearing a shapeless, shabby dress and cowl-de-sexed.

Even empty, the wheelchair means something to other characters, to the disabled user, or to the audience. In a scene in Interrupted Melody, soon after Marjorie's crippling, it signals, "Keep your hands off." Two young men trolling the beach see an attractive woman lying on a blanket—-the Parker character-and try to pick her up. But as soon as they notice the empty wheelchair nearby, they freeze, then apologize and scoot off without asking any questions. She is effectively neutered by the chair.

Sometimes the chair sits voicelessly like an unwelcome visitor, as it does in another scene from Interrupted Melody. Depressed by the damage to her career and furious about her inability to walk, she refuses the encouragement of her husband (Dr. Thomas King, played by Glenn Ford) to get out of bed and start her physical therapy. Here the wheelchair is eloquent as it sits by the bed, representing all Marjorie has lost or imagines she has lost. Even when her husband plays a recording of one of her operatic performances, knowing it will disturb her, she doesn't try to use the wheelchair to reach the phonograph to turn off the record, preferring instead to collapse onto the floor and crawl over. As Norden points out, 
even when Lawrence finally appears on stage in an opera, she rejects the wheelchair, preferring to lean on props or use disguised, stationary seating. ${ }^{161}$

Not being in the chair is very important in The Men, too, which features a ward of World War II vets. While the Marlon Brando character does adjust rather flawlessly—and rather unrealistically—to using a chair, he spends the better part of fifteen minutes of the movie working to not be in the chair on his wedding day. Seen in this series of sequences (fig. 38), he works out ferociously, lifting weights, doing sit-ups, and climbing ropes so that he will be able to rise from his chair on the day he gets married-demonstrating a phallic power still resident in his physical body.

The empty chair is used to great effect in Baby Jane. In one crucial scene, after Jane has tied up and tortured her sister Blanche, whom we have not seen for several frames, the appearance of an empty chair in the kitchen signals disturbing possibilities to the viewer. What has happened to its occupant, who has now become completely identified with the chair? The disturbance increases when the clueless and drunk Edwin (Victor Buono), whom Jane has lured in to help bring her childhood act back to life, sits in the chair, places Jane's look-alike doll in his lap, and takes her for a ride. Even Jane, spying Edwin whizzing by with the doll in his lap, cries out with horror. When the weirdly realistic doll finally slips to the floor, once again leaving the chair unoccupied, we are genuinely afraid for Blanche. Perhaps she is like the doll, with her cracked head, thrown out of her wheelchair (fig. 39).

\section{The Wheelchair in Motion and Emotion}

${ }^{161}$ Martin F. Norden, “Reel Wheels,” 194. 
The wheelchair is equally expressive when in motion as a vehicle, as we can see in scenes from The Men and Baby Jane. It can, for example, betray its owner's anxiety, as when Bud's chair, in The Men, develops a small, audible squeak when he first enters the home that he and Ellen are to share after their marriage. It seems to snag on the new carpeting; it has trouble rolling over the nap. It is clearly an intruder. "Have to oil that later," he says.

But the squeak is an omen: By the time the evening's out, Bud is furious and Ellen is in tears; she admits she is sorry she married him, and, racked with emotion, he asks, “Why'd you have to wait till we were married?" Then he tears out of the house, recklessly pushing his chair out the door. We next see Bud rolling through the halls of the hospital in angry, powerful strides, his arms propelling the wheels forward with great determination and focus. Finally, Bud enters the TV room, where several of his friends have gathered to watch what sounds like a prizefight. The guys exchange looks; Bud is supposed to be living with his wife, and they are upset that he's back at the hospital. "What are you looking at?" Bud demands; enraged, he thrusts the wheelchair forward across the small room in one violent burst, picks up a poker, and smashes out several large windows (fig. 40). Even before he breaks the windows, Brando uses the wheelchair itself to expose the character's feelings. The wheelchair has become, as the disability studies researcher Myriam Winance puts it, "the mediator of action."162

162 Myriam Winance, "Trying out the Wheelchair: The Mutual Shaping of People and Devices through Adjustment," Science, Technology and Human Values, 31, no. 1 (January 2006): 60. 
Another scene in The Men allows Jack Webb's character, Norm, to make expressive use of the chair. Swindled and jilted by his girlfriend, Norm makes his way back into the ward, and we know, even before he says a word, that he is drunk. As opposed to the expert, easy rhythm he has generally adopted when maneuvering his wheelchair, here he tools sloppily into the room, weaving around, and bumping into the end of the bed before righting himself.

In a scene from Baby Jane, Joan Crawford also makes dramatic use of the moving wheelchair. She is awaiting her lunch. Earlier her pet bird has disappeared and then reappeared on her plate like a chicken leg or a piece of roast. Jane brings in the tray, then, on her way out, says, offhand: "You know, Blanche, we've got rats in the cellar." Now Blanche is primed and anxious: Her nervousness shows up first in the way she seems to uncertainly wheel up to the tray table; then, as if acknowledging her hunger, she decisively stops and uses her hands to snap down, one by one, the brakes on her chair. She opens the lid of the serving dish, only to find an enormous dead rat. Slamming down the lid with disgust and horror, she uses the chair to express her near-hysteria over the incident, twirling around and around in circles in a small arc at the center of her room, as the camera traces her overhead. In a moving, and very different, sequence from Interrupted Melody, we also trace emotion through the inhabitant's intentional and unconscious movement of the wheelchair. Disconsolate over the presumed loss of her career, the character Marjorie Lawrence has been persuaded by a friend of her husband's to entertain the soldiers in a nearby military hospital. Other attempts at a comeback have ended in 
failure, so we know she is apprehensive, and she admits this to the young soldier who is accompanying her on piano.

She has chosen to sing "Somewhere Over the Rainbow." At first she is tentative and fairly still, using only her hands but not the chair; as she begins to relax, she rests her hands on the large rear wheels and begins to move her arms: The chair glides. Now, she accentuates rhythms as she continues to sing, punctuating pauses and notes with a roll of the wheel. She is in the groove; she seems to breathe with the chair. Her voice and movement match. She stops and sits for a few seconds in front of several soldiers in wheelchairs, delivering the poignant lines, "Birds fly over the rainbow/Why oh why can't I?" Near the end, the veterans take their place in line behind her, following her lead, wheeling themselves to her rhythm. (See fig. 41.)

\section{The Wheelchair as Impediment}

For their parts in, respectively, The Men and Whatever Happened to Baby Jane?, Marlon Brando and Joan Crawford spent many hours learning to use a wheelchair smoothly and adeptly. Eleanor Parker was known to be skillful with a wheelchair; she also played a wheelchaired character named, intriguingly, Zosch Machine, in the 1955 Man with the Golden Arm. ${ }^{163}$ Brando famously lived for three weeks in the Birmingham Veterans Hospital near Los Angeles observing disabled soldiers and learning to maneuver a wheelchair. He prepared for his role as a true Method actor,

163 Michael Bubbo, "Eleanor Parker: Woman with a Thousand Faces," In The Women of Warner Brothers: The Lives and Careers of 15 Leading Ladies (Jefferson, NC: McFarland and Co.), 2008. 
going through the same physical therapy routines as the other vets, getting measured for leg braces, and hanging out with the other patients. "By the end of the third day, \{two of them insisted he meet them at their favorite hangout, the Pump Room. Once they arrived, they mercilessly kidded him as he struggled to unfold his wheelchair getting out of the car."164 But his difficulties eventually evaporated, and by the time the movie was filmed, Brando's wheelchairing was fluent and athletic.

Joan Crawford also describes many hours of learning to use the chair offscreen: "I worked in the wheelchair all weekends," she said in a taped interview from the1960s, describing the blisters she would get on her fingers. "As a matter of fact, I took the wheelchair home with me nights to figure out how to get through doors." 165

Yet the very fluidity of these actors' movements belies the gritty reality of wheel-chair use, which often involves scraping by walls and crowds and furniture, or bumping up against physical barriers. The heavy clumsiness of a wheelchair, its awkwardness in certain situations, its corporeality, is generally missing from these films. (It's interesting that we spend much time watching Bud pump up for his wedding when he will have to stand, but no time watching him struggle while learning to use the chair.) But, fleetingly, in two very different scenes, one in Baby Jane and one in The Men, it is apparent.

In the first sequence, Baby Jane has committed one crime to hide the other.

164 Manso, Brando, 278.

165Joan Crawford, interview with Philip Jenkinson, BBC Movie Star Interview. Part 3 of 4, 1966. https://www.youtube.com/watch?v=xqLdB7hiHE0. Uploaded January 24, 2010, accessed April 2, 2014. 
Afraid that the maid, Elvira, will discover that she is torturing Blanche, Jane murders her; later, frantically, she tries to figure out where to hide the body. She decides to load her into the car and then dump Elvira. To carry this out, Jane takes the nowunoccupied wheelchair-she has tied Blanche to the bed upstairs—and places Elvira there, wrapping her in a blanket. Then she opens the back door near the garage, and begins to descend the stairs with the chair. But the chair is so difficult to use, so heavy and clumsy! It bumps down each step, noisily, as Jane glances around furtively. Its wheel catches on a pebble. It threatens to fall over. Here the wheelchair is not easy or smooth or accommodating; its physicality betrays Jane's guilt, haste, and fear.

The other scene is sweeter, but also injects a note of reality. "Bud" has essentially been barred from living in the hospital. Finally accepting that he must return to Ellen, he gets into his car and drives to her parents' home, where she has apparently been staying. For the first time we see Bud struggle with the wheelchair; we see its heaviness. He moves up the slight slope of the path to the front door with effort. And then he reaches a step. He stops and looks down at the leg rest, bumping up against the brick. Finally, his estranged wife comes out. "I was wondering," he says. "Would you maybe like to go out to the movies tonight?" After a moment, she replies: "Yes, I would." And then she asks, "Would you like some help getting inside?" When he says yes, she pushes the chair over the step. This exchange over the step signals a new, positive direction in their relationship. 


\section{The Wheelchair as Shelter}

I have not spoken so far of Rear Window, which is in many ways very different from the other movies. Here, movement is not important-it hardly happens at all-and Stewart does not really make dramatic use of the chair. Because Jeff's disability is temporary, the chair does not signal tragedy or loss in the same way it does in other movies. This is why Jeffries accepts the chair so readily and comfortably. As far as we know, the only time he leaves it is when the visiting nurse comes to give him a back rub; she helps him and in and out of the chair; there seems to be no question of him sitting or lying somewhere else or possibly leaving the apartment. He is shown several times waking up in the chair in the mornings; he has obviously slept there. His girlfriend Lisa brings him affection as well as delivering food from "21"; his employer calls now and then; and he spends the rest of his time gazing through the giant lens of his camera through his large windows, where he spies on "Miss Torso" and other neighbors who live around the courtyard. (See fig. 42.)

Yet the wheelchair is important. Hitchcock has said that he used the chair to indicate Jeff's confinement, his entrapment, his powerlessness. But Marc Shell, in his essay on Rear Window in Polio and Its Aftermath, alludes to the chair as a cocoon, and of Jeff's relationship with Lisa as "an enchantment." And I would propose that the wheelchair also serves as a shelter, a place of safety, a womb, even. For here all of Jeff's needs are met; he is surrounded by willing and caring women; all of life passes before his eyes without his lifting a finger. He is perfectly content. In Rear Window, the wheelchair becomes no longer simply a machine for sitting, as Le 
Corbusier would have it, but a machine for watching, thinking, locomoting, eating, sleeping, and embracing. ${ }^{166}$

In his "Homes for Cyborgs," Vidler reminds us of the opposing ideologies of the Modernists and the Surrealists: "Against the cold rationalism of the modernists, the Surrealists called for an architecture more responsive to psychological needs: what Tristan Tzara called an 'intrauterine architecture'.... When entered through 'cavities of vaginal form,' these...houses were dark, tactile, and soft. They imitated the play-constructed shelters of childhood." 167 How ironic that the perfect womb, which we usually associate with warmth and flesh, becomes the tubular steel and plastic leather of a wheelchair! The wheelchair would thus unite Le Corbusier's idea of the machine for sitting with a Surrealist notion of the house as womb. Perhaps it isn't the materials of the chair that matter. Perhaps it is the fusion of human and machine that makes the difference.

Fascinating and ironic, too, is a relevant observation made by two disability studies writers in 1979.

An important aspect of growing up...is the evolution of a concept of personal shelter. From infancy children begin to seek a "shelter," first by crawling into and under things, hiding in small places, and selecting a small corner...as the setting for their play. Adolescents... \{seek\} an alternative shelter; the car or van, the attic or basement room.... Those who are disabled from early childhood often miss or only

166 Le Corbusier actually wrote: "A house is a machine for living...An armchair is a machine for sitting." Le Corbusier (Charles-Edouard Jeanneret-Gris), Vers une architecture (Towards a New Architecture), trans. of 1928 printing, John Goodman, Paris: G. Cres, 1924; Los Angeles: J. P. Getty Trust, 2007), 151.

167 Anthony Vidler, "Homes for Cyborgs," in The Architectural Uncanny: Essays in the Modern Unhomely (Cambridge, MA: MIT Press, 1992), 151. 
partially experience these activities....They may be so "sheltered" by concerned parents that there is no need or opportunity to develop a concept of shelter of their own...."168

Yet the wheelchair may provide exactly that for the disabled youngster, a shelter, albeit not of his own construction or his own liking, though he may, and perhaps often does, use it imaginatively. Interestingly, in a film about someone who is only incidentally and temporarily in a wheelchair, we may learn much about the imaginative space of the permanently disabled.

\section{The Wheelchair as Machine}

As Anthony Vidler points out in "Homes for Cyborgs": "In the first machine age...the line between nature and the machine, between the organic and inorganic, seemed crystal clear; organicism was a metaphor, not a reality..... Now the boundaries between organic and inorganic, blurred by cybernetic and biotechnologies, seem less sharp."169

This is true for all sorts of objects that we use, as Sarah Jain says in her oftquoted, incisive article "The Prosthetic Imagination: Enabling and Disabling the Prosthesis Trope": "As a number of recent theorists point out, the use of tools and artifacts requires a degree of incorporation into the body; Elaine Scarry...calls this process the 'labor of animation.'"170

168 Raymond Lifchez and Barbara Strong Winslow. Design for Independent Living: The Environment and Physically Disabled People (London: Architectural Press), 1979, 63.

169 Vidler, “Homes for Cyborgs," 147. 
But a prosthesis takes this idea further. Jain explains, citing Mark Wigley:

A blurring of identity is produced by all prostheses. They do more than simply extend the body. Rather, they are introduced because the body is in some way "deficient" or "defective," in Freud's terms, or "insufficient," in Le Corbusier's terms. In a strange way, the body depends on the foreign elements that transform it. It is reconstituted and propped up on the "supporting limbs" that extend it. Indeed, it becomes a side effect of its extensions. The prosthesis reconstructs the body, transforming its limits, at once extending and convoluting its borders. The body itself becomes artifice. ${ }^{171}$

Jain includes wearing eyeglasses in such a definition of prosthetic, as I have included wheelchairs, and she insists on the ways prostheses change the body: "Differences do necessitate transformation: wearing glasses adjusts vision but also changes the comportment of the head and neck and over years changes the contour of the muscular-skeletal infrastructure...."172

She goes on to remind the reader of the blind man's stick in Gregory Bateson's analysis: "If you ask anybody about the localization and boundaries of the self...confusions are immediately displayed. [C]onsider a blind man with a stick. Where does the blind man's self begin? At the tip of the stick? At the handle of the stick? Or at some point halfway up the stick? These questions are nonsense because the stick is a pathway along which differences are transmitted under transformations, so that to draw a delimiting line across this pathway is to cut off a

170 Sarah Jain, "The Prosthetic Imagination: Enabling and Disabling the Prosthesis Trope," Science, Technology, \& Human Values 24, no. 1 (Winter, 1999): 32.

${ }^{171}$ Jain, "Prosthetic Imagination," 38.

172 Jain, “Prosthetic Imagination,” 41. 
part of the systematic circuit which determines the blind man's locomotion."173

There is an incorporation of person and prosthesis, which we have seen to a certain degree is also true in this study of wheelchairs. The disability studies researcher Myriam Winance describes the adjustment of human and wheelchair as "a common materiality that emerges" in which "the aid becomes part of the body and the person in the sense that it modifies the way the person perceives, moves, and relates to the world." Winance describes a scenario in which a small boy, Theo, who cannot walk, is introduced to his power wheelchair. During a period of several hours, he is instructed in the use of this new instrument by his mother and the technician who has come to his house, learning to negotiate doors and furniture and to give the right touch of the thumb to the joystick to move the chair. Slowly, chair and boy adjust to each other; by the end of the day, they have become one. "Theo feels and lets the action flow from him through the wheelchair...the wheelchair becomes part of the body....Now when I speak of Theo," says Winance, "I mean Theo and his wheelchair."174

There is also, as Vidler points out, a queasiness about this machine-human interaction, as though the object may turn on the person who has animated it. It may be this sinister aspect of the cyborg, which Vidler dates back to the automaton, which makes it a good fit for a horror film like Baby Jane. It can also make the wheelchair funny, as in Dr. Strangelove or in the first scene of Woody Allen's Sleeper, where the wheelchair seems to have a mind of its own.

173 Jain, "Prosthetic Imagination, 40-41.

174 Winance, "Trying out the Wheelchair," 60-61. 
In Chapter 5 we will see how the wheelchair in later movies can be slave or master, how, in symbiosis with the wheelchairist, it can empower, and on the other hand, how it can suddenly and completely disempower. In these late-century and early-twenty-first-century films, we will see manual and power chairs that become fused and identified with their owners, that become parts of the body, and we see wheelchair users who move in sync with their machines, who become "enwheeled." 


\section{Chapter 5. The Later Movies: Wheelchair as Self}

"Mastery over motion proves the existence of a relatively autonomous self." Mihaly Csikszentmihalyi and Eugene Rochberg-Halton ${ }^{175}$

In this chapter, I examine six full-length films that bear on wheelchair/user interactions and appeared between 1989 and 2013: Born on the Fourth of July (1989), Aaltra (2004), Murderball (2005), Body of War (2007), Darius Goes West: The Roll of His Life (2008), and Come as You Are (2011). Four of these films are American, two Belgian; three are documentaries, three are fictional. I've drawn on many other commercial movies in this study, including Coming Home (1978), Water Dance (1992), the French film The Intouchables (2011), and Sympathy for Delicious (2010), as well as the unique Rolling (2007), made by the physician Gretchen Berland and broadcast on PBS. In Rolling, Berland asked three wheelchair users, Vicki, Galen, and Eric, all adults with different disabilities, to film their daily lives by mounting cameras on their wheelchairs. Other, relevant films are sometimes referred to in the text; all appear, with credits, in the appendix.

In two cases, Come as You Are and Born on the Fourth of July, fictional films have been based on real-life, available documentary footage; others, such as

175 Csikszentmihalyi and Rochberg-Halton, The Meaning of Things, 117. 
Murderball, Body of War, and Darius Goes West are themselves documentaries. Aaltra, a fictional, dark comedy from Belgium, is the exception: Its general focus on mobility, vehicles, and their meaning to humans is what interests me.

As I have already noted, nondisabled actors in films have used the same wheelchairs as people with disabilities have used over the century; sometimes these categories have overlapped, as in the case of Lionel Barrymore. All have had to adjust themselves to the wheelchair. Many have spent weeks or months learning to use the equipment in order to make their acting lifelike. I have made it a point to go back and forth between fictional and documentary film in order to gauge my perceptions. In some cases, I have had the opportunity to compare a character in a fictional film directly with documentary footage of the real person, as in the case of Ron Kovic and Born on the Fourth of July. As in literature, fiction and nonfictional accounts display truths differently; documentarians frame and shape experience and so also create a kind of fiction. Fictional films, on the other hand, sometimes tell the same story more effectively, even if characters or scenes do not exactly replicate "reality."

Here, once again, I introduce the movies individually and then discuss them thematically, dividing the chapter into sections that interpret wheelchair use: "The Wheelchair as Expressive Vehicle," "The Wheelchair as Identity," “The Wheelchair as Mediator/Transactor of Emotions," "The Wheelchair: Coming Apart and Coming Together," and "Wheelchair and User as Master and Slave."

Come as You Are, also known as Hasta la Vista (2011), is a Belgian-made coming-of-age film by the director Geoffrey Enthoven. It was based on a BBC 
documentary about the wheelchair user Asta Philpot, who co-wrote the script. ${ }^{176}$ In the film Philip, Lars, and Josef, are all young disabled men: Josef is visually impaired, Lars in the later stages of a terminal brain tumor, and Philip is quadriplegic. (See fig. 43.) They all set out in a van from their homes in Belgium to visit a brothel in Spain with the aim of losing their virginity. Their parents think they are off on a winetasting tour. Their driver, Claude, is gruff, overweight, and supremely competent; they treat her badly at first and then grow to love her. The men's interactions with their parents, who eventually find them and try to retrieve their strong-willed sons, feel heartbreakingly real. The movie was released in Europe in 2011 and was the opener for the Ostend Film Festival but was not shown in the U.S. until early in 2013, at the Reelabilities film festival at the Jewish Community Center in New York. ${ }^{177}$ Its American release was October of the same year.

Born on the Fourth of July (1989) is a Hollywood film starring Tom Cruise and directed by Oliver Stone. It was based on the 1976 autobiography of the same name by Ron Kovic, a Viet Nam war veteran turned activist against the war. It follows his journey from rehab to anger to action; it is The Men after a different war, with a heavy dose of politics thrown in. Kovic is listed as a co-writer and served as advisor

\footnotetext{
176 Philpot has the disability arthrogyrposis, which impairs his ability to move. He is essentially quadriplegic. The BBC film was called "For One Night Only," and chronicled the journey of himself and two other physically disabled men he persuaded to accompany him to a Spanish brothel he had discovered on an earlier trip with his parents.

177The ReelAbilities: NY Disabilities Film Festival "promot[es] awareness and appreciation of the lives, stories and artistic expressions of people with different disabilities. Initiated in NY in 2007, the festival presents award winning films by and about people with disabilities." http://newyork.reelabilities.org/films.
} 
on the film. ${ }^{178}$ The film was nominated for eight Academy Awards, including best director and best actor in a leading role. It won two, for best directing and best editing. Born on the Fourth of July was a huge success, grossing more than $\$ 161$ million worldwide.

The documentary Body of War (2007), tells the story of another war veteran, Tomas Young, who during his first and only week in Iraq sustained a paralyzing spinal cord injury. Like Kovic, after a struggle with his patriotism, he turns against the war in which he fought and becomes an outspoken activist. Part of what makes this film unusual is the explicit, sometimes harrowing detail we see in Tomas's life, from his mother inserting a catheter into her son's penis to the forthright narrative from his young wife, who recounts the difficulties and the frustration of trying to have both a sexual and emotional relationship with this wounded man. (They eventually separate.) The story is backgrounded by the arguments and dramatic final vote by Congress before the decision to invade Iraq. The consequences of that decision are shown in the daily struggles of Tomas and others like him. The film was produced and directed by Phil Donahue and Ellen Spiro. ${ }^{179}$

${ }^{178}$ In tandem with Born on the Fourth of July, I watched the hour-long documentary Operation Last Patrol, a Cinema Libre production (directed by Frank Cavestani and Catherine Leroy, 1972), which chronicles a Viet Nam war protest organized by a group of veterans including Kovic, who travel from California to the Republican National Convention in Miami. While it is not a story, exactly, of Kovic and his life, it provides an opportunity to see how he uses his wheelchair and to compare it with the depiction by Cruise.

179 Young made headlines in 2013 when he said he was planning to end his life due to his further medical decline. He has since rethought that and now is in hospice care. See Nick Wing, "Tomas Young, Dying Iraq Veteran, Chooses to Live: I'll Hold On as Long as I Can," The Huffington Post, posted May 30, 2013, accessed December 16, 
In the documentary Darius Goes West: The Roll of His Life (2008), a teenager with Duchenne muscular dystrophy, a degenerative neuromuscular disease, sets out on a cross-country journey with one goal in mind: to convince the producers of the MTV show Pimp My Ride, who usually customize a car according to the owner's wishes, to "pimp" his power wheelchair. The quest ultimately fails, the show's producers turning him down because of "liability issues." Nevertheless, the trip itself, in a van financed by a fund-raising effort in his hometown of Athens, Georgia, with the help of several young men who were his camp counselors, is worth the effort: It's the first time Darius, an African-American cared for by a single mom, has ever left home. He visits the ocean, the Grand Canyon, and Carlsbad Caverns (fig. 44). Along the way he drums up attention to the disease he has and the difficulties encountered by someone in a wheelchair. And when he arrives back in Athens with a worn-out, nonfunctional power chair, he finds a surprise: a dream chair made by a local Lamborghini dealership, decked out with all the items Darius has enumerated to MTV.

Aaltra (2004) is a dark comedy from Belgium about two ne'er-do-well neighbors and enemies who, through a farm-machinery accident, both become paraplegics. The crazy journey of these hitchhiking wheelchair companions with nothing left to lose takes them from Belgium to Finland, where they hunt down the company that manufactured the faulty equipment. These are not the two nicest guys on the planet, but that's part of the film's comedy: For example, they try to sell handicapped spaces in a parking lot to raise money, blocking cars as they pull in (fig. 
45); demand charity from passersby, physically molesting those who don't give; and temporarily steal a famous Motocross rider's bike for a joy ride. (They end up crashed, in a hysterical, breathless heap by the side of the road.) But there is also real pathos as they are carried and pulled, weightily, into vans, and across thresholds; as they are cursed by another fan at a Motocross event, and as they are beaten up and robbed of their train tickets and passports. The film is completely shot in black-and-white, with big moody landscapes and machinery that often dwarfs the people; although made in 2004, it feels very New Wave. Every sort of moving device from a baby's mobile to an airplane is given attention and thought. Gustave de Kervern and Benoît Delépine wrote, directed, and star.

No one is less pathetic than the elite quad rugby champ Mark Zupan, one of the stars of the Oscar-nominated documentary Murderball (2005), directed by Alex Rubin and Dana Adam Shapiro. ${ }^{180}$ When I saw Zupan for the first time (fig. 46), I was reminded forcefully of an Italian renaissance warrior decked out in his armor. Zupan is compact and athletic, with a short, shaped blond beard, and swirling, complex tattoos covering all of one shoulder and one leg. The tattoos, and the details of his specialized wheelchair are reminiscent of the "war-ware" crafted by the Negroli family in Milan in the 1560s-fabulous silver helmets, shields, and swords often decorated with images like the Medusa head, meant to give the soldier courage and scare the heck out of the other guy. The tattoos transmit what I would imagine to be a similar magic, and with those, and his perfectly tuned titanium

180 See Cooper, Rory, Wheelchair Selection and Configuration, chap 10.6.3, Quad Rugby Wheelchairs, in the chapter "Sports and Recreational Wheelchairs," 288, for a detailed description of the chair used in this sport. 
machine, Zupan, who was left a quadriplegic after an alcohol-fueled accident in his adolescence, is a terrifying opponent. ${ }^{181}$ (He also seems, oddly, reminiscent of Phroso the magician in the 1929 film West of Zanzibar. (See chapter 3.) In both films, the wheelchair is a kind of power-enhancing throne; both Phroso with his fire eating and costumes, and Zupan with his primitive-looking tattoos, transmit a potent, somewhat frightening energy. But there are many terrifying men in Murderball, which follows the rivalry of the elite U.S. and Canadian teams that are vying for the gold in the 2004 Athens Paralympics Games. The latter team is coached by a former American rugby player (Joe Soares) who is dying to unseat his old team. Along the way it tells the stories of these extraordinary athletes, all of whom have suffered devastating injuries or illness but are a remarkably upbeat, confident, and powerful group of men who love this brutal but thrilling game..$^{182}$

\section{The Wheelchair as Expressive Vehicle}

In Murderball, wheelchairs are used as weapons. The highly cambered, large back wheels of these chairs-leaning inward at 15-20 degrees-are covered by giant aluminum plates, scuffed and dented, which in motion look like revolving, reflecting tin drums—or battered shields. Curved metal pieces that look like cowcatchers protect, to some extent , the chair's and user's front and sides. (Interestingly, these players don't wear helmets). But they aren't protected from much: This is a game where collisions are frequent and intended, where wheelchairs

181 "Quadriplegic" doesn't mean, as is commonly thought, that all four limbs are paralyzed. In quad rugby, at least three limbs must be affected, and a point system is used to designate levels of impairment. Each side can have eight points.

182 Some quad rugby teams are mixed-gender, like the British one, which in the 2012 Paralympics included a woman. 
and players are sideswiped, upended, and thrown aside. Though the aggressors are people, the people often become an afterthought. The first question after a collision, says one young player on a video featuring the team from Great Britain, is "not are you $\mathrm{OK}$, but is the wheelchair $\mathrm{OK}$ ?"183 There is a powerful line in the film that helps explain the aggressive posture of these athletes, when Zupan and teammates visit a rehab hospital and meet a newly quadriplegic young man, who can't wait to try out the rugby chairs, despite the anxiety of the nursing staff. "I just want to hit stuff!" he proclaims, and you understand just what he means. What's fascinating here is to see anger, loss, and heartbreak turned on its head into a machismo fantasy of rage. And they use their wheelchairs to do it.

Anger is expressed in a number of films, notably in Born on the Fourth of July, in which Cruise/Kovic's rage becomes dramatically important; his anger mounts and then resolves as his activism progresses. In the scenes after he first arrives home, he bounces off walls, careers down hallways off kilter, scraping and gouging plasterboard along the way. At one point, at the height of his smoldering fury, he rather menacingly grips his wheels and backs his chair into the space of an older Marine in a pool hall, who has accused him of being a coward and a traitor. And he and the character played by Willem Dafoe, also in a wheelchair, engage in a scrap in the desert, which begins with a faceoff where the two wheel in circles around each other threateningly (fig. 47).

183 "Murderball: The World's Most Violent Sport?" Interview with Steve Brown. NBC News website, August 28, 2012. Accessed December 23, 2013. http://www.nbcnews.com/video/nbc-news/48798883\#48798883. 
In a scene from the film Waterdance (1992), two men in a rehab unit, infuriated because the hospital's communication center cut off a call for help from a former patient and friend, storm the center. One of them (the character Joel Garcia, played by Eric Stoltz) after rocketing down the hallways and across the grounds, launches his chair at a telephone operator; a moment afterwards, his pal Bloss (William Forsythe) uses his chair in a similar fashion to prevent the female operator from calling Security. When they have played out their anger and Garcia is lying exhausted on the floor, Bloss says to him, teasingly, "You really oughta channel that hostility," echoing, one suspects, a line from a counseling session at the hospital. I suspect that one of the reasons these scenes feel so effective is that the manual chairs require so much muscle power to wheel that it gives the actions extra weight, so to speak. Certainly rage ripples through the hard-wheeling movement of the burly "ouvrier agricole" in Aaltra, when he and "l'employé" finally reach what they believe is the Finnish plant that manufactured the faulty farm machinery. 184 Revving up his chair outside the factory, as though anticipating a giant leap, he grunts and begins rolling fiercely up the muddy parking lot, then inside the plant. Cutting boldly across the factory floor, putting his full, bullish weight into his wheels, passing machines, earth-moving equipment, workers, and rows of floor-toceiling wire-mesh shelving, he shouts, "Give us our legs back!" Interestingly, l'employé follows more meekly, struggling to catch up, in his power chair. There is no scene in these films that shows aggression in a power chair, but it is implied in one scene in Darius: One of the young camp counselors, when interviewed,

184 These are the only names given to these characters in the film. 
volunteers, "I'm kind of afraid of his wheelchair...Have you seen how fast he drives? It's kind of creepy...."185 Darius seems like a civilized and gentle young man, but feelings of aggression among disabled people are not always obvious and may be displaced. ${ }^{186}$ Here those feelings ride, like an extra passenger, in the speed and presumed recklessness with which Darius drives the wheelchair.

It's hard to tell, in an early scene from Aaltra just what motivates l'employé, still in his manual chair, when he blocks a motorcycle from leaving its parking spot on the street, but he places his wheelchair in front of the cycle and refuses to move, planting himself firmly even when a man and woman both try to move him away; he has locked his brakes. In another scene the two, riding along on a bicycle path, refuse to give way to cyclists, despite repeated ringing of bells and demands to move aside. Is this rage or just stubbornness?

If aggression is one emotion that can be observed through the performance of user and wheelchair, so are joy, confusion, anxiety, and solidarity. Those in manual chairs, especially, often lift up their front wheels to signal happiness; we see this in a scene from Born on the Fourth of July: Returning from a tryst with a Mexican prostitute—his first sexual experience since his injury—Cruise/Kovic underlines his joy by weaving around and then tipping up on his rear wheels several times and

185 There is an interesting if blurry tape of Ed Roberts, considered the father of the Independent Living Movement, using his power chair to perform karate. Roberts, who had very limited motor skills, raised the footrests of his chair to nearly the height of his seat and was able to successfully block and strike. "Ed Roberts in NY." Archives of the Independent Living Movement, Bancroft Library, University of California, Berkeley, \#203,

${ }^{186}$ See Spencer E. Cahill and Robin Eggleston, "Managing Emotions in Public: The Case of Wheelchair Users," Social Psychology Quarterly 1, no. 4 (December 1994): 300-12. http://www.jstor.org/stable/2787157. 
balancing there during a conversation with his friend, the William Dafoe character. ${ }^{187}$

In Darius, his pals often playfully hitch a ride on his chair- - My friends ride so much I need to charge admission," he raps in one of his missives to MTV—and he holds a small child in his lap as he scoots down a hallway at his camp. In both Come As You Are and Aaltra, the motor chair users propel their manual-chair pals in a friendly and joyous demonstration. In a newsreel from the 1960s ("Honoring the Handicapped"), which shows several sporting events including competitions in archery and shot put, we see real-life athletes recovering from a race by twirling and lifting their front wheels in a similar fashion. ${ }^{188}$ So too, do the veterans coming off a plane in the 1946 government film What's My Score: doing "fancy loops with \{their\} chromium job $\{\mathrm{s}\}$ " as the narrator phrases it. ${ }^{189}$

There's a lovely scene in Aaltra after L'employé finds a power scooter at the side of the road and steals it, for a while pushing his manual chair along and then abandoning it. At the next roundabout, we see him first with the two chairs and then circling the roundabout in a kind of glory lap, elated, savoring the power and freedom of the power chair. He circles in sync with trucks and cars, an orderly 187 The wheelchair dancer Alice Sheffield describes the wheelie as "a moment of integration...Not about pulling back and balancing your chair as if they were separate...it is about suspending your body, virtually weightlessly, in space." Sheffield, "Showing Spine," 12.

188"Awards and Athletics at Annual Meeting," Employment of the Handicapped "Honoring the Handicapped," MCA/Universal, vol. 39, release 36, 05/02/1966. National Archives identifier 2050956.

${ }^{189}$ Records of the Department of Veterans Affairs, Washington, DC, 1946, National Archives identifier 1367, Moving Images Relating to Veterans, ca. 1945-1975. 
procession of motorized vehicles. The spell is broken when his partner, l'ouvier agricole, arrives and has to struggle madly in his manual chair to make it around the traffic circle.

\section{The Wheelchair as Mediator/Transactor of Emotion}

Complex emotional transactions may be mediated by the wheelchair. I am thinking particularly of Born on the Fourth of July, in which Cruise/Kovic, the young veteran, comes home for his first time in the wheelchair. This is a moment of drama: How will he and his family negotiate their changed relationships? "Everything looks so...different," Kovic remarks as he arrives, and we know he doesn't just mean that the house is painted a new color. Unsure of how to respond to one another, Kovic and his father use the wheelchair to express their feelings. Though his father lifts him out of his car seat, there is a repeated struggle over who will "drive" the chair; "I got it, I got it," Kovic says as his father adjusts the foot rests and begins to push his son. Kovic places his hands on the wheel rims and begins to propel himself, but once again his father attempts to take over. "I'm OK, I'm OK," Kovic says-and he repeats that phrase when his mother finally comes out of the house and embraces him. Is he OK? The struggle over directing the wheelchair becomes intertwined with emotions about the injury; what can this man/boy actually do for himself? What does this loss mean? Certainly this echoes the concerns in The Men, where the questions for the World War II veterans are essentially the same.

We see the wheelchair in an emotional transaction again when Kovic visits the family of his young comrade who fell in friendly fire at Kovic's hand in the confusion of the battlefield. Kovic confesses his "crime" to the father, mother, and 
sister, and we are not entirely sure how they respond; the scene ends unresolved.

But as Kovic leaves the house and makes his way towards a waiting taxi, he is pushed along in his wheelchair by the boy's father. We take this action as a kind of resolution—sympathy, possibly forgiveness. It is a gesture of compassion and intimacy to push the chair.

Here we can see how the chair becomes a mediator of feeling, a third party, a fulcrum between players. In Trying out the Wheelchair (see introduction and chap. 4), Myriam Winance examined the interactions between people and wheelchairs at the moment the appliances were first being fitted and tested. In analyzing the way people "became enabled" to use their wheelchairs, as she puts it, she draws on actor-network theory: Action depends on what she calls a "hybrid collectif,"190 which consists not only of the person and the chair but the other actors, human, and nonhuman, in the environment. "The process of adjustment, which is both emotional and material, makes action possible and fluid," she says. The collectif unmakes and makes a new identity for the user. ${ }^{191}$

\section{The Wheelchair as Identity}

If an athlete like Zupan is able to express his feelings through the combined physical movement of his chair and body, the young man in Darius Goes West has to resort to different means. Here we come rather abruptly to the basic difference between manual and powered chairs and the people who use them. In a manual

${ }^{190}$ Here she draws on and acknowledges the work of Madeline Akrich and Bruno Latour. See reference list in Myriam Winance, "Trying out the Wheelchair." ${ }^{191}$ Winance, "Trying out the Wheelchair," citing her own Ph.D. dissertation: "Thèse et prosthèse. Le processus d' habilitation comme fabrication de la personne," (Paris: La Association Francaise Contre les Myopathies Face au Handicap, Centre de Sociologie de l'Innovation, 2001), 67. 
chair, those with upper-body strength are able to self-propel, and thereby may express both physical strength and emotion through their own muscle power. (One of Zupan's teammates who has virtually no limbs—-just one half-arm -is still able to use the thrust of his body to propel his chair.)

In the power-wheelchair user, we come upon someone who concentrates his entire physical being into one small spot, one point, really, the joystick of his chair. This is mostly due to the user's extreme disability; the power chair was invented for those who could not propel themselves in manual chairs. The user will nearly always keep his hand or fingers on the joystick, which is set into the armrest of the chair on the favored side. As we will see later, in Come As You Are, the joystick and the power that flows through it become literally a lifeline for the motorizedwheelchair user. (See fig. 48.) This relationship with the joystick seems almost explicitly sexual-as when the phallus is seen as the only erotic spot in the body-and all the physical energy of the user, such as it is, is expressed there. ${ }^{192}$ (This seems remarkably similar to the discussion of the Nuer tribesman's spear in Csikszentmihalyi and Rochberg-Halton's The Meaning of Things: In their discussion of preliterate societies, the authors note that while the spear is mostly symbolic; "his weapon conveys to the man the power that he lacks."193 Citing the anthropological study of Evans-Prichard, they write: “...a Nuer is very proud of his spear, ... In a

192 In a 1995 video interview with the attorney and activist Evan Kemp, who had a form of muscular dystrophy, he often seems to stroke the joystick upon which his fingers rest, especially when talking about compassion. Disability Rights Leadership Archives (Motion Pictures 942D, \#142), Bancroft Library, University of California, Berkeley.

${ }^{193}$ Csikszentmihalyi and Rochberg-Halton, The Meaning of Things, 26. 
sense it is animate, for it is an extension and an external symbol...which stands for the strength, vitality and virtue of the person."194

Cars and power wheelchairs may both be seen as vehicles—as motorized cousins, so to speak; perhaps this is why Darius Weems's request to be on MTV's Pimp My Ride seems both obvious and radical. ${ }^{195}$ If you can deck out your car any way you please, whether it's with a turbo engine, a high-grade stereo system, lowriding wheels, or those dangly dice-why not a wheelchair? Yet, as the journalist John Hockenberry points out in a 2012 TED talk called "We Are All Designers," people in wheelchairs, himself included, rarely adorn their chairs. ${ }^{196}$ When his sixyear-old twins, picking up a wheelchair catalog in their home, pointed to a pair of shiny flashing wheels that they encouraged their dad to buy, he initially demurred. "I am a serious journalist," he told them, presumably not someone to express frivolous thoughts. But at their insistence he purchased the wheels, and he claims it changed his identity, for himself and others. No longer was the wheelchair a transmitter of tragedy and angst; now it became a subject of interest and delight. And to a degree, it forged a new image for Hockenberry of himself. "I chose to enhance this rolling experience," he says. "I was no longer a victim. I was commander of the Starship Wheelchair." In making this a "rolling experience,"

${ }^{194}$ E. E. Evans-Prichard, Nuer Religion (New York: Oxford University Press, 1956, 1974), 233, cited in Csikszentmihalyi and Rochebrg-Halton, The Meaning of Things, 26.

195 On the show, which began in 2005, a car in poor condition is "pimped" up, that is, restored and customized, according to the owner's wishes. The original version was hosted by the rapper Xzibit. In Darius Goes West, Weems, in a bid to get on the show, sends in rap songs to make his case.

196 John Hockenberry, "We Are All Designers," TED talk, March 2012, Accessed April 1, 2014.http://www.ted.com/talks/john hockenberry we are all designers.html. 
Hockenberry and the chair as "actants" continue to make and remake the process of identity.

So, too, when Darius imagines his new wheelchair, which he narrates to MTV in a number of drawings and rap-song missives, he is reimagining himself. Now he isn't just the young man with muscular dystrophy with "the raggely wheelchair" which "deserves a tweak" — trailing loose wires, duct-taped and scratched—he is the hip owner of a cool vehicle complete with a Play Station 2, tires with spinners, a flatscreen TV, a hands-free microphone, and a stereo system. This is who he wants to be, the way he sees himself. The wheelchair embodies him, empowering him in a way similar, again, to the Nuer tribesman and his spear. The object doesn't "simply reflect but creates a sense of power" in the user. ${ }^{197}$ The wheelchair of Darius gives him power in a similar way.

Elaine Scarry's work seems particularly appropriate in describing the process of creating Darius's chair: In The Body in Pain: The Making and Unmaking of the World, Scarry says, "The phenomenon of creating resides in and arises out of the framing intentional relation between physical pain on the one hand and imagined objects on the other, a framing relation that as it enters the visible world from the privacy of the human interior becomes work and its worked object... The freestanding made object is a projection of the live body that itself reciprocates the live body...." ${ }^{198}$ The imagined object, the chair, which Darius may literally have

197 Csikszentmihalyi and Rochberg-Halton, The Meaning of Things, 26-27. 198 New York: Oxford University Press, 1987, 280. 
created out of his physical_-or mental_-pain, becomes actual, and that in turn allows for a reimagining of himself.

Perhaps no one's identity is more reimagined than the quad rugby players in Murderball, whose lives are first disrupted by injury or illness and then remade by their involvement in their sport. ${ }^{199}$ For example, in a Youtube video, Steve Brown, captain of the British team in the London Paralympic games, describes hearing the announcement that the games would be played in London "from my hospital bed, where...I couldn't move a muscle..." (fig. 49). He had been working in the travel industry, until he fell off a balcony one day and broke his neck, which resulted in paralysis from the chest down. "No way did I think I'm going to recover from my injuries...and end up leading the team into the Games," he remarks to the interviewer. What he doesn't say but is implied is that he could not have done that without his special wheelchair, which is part and parcel of his rehabilitation and of the game. The process of reimagining and remaking himself came about because of the combined efforts of himself, the chair, and the other actors in his environment. Watching the sport may also remake the notions of others, who have thought of the disabled as invalids and are now confronted by these powerful, aggressive beings. "The concept that someone in a wheelchair can be athletic and compete at high levels of sport," says Rory Cooper, " has helped to remove the stigma of being sick that was long associated with physical impairment."200

In both the cases of Darius and the quad rugby players in Murderball-and

199 Many videos of quad rugby players as well as the film Murderball itself attest to this. See "The World's Most Violent Sport?" Interview with Steve Brown. 200 Cooper, Wheelchair Selection, 271. 
for that matter, in Hockenberry's case-it is the collectif that remakes identity, the counselors, the teammates, and the wider world that interacts with the wheelchair user.

\section{The Wheelchair: Coming Apart and Coming Together}

It is not surprising that the human/machine interaction can cause friction as well as harmony. Even Freud, who himself employed a prosthetic palate due to cancer of the jaw, noted: "When [man] puts on all his auxiliary organs, he is truly magnificent; but those organs have not grown on and they will give him much trouble at times." 201 In films, much comedy has been derived from the mismatch of man and machine, in everything from Modern Times (1936) to Desk Set (1957), and even the wheelchair in particular has been used comically many times, for example, in the first scene of Woody Allen's Sleeper (1973), when Miles Monroe awakens from his frozen slumber; placed in a motorized wheelchair, he begins to weave around and into the assembled doctors. Peter Sellers, too, uses the wheelchair as a comic prop in Dr. Strangelove (1964), during a scene in the war room. Here his arm becomes almost machine-like, detached from him and out of control; at times the hand clamps onto the wheel or the armrest, wrestling the chair back and forth. And as we saw in the 1914 Charlie Chaplin/Mack Sennett silent film The Good for Nothing (see chap. 3), an attendant (Chaplin) tries to maneuver a wheelchair holding a man with a broken leg over a curb, and is stymied over and over again by the third, caster wheel on the back of the chair. Of course, the Chaplin character falls

201 This famous quote from Civilization and Its Discontents is cited in Morra and Smith's introduction to The Prosthetic Impulse, as well as by Sarah Jain in "The Prosthetic Imagination: Enabling and Disabling the Prosthesis Trope." 
and trips multiple times, whether propelling it forward or trying to back it over a curb.

We continue to see this mismatch in the later movies: In Aaltra, for example, man and machine often work at cross-purpose. In an early scene l'employé reaches home from the hospital only to find his new wheelchair cannot cross the raised threshold; he has to abandon his chair by throwing his weight forward and crawling into the house. (The abandonment by his wife-he calls out several times, but no one comes--is in sharp contrast to the scene in The Men (see chap. 4) when Teresa, seeing her husband's predicament when encountering a step in his wheelchair, comes running out to help him.) And there is a parallel in Aaltra between the loss of the chair and the loss of his wife, both beings on which he depends but has to give up.

In Born on the Fourth of July we see Cruise toiling across the uneven surface of a cemetery in winter, on his way to pay his respects to the buddy he mistakenly killed in Viet Nam. Here the difficulty emphasizes the emotional labor required to confront the loss.

In Aaltra, being in the wheelchair is often hard. Kevern (l'ouvrier agricole), in particular, always seems to be laboriously wheeling, and the filmmakers highlight this, placing him on awkward surfaces like grass, cobblestones, and sand. The contrast with other vehicles-trains, motorcycles, airplanes, even the blades of wind turbines--which move easily in the background of various scenes, is obvious.

Aaltra's seeming political incorrectness is also interesting, and harks back to the early-film era, when it seemed acceptable to portray disabled characters in a 
comic way and to use the wheelchair as a prop. The subdued slapstick of Aaltra, with its concomitant pathos, is reminiscent of Chaplin, who made use of characters consistently down on their luck. Like the grumbling uncle or the beggar-cripple who inhabit the boardwalk in The Good for Nothing, Aaltra's characters are never angels. To make their way in the world they beg, borrow, and steal. And it's funny.

But for the real user, the wheelchair is a vital object, and when it doesn't jibe with its human counterpart, the result is usually not comic-or at least it always contains a dose of frustration and, sometimes, pathos. When the power chair of Darius, taped-up, scratched, and over-used, finally dies, we see Darius lose a measure of his independence. When Vicki's power chair in Rolling fails her, she is, as she puts it, stuck. This is made tragically clear one day when, after a number of trips to the repair shop, her wheelchair stops working again while she is on a specialized transit bus. The driver, who cannot bring her into her house-it's against union rules-leaves her and her chair at the curb. Vicki can't get a signal on her cell phone, and she sits in the cold for two hours before a neighbor comes along to rescue her. Here the E and J catalog line "You are the master and the chair is your slave" seems mockingly false. ${ }^{202}$ We might in fact see Vicki as the slave to her mechanical beast. At times, the not-working is dramatically telling, as in Body of War, when during his wedding, Tomas's chair becomes snagged in the train of his bride's gown; the documentarians, knowingly or not, foreshadow the failure of this marriage. (See fig. 50.) These two can't move ahead. This parallels a remarkably similar scene in The Men, when Marlon Brando's wheelchair locks on the napped carpet, also an

202“Premier “catalog, Everest and Jennings, April 1972. 
indication of problems in his marriage.

It is easy to see how the wheelchair and user are united in Murderball; the streamlined performance of person and machine is obvious. The large spinning wheels occlude the athletes' legs, and man and machine really do seem merged as they zoom, gloved hands spinning, across the court. The specialized wheelchairs, with cambered back wheels and a radical seat angle, are not only perfectly fitted to the athletes; like other athletic chairs, they are built to maximize what power and strength the users have and minimize their disabilities. As the athlete says in a BMW video in which he talks about his racing wheelchair, "The chair must be part of you, so you flow into the machine. It should fit to the millimeter."203 These are performance vehicles in the way racecars are-except, one might say, in that they complete their human users, who are lacking a part or ability.

There are many more subtle ways in which we see this union of person and wheelchair in other late-century movies, and they may be even more profound. If we pay close attention to the language and movements of the characters, we can pick up understated clues to the ways wheelchaired individuals perceive themselves and their chairs. In one early scene in Come as You Are, for example, Philip, in a snit, lashes out at the driver Claude. As they are leaving a hotel one morning after a rocky night, Claude, as usual, goes to load all three into their van, Philip, last, through the rear door, by way of a motorized lift. Claude reaches out to touch a handle on the

${ }^{203}$ BMW Presents Men and Machine with David Weir, "March 21, 2012. Accessed December 21, 2013. https://www.youtube.com/watch?v=x7NKsiBqZ1U. 
back of his wheelchair in order to be helpful. “Don't touch me!” Philip shouts, although she has handled his chair and not himself.

In another scene, the young men's parents, furious and worried that their disabled sons have left without telling them, track them down in a hotel just days before they are to arrive in Spain. The confrontation with their sons in a hotel conference room turns intense, becoming a physical conflict. As Philip and Lars swivel madly around the room, Philip's father makes a movement toward the on/off switch of his son's power chair. Philip pleads, “Dad, don't switch me off! " Not “Don't switch off the chair.") Lars, too, when his father puts a hand on the back of his manual chair, shouts, “Don't touch me!” and “Let go!" In all these cases, the chair and its mechanism are blurred with the person. The unity of wheelchair and person is thus articulated, probably without the conscious knowledge of the user. The "power" chair is powerful in the way Phroso's manual chair is in West of Zanzibar, or to the Nuer warrior; it endows a magical selfhood—but only when enabled by or through the touch of its owner.

It is striking that not only wheelchair users but others around them also instinctively comprehend this merging; not only the wheelchair chair user but also others accept the chair as a body part. As Pazzaglia et al. note, it is not just that the machine and body mingle, but that their identity becomes one, to themselves and others. The people become, in the terms of Pazzaglia's group, "enwheeled," whereas the chair becomes humanized. 204

Two interactions in Body of War also make this clear. In one scene when

${ }^{204}$ Pazzaglia et al, “A Functionally Relevant Tool," 5. 
Young and his wife appear on 60 Minutes, the camera follows them as the commentator Mike Wallace accompanies them out of the studio and onto the street. Wallace, in a fatherly, sympathetic gesture, puts his arm around the young wife, but in Young's case, in a gesture of support, Wallace places his hand not on the veteran's shoulder but on one handle of his wheelchair, guiding the chair down the street.

In the documentary Operation Last Patrol (fig. 51), as part of a procession making its way towards the Republican National Convention to protest the Viet Nam war, Kovic and his wounded companions show their solidarity by gripping the arms of each other's wheelchairs while they are being pushed by others. Probably without even thinking of it, they are substituting the arms of their wheelchairs for the arms of their bodies. This is an interesting contrast to the fictional Born on the Fourth of July. Generally, Oliver Stone is faithful to Kovic's story, and Cruise has obviously studied and replicated Kovic's movements. Yet in a similar scene (fig. 52) with a nearly identical procession, Cruise/Kovic and companions do not touch each other's chairs, as they do in the documentary, and directly afterwards Cruise/Kovic is seen gripping the actual shoulder of one of his wheelchaired friends. This seems not as carefully observed and constructed as other, possibly more realistic, scenes.

In the final scene of Body of War, we again see a character offering support by touching the wheelchair rather than the wheelchairist's shoulder. Senator Robert Byrd, who is one of the heroes of the film, is by 2010 old and fragile; he leans hard on his canes when the two leave his office to make their way through the halls of 
Congress. ${ }^{205}$ But as they proceed, Byrd moves both canes to one hand and places his other hand on the wheelchair's push handle. "I prefer it this way," says Byrd. The two move in concert, each lending support to the other, Young pushing forward on his hand rims while Byrd pushes and leans on Young and the wheelchair. The machine moves forward, the person is supported both emotionally and physically.

It's an emotional moment, demonstrating again the melding of chair with person. The handle of the chair becomes, in effect, the veteran's shoulder (fig. 53).

\section{The Wheelchair and User as Master and Slave}

We have seen in the case of Vicki in Rolling how the wheelchair, in a kind of passive-aggressive way—by refusing to function--can assert itself as master. Darius's power chair also (in his eyes), obstinately stops working: "It didn't want to come on no more or nothing," as he explains to the camera. He, too, like Vicki, becomes almost inert with the loss of the power chair, his hands crossed in his lap, a spark of gaiety gone, no longer able to scoot around on his own or offer lifts to friends. The machine gives him energy, but it can also rob him of it. As Tiffany Funk writes, the prosthetic "is always adding, advancing, and giving power to that which it is extending. " ${ }^{206}$ This gives the machine great power, and can even be frightening or anxiety-provoking. When the young counselor in Darius Goes West calls it "creepy" that his friend can drive his wheelchair so fast, he is feeling the anxiety of

205 Byrd, a Democrat from West Virginia, was a member of the House of Representatives from 1953 to 1959, and U.S. Senator from1959 to 2010. At the time of his death in 2010 at the age of 93, he was the longest-serving member of the Senate.

206 Tiffany Funk, "The Prosthetic Aesthetic: An Art of Anxious Extensions," MidAmerica College Art Association Conference 2012. Digital Publications. Paper 1, 3. http://digitalcommons.wayne.edu/macaa2012scholarship/1 
the machine's power in addition to, possibly, the veiled aggression of the user.

Fear of the machine is as old as the Industrial Revolution: Think of the magnificent Corliss Engine inspiring awe and dread as well as amazement because of the power it both promised and threatened to unleash. ${ }^{207}$ Who controlled this manmade yet man-controlling object that could easily kill or maim a worker? Yet what freedom and energy these machines could provide! (Of course there were and are fears by many that machines could rob them of their livelihood, which in many cases have proven true.) Conversely, there is the fear and/or excitement about humans becoming technologized, incorporating the artificial, of people becoming cyborgs. 208

In her dissertation, Funk describes "the shifting of autonomies in our relationship with technology, and how perceived balances and imbalances disrupt the ego and define our autonomy." ${ }^{209} \mathrm{We}$ can almost see this struggle, it seems to me, in the video of the dance company Axis, in the performance called "Full of

207 See Adam Goodheart, "The Machine of the Myth," Design Quarterly 155 (Spring 1992): 24-28; and Gyngell, Adam. "Mechanisms of Fear: Man and Machine at the Dawn of the 20th Century" Brainwave. Posted December 16, 2009. Accessed December 17, 2013.http://www.brainwaving.com/2009/12/16/mechanisms-offear-man-and-machine-at-the-dawn-of-the-20th

208 This idea certainly persists: I happened to see a trailer for the new Robocop movie, in which a corporation creates a new police officer who is half-man, half robot. Naturally, this cyborg gets out of control, and terrible things happen. "Who Is in Control, Man or Machine?" is the message literally plastered across the screen. It is interesting that the new officer is created out of a man who has sustained devastating injuries. "Robocop Trailer 2014 Movie: Official 2013 Teaser," YouTube http://www.youtube.com/watch?v=x4ukwHdACDw, accessed May 3, 2014. One wonders, too, if there is some kind of weird, half-wished-for morality tale in the amazing and tragic, real-life story of the amputee super-athlete Oscar Pistorius, who seemed a near-cyborg with his Cheetah legs, but who in February 2013 was arrested for murdering his girlfriend.

${ }^{209}$ Funk, "The Prosthetic Aesthetic, " 3. 
Words," in which a wheelchair dancer tips, thrusts, wrestles, and at times abandons the chair, as though in a human struggle for power. ${ }^{210}$

There are clearly differences between manual and power chairs in this regard. The user of a motorized chair cannot engage in a physical struggle for possession or control; he can only utilize an off/off switch and control a joystick. Still this implies a symbiosis; neither wheelchair nor user can function without the other. A manual chair is typically used by someone with more strength, and here the interdependency of chair and user seems sharper. I am particularly intrigued by the paraplegic or quadriplegic who can himself take apart and stow his own wheelchair and then depend on the chair for his mobility. There is no complete demonstration of these actions in the later movies; we see this on screen only in The Men from 1950, where Marlon Brando (Bud) folds and stows his chair in the back of his vehicle before he climbs, metaphorically and literally, into the driver's seat, In "Rolling," there is a scene in which Galen drives, and we assume he has placed his chair in the car, but it is not shown. The same is true in Operation Last Patrol, the Ron Kovic documentary. We see Mark Zupan in Murderball propelling not only his everyday chair in an airport terminal but actually collecting his quad ruby chair from Baggage and then rolling it along.

But clearly the stowing and driving - the dependency of each on the otherhappens daily: I have personally witnessed my friend, the disability advocate and anthropologist William Peace, grabbing his rigid frame chair from his car, affixing the wheels, setting it down outside the car door, and transferring from car seat to

${ }^{210}$ Axis Dance Co., Choreography by Marc Brew, posted October 26, 2011, accessed May 2, 2014. https://www.youtube.com/watch?v=AaXn62CEhQk. 
wheelchair, and going on his way, propelling himself in his manual chair-and vice versa. $^{211}$

In these late films, both fictional and documentary, we see a broad array of wheelchairs during a period of innovation. In Body of War and Born on the Fourth of July, lower-tech manual chairs are often so powerfully linked to their users that in language and action, the characters themselves and others acknowledge that wheelchair and user are one: the wheelchairist may refer to parts of his machine as body parts, as himself; a friend or relative might lean on the handles of the chair the way one would lean on a shoulder, realizing that the personal space of the user includes his wheelchair. The nimble athletic chairs that began to appear in the late 1970s star with their users in movies like Murderball, in which young men and their machines remake their identities and themselves in an aggressive game. And the advanced power chairs in Come As You Are and Darius Goes West enable people with severe disabilities, like Philip or Darius, to live and travel and partake in activities others take for granted. The chairs are their lifelines and also their expressions or vehicles of potency and selfhood. In all cases, the relationship between user and chair is a symbiosis, which occasionally fails—as is the case with Vicki and her chair in Rolling - but in which the actants are truly interdependent, only coming alive when both engage.

\section{Conclusion}

${ }^{211}$ For a demonstration of the wheelchair/car maneuver, watch the Youtube video "Paraplegic Transfers In and Out of Four-Door BMW with TiLite ZR." Accessed April 1, 2014. http://www.youtube.com/watch?v=Ete8Wflvvv0. 
"When an object is imbued with qualities of the self, it expresses the being of that person, whether in written words or a chair that was crafted or a photograph. It becomes an objectified form of consciousness no less than words spoken into someone's ear...."

\section{Csikszentmihalyi and Rochberg-Halton, The Meaning of Things 212}

Little has been written on the relationship of human to wheelchair. Yet what has been often reveals the most profound attachment and kinship, as evidenced by the words of such users as Galen Buckwalter, the psychologist who appeared in Rolling. "I live in a manual wheelchair, which is, in a meaningful sense, my legs. I enjoy the gentle dance of playing with gravity as I swivel down slight grades and the jarring thwack of timing the jump across a large crack in the sidewalk - every bit as much as I used to love the feel of freshly cut grass on bare toes...."213

Wheelchair users including William Peace, Leonard Kriegel, National Public Radio's John Hockenberry, the activist Simi Linton, and the dancer Alice Sheffield have also described an extraordinary, interdependent relationship of object and person, wherein the wheelchair merges with or extends the user. One experiences the chair as one might experience one's own body. "I love my wheelchair--every piece of it," says Peace in a posting on his blog Bad Cripple. "It is a part of me, akin to my leg or arm. I cannot envision life without it. It is a vibrant positive part of who I am.” 214

First through an examination of nineteenth-century ephemera, and then

212 Csikszentmihalyi and Rochberg-Halton, The Meaning of Things, 190.

213 J. Galen Buckwalter, “The Good Patient.” New England Journal of Medicine. December 20, 2007:357:2534-535. doi:10.1056/NEJMp078226.

214 "Bad Cripple" blog, posted October 24, 2013, accessed December 23, 2013. http://badcripple.blogspot.com/2013/10/an-ode-to-my-wheelchair.html. 
through a study of modern films, I have explored the relationship of wheelchairs and users, and found numerous examples of this bonding. Unlike Norden's studies, which concerned themselves primarily with the often stereotypical depiction of disabled individuals, I have focused on the object/subject relationship. Using Latour's actor-network theory and drawing on the ideas of Csikszentmihalyi and Rochberg-Halton, I have looked at the emotional transactions and the redefining and remaking of self through these interactions. The primacy of objects in thing theory and in Tom Gunning's "cinema of attraction" have also been essential to this study. Like the scientists Pazzaglia and colleagues, who found that the body schema of many people with spinal cord injuries was rearranged to incorporate their wheelchairs, and Myriam Winance, who demonstrated that user and chair become one entity through a making and unmaking process of the collectif, I have shown the "enwheelment" of the wheelchair user and the manner in which the wheelchair may become the fulcrum of emotional transactions. In all of these instances, the objectthat is, the wheelchair-has it own agency that has not always been acknowledged, an agency that works in tandem with the human-like the Nuer tribesman's spear, which both symbolizes the self and grants the user the power he lacks. The two are a creative whole.

In addition, I have examined how users mark and identify their wheelchairs, and how the users become identified with and molded by their chairs. This is sometimes intentional: for example, the name "DARIUS" is spelled out on the interior of Weems's old wheelchair, and he further expresses his identity by imagining his new chair in all its all glittery excess. But he has also marked his old 
chair in more subtle and less intentional ways, his massive shape and his tendency to lean toward the joystick imprinted onto the seat cushion, the scratches and gouged-out pieces of his armrest, the dragging, taped-up wires. ${ }^{215}$ In Murderball, too, the scratches and dents attest to hard use. The history of its owner is written into itself, like wrinkles on an aging face.

A less-often-considered aspect of the chair is the physical impact it may have on its owner: In Rolling, Galen Buckwalter, who has used a manual wheelchair for decades, is considering switching to a power chair in part because of the physical wear and tear on his own body from wheeling the machine for so long. "Parts of my body have had to absorb the wear and tear of sitting all the time," he says in the film. “I've had increasing pain in both my shoulders, It's not surprising considering I've spent so many years pushing my chair. I've made thousands of transfers in and out of it."

Wheelchairs are freighted with emotion. I mean by this not only that they carry a message just by their being—which they often do, intentionally or not—but also that wheelchairists express emotion through their chairs: aggression, anxiety, joy. The chair can be used as a kind of third party, a transactor of otherwise unexpressed feelings. This is often seen in the movie Born on the Fourth of July, where the Kovic character, newly injured, needs to renegotiate his relationships with family and society.

215 The wheelchair of Ed Roberts, leader of the Independent Living Movement, is a famous example of this: His well-worn chair with its Porsche automobile seat and massive headlights was donated to the Smithsonian by his friends, who drove the chair up to the steps of the Castle directly after a memorial service in Washington, DC, where it now resides permanently as a tribute to his remarkable life. http://www.smithsonianlegacies.si.edu/objectdescription.cfm?ID=127 
In some transactions, the user and/or the others around him literally consider the chair part of his being; we can see this in language and movement: Someone sympathizes by placing a hand on the chair's arm rather than the arm of the wheelchairist himself; a user like Philip in Come as You Are pleads with his father, "Don't switch me off." He means the on/off switch of his wheelchair. The chair's power is his lifeline as much as any vein or artery.

Chair and user represent a unified dyad much of the time, but sometimes things fall apart, and then we don't know if the wheelchair is slave or master, something to depend on or something to abandon, a monster or a lover that turns against its flesh-and-blood user. There is usually a symbiosis between man and machine, but sometimes that fails. Using the machine can be hard, dangerous, faulty, lacking the beauty and ease of interdependent beings. The road can be bumpy, even treacherous.

Yet the road continues. The user needs to move, the wheelchair needs him to turn on a switch, to steer, to animate. Neither can act without the other. When they do, man and machine mesh. To quote David Weir, commenting on his relationship with his racing chair, "The chair must be part of you, so you flow into the machine."216 Perhaps this completes some modern-day fantasy where the wedding of human and technology is consummated.

Readings and personal observations about the closeness of the wheelchair/user bond brought me to this subject. But it was from the point of view of a design scholar that I wrote this thesis, bringing together ideas about the

216 Video, "BMW Presents Man and Machine with David Weir." 
evolution of technology, about our deep and transactive relationship with objects, and how a unique object—-the wheelchair-can be examined historically and aesthetically in film. While the ephemera of the nineteenth century provide a varied and often eloquent record of earlier use and manufacture, the magnified and repeated images of the wheelchair/user unit in twenty- and twenty-first-century films powerfully demonstrate what I have set out to show in my thesis: the embodiment of this specialized machine and the enwheelment of its user.

\section{Bibliography}

Aaltra: A Film by Benôit Delépine, Gustave de Kervern. (Press Kit.) Film Movement. http://www.filmmovement.com/downloads/press/aaltrapresskit.pdf

Ames, Kenneth. "Meaning in Artifacts: Hall Furnishings in Victorian America." Journal of Interdisciplinary History 9, no. 1 (Summer 1978): 19-46.

- - Death in the Dining Room and Other Tales of Victorian Culture. Philadelphia: Temple University Press, 1995. 
Barounis, Cynthia. "Cripping Heterosexuality, Queering Able Bodiedness. " chapter 33, 443-59. In The Disability Studies Reader, third edition, edited by Lennard Davis, New York: Routledge, 2010. doi: 10.1177/1470412908091938.

Bateson, Gregory, "The Cybernetics of Self": A Theory of Alcoholism." Steps to an Ecology of Mind. Psychiatry 34, no. 1 (1971): 1-18.

Buckwalter, J. Galen. “The Good Patient.” New England Journal of Medicine. December 20, 2007: 357:2534-35. http://www.nejm.org/doi/full/10.1056/NEJMp078226.

Burns, Stanley B. Shooting Soldiers: Civil War Photography by R. B. Bontecou (New York: The Burns Archive), 2011.

Brown, Bill. “Thing Theory,” Critical Inquiry 28, no. 1, Things (Autumn 2001): 1-22.

Campbell, Courtney, Lauren A. Clark, David Loy, James F. Keenan, Kathleen Matthews, Terry Winograd, and Laurie Zoloth. "The Bodily Incorporation of Mechanical Devices: Ethical and Religious Issues (Part I)," Cambridge Quarterly of Healthcare Ethics 16 (2007): 229. doi:10.1017/S0963180107070259

Cardinali, Lucilla, Francesca Frasinnetti, Claudio Brozzoli, Christian Urquizar, Alice C. Roy, and Alessandro Farné "Tool-Use Induces Morphological Updating of the Body's Schema." Current Biology 19, no. 12, R478-79. doi:10.1016/j.cub.2009.06.048.

Carlson, Thomas. "Rapid Assimilation of External Objects into the Body Schema. Psychological Science 21, no. 7, (July 2010): 1000-05.

Chivers, Sally, and Nicole Markotić, ed. The Problem Body: Projecting Disability on Film. Columbus: Ohio State University, 210.

“Cine-Things: 1924." Thing Theory blog, posted June 29, 2009. accessed Jan. 22, 2014. http://thingtheory2009.wordpress.com/author/brookhenkel/

Colson Corporation, Wheel Chairs catalog. Elyria, Ohio (1948), unpaginated. NMAH Trade Literature Collection, Smithsonian Institution, Washington, DC.

Cooper, Rory A., Wheelchair Selection and Configuration. New York: Demos, 1998. "Wheeled Mobility: Wheelchairs and Personal Transportation." in The Biomedical Engineering Handbook, edited by Joseph D. Bronzino. Boca Raton, FL: CRC Press, 2000. 
Csikszentmihalyi, Mihaly, and Eugene Rochberg-Halton. The Meaning of Things: Domestic Symbols and the Self. New York: Cambridge University Press, 1981.

Davis, Lennard, ed. The Disability Studies Reader. Third edition. New York and London: Routledge, 2010.

Evans, Nancy Goyne. Windsor Chairs: Specialized Seating. New York: Hudson Hills, 1997.

Everest and Jennings. "Lightning” wheelchair brochure. 1983. NMAH Trade Catalogs. Smithsonian Institution.

—__."Premier" Wheelchair Brochure. April 1972. NMAH Trade Catalogs. Smithsonian Institution.

"The First Century of Disability Portrayal in Film: An Analysis of the Literature." Journal of Special Education 3 no. 4 (Winter 1998): 467-79.

Forty, Adrian. Objects of Desire: Design and Society since 1750. London: Thames \& Hudson, 1986.

Funk, Tiffany, "The Prosthetic Aesthetic," An Art of Anxious Extensions" MidAmerica College Art Association Conference 2012. Digital Publications. Paper 1. http://digitalcommons.wayne.edu/macaa2012scholarship/1.

Garland-Thomson, Rosalind. "Shape Structures Story: Fresh and Feisty Stories about Disability." Narrative 15 (1): 113-23

Garrett, Elizabeth Donaghy. At Home: The American Family 1750-1870. New York: Harry Abrams, 1990.

Giedeon, Sigfried. Mechanization Takes Command. New York: Norton, 1969.

Godfrey, Jan, and Marilee Weisman. “A History of Wheelchair Sports: Dr. Lewis Guttmann.” Accessed Sept. 29, 2013.

http://www.spitfirechallenge.ca/Sir\%20Ludwig\%20Guttmann\%20early\%20histor y.htm

Goldsmith, Selwyn. Designing for the Disabled: The New Paradigm. Oxford: Architectural Press, 1997.

Goodheart, Adam. “The Machine of the Myth,” Design Quarterly 155 (Spring 1992): 24-28. 
“Gordon Invalids' Chairs.” Toledo, OH: Gordon Manufacturing Company, (19001910?).

Gunning, Tom. "The Cinema of Attraction," Wide Angle 8, nos. 3-4, (1986): 63-70.

Gyngell, Adam. "Mechanisms of Fear: Man and Machine at the Dawn of the 20th Century" Brainwave. Posted Dec. 16, 2009. Accessed December 17, 2013. http://www.brainwaving.com/2009/12/16/mechanisms-of-fear-man-andmachine-at-the-dawn-of-the-20th

Hanks, David A. Innovative Furniture in America from 1800 to the Present. New York: Horizon Press, 1981.

Harvey, Karen, ed. History and Material Culture: A Student's Guide to Approaching Alternative Sources. London and New York: Routledge, 2009.

Hellman, Mimi. "Furniture, Sociability, and the Work of Leisure in EighteenthCentury France," Eighteenth Century Studies 32, no. 4 (1999): 415-45.

Hockenberry, John. Moving Violations. New York: Hyperion, 1995.

———. "We Are All Designers," TED TALK, June 11, 2012.

http://www.ted.com/talks/john_hockenberry_we_are_all_designers.html.

Jain, Sarah S. "The Prosthetic Imagination: Enabling and Disabling the Prosthesis Trope." Science, Technology, \& Human Values 24, no. 1 (Winter 1999): 31-54. http://www.jstor.org/stable/690238.

Kamenetz, Herman L. The Wheelchair Book: Mobility for the Disabled. Springfield, IL: Charles Thomas, 1969.

Karp, Gary, Choosing a Wheelchair: A Guide for Optimal Independence. Sebastopol, CA: O’Reilly Media, 1998.

Keilbach, Judith. "Houses, Vases, Bicycles, and Rocking Horses: 'Aryanized' Objects in the Documentaries Die Akte Joel and Marianne Heimkehr." Trans. Gabriele Rahaman. Leo Baeck Institute Yearbook 57, no. 1 (2012). 10.1093/leobaeck/ybs014.

Kriegel, Leonard. “Wheelchairs.” Missouri Review 15, no. 3, 1992.

Latour, Bruno. Reassembling the Social: An Introduction to Actor-Network Theory, New York: University Press, 2005). http://dss-edit.com/plu/Latour_Reassembling.pdf. 
Leonard, Robbie B., “To Fold Or Not to Fold?" Rigid vs. Folding Wheelchairs. wheelchairnet.org. TeamRehab Report. March/April 1992: 30-32. http://www.wheelchairnet.org/wcn_prodserv/Docs/TeamRehab/RR_92/92 03art4.PDF.

Lifchez, Raymond and Barbara Strong Winslow. Design for Independent Living: The Environment and Physically Disabled People. London: Architectural Press, 1979.

Loukides, Paul, and Linda K. Fuller. Beyond the Stars: Studies in American Popular Film, Volume 3: The Material World in American Popular Film. Bowling Green, OH: Bowling Green State University Popular Press, 1993.

Marshall, Jackson. "Electric Wheelchair Sprung from Old Types," New York Times, July 4, 1915.

Marten, James. Sing Not War: The Lives of Union and Confederate Veterans in GildedAge America. Chapel Hill: University of North Carolina Press, 2011.

Mihm, Stephen, Katherine Ott, and David Serlin, ed. Artificial Parts, Practical Lives: Modern History of Prosthetics. New York: New York University Press, 2002.

Moore, Rachel Olivia. "Savage Theory: Cinema as Modern Magic." Ph.D. diss., New York University, 1997.

National Foundation for Muscular Dystrophy. Muscular Dystrophy Digest. May 1955 (vol. 1, no. 2); January 1956 (vol. 1, no. 4); March-April 1959 (vol. 3, no 1).

Norden, Martin T. The Cinema of Isolation: A History of Physical Disability in the Movies. New Brunswick, NJ: Rutgers University Press, 1994.

_-_."Reel Wheels: The Role of Wheelchairs in American Movies." In Beyond the Stars: Studies in American Popular Film, vol. 3, "The Material World in American Popular Film," edited by Paul Loukides and Linda K. Fuller. 187204. Bowling Green, OH: Bowling Green University Popular Press, 1993.

Padilla, Jalynn Olsen. “Army of 'Cripples': Northern Civil War Amputees, Disability, and Manhood In Victorian America, Ph.D. diss., University of Delaware, 2007.

Paraplegia News. Phoenix, Arizona: Paralyzed Veterans of America, 1950-1956.

Pazzaglia, Mariella, Giulia Galli, Girogio Scivoletto, and Marco Molinari. "A Functionally Relevant Tool for the Body Following Spinal Cord Injury," PLOS ONE. March 2013, vol. 8, no. 3, e58312. doi:10.1371/journal.pone.0058312,

Peace, William. Bad Cripple blog. Various posts. badcripple.blogspot.com. 
Phillips, Lynn, and Angelo Nicosia. "Clinical Perspectives on Wheelchair Selection." Journal of Rehabilitation Research and Development 24, suppl. 2 (1990): 1-7. http://www.rehab.research.va.gov/mono/wheelchair/phillips.pdf.

Pozzo di Borgo, Philippe. A Second Wind: The True Story that Inspired the Motion Picture The Intouchables. Translated by Will Hobson. New York: Atria,

Presley, Gary. Seven Wheelchairs: A Life Beyond Polio. University of Iowa Press, 2008.

Prown, Jules David. “Style as Evidence," Winterthur Portfolio 15 no. 3 (Autumn 1980): 199.

Pynt, Jennifer, and Joy Higgs. A History of Seating, 3000 B.C. to 2000 A.D.: Function versus Aesthetics. London: Cambria Press, 2010.

- - “Nineteenth-Century Patent Seating: Too Comfortable to be Moral?" Journal of Design History 21, no. 3. (Sept. 1, 2008): 277-88.

Rollins, Peter. Hollywood as Historian. Rev. ed. Lexington: University Press of Kentucky, 1998.

Safran, Stephen P. "The First Century of Disability Portrayal in Film: An Analysis of the Literature." Journal of Special Education 31, no. 4 (1998): 467-79.

Scarry. Elaine. The Body in Pain: The Making and Unmaking of the World. New York: Oxford University Press, 1985.

Serene, Frank H. Reference Information Paper No. 1XX. (no date)“Federal Records, Presidential Libraries, and Donated Materials Relating to Disabilities in the Holdings of the National Archives and Records Administration." www.archives.gov/research/...with-disabilities/reference-info-paper.pdf.

Shapiro, Joseph P. "Re-inventing the Wheel," Alicia Patterson Foundation blog. April 15, 2001, accessed September 16, 2013. http://aliciapatterson.org/stories/re-inventing-wheel

- - " "The Screaming Neon Wheelchair," in No Pity: People with Disabilities Forging a New Civil Rights Movement. New York: Random House, 1994, 21136.

Shell, Marc. "The Cast of Rear Window; Or, Cinema and Akinesia." 150-77. In Polio and its Aftermath. Cambridge, MA: Harvard University Press, 2005.

Sheppard, Alice. "Showing Spine," unpublished paper, presented at Future of Disability Studies workshop, Columbia University, February 9, 2012. 
Sheumaker, Helen, and Shirley Teresa Wadja. Material Culture in America: Understanding Everyday Life. "Disability and Disability Studies," 152-56. Santa Barbara, CA: ABC CLIO, 2008.

Smith, Marquard and Joanne Morra, ed. The Prosthetic Impulse: From a Posthuman Present to a Biocultural Future. Cambridge, MA: MIT Press, 2007.

Sobchack, Vivien. "A Leg to Stand On." In The Prosthetic Impulse: From a Posthuman Present to a Biocultural Future, edited by Marquard Smith and Joanne Morra. Cambridge, MA: MIT Press, 2007.

Sokolove, Michael. "The Fast Life of Oscar Pistorius," New York Times Magazine, January 18, 2012. http://www.nytimes.com/2012/01/22/magazine/oscarpistorius.html?pagewanted=all\&_r $=0$.

Spastic Review. Volumes 1-10, 1940-1949.

"The Electriquette Is Back." Committee of One Hundred. Spring 2013, unpaginated. http://www.c100.org/newsletter/archive/2013-1.pdf.

Tremblay, Mary. "Going Back to Civvy Street: A Historical Account of the Impact of the Everest and Jennings Wheelchair for Canadian World War II Veterans with Spinal Cord Injury." Disability \& Society 11, no. 2 (June 1996): 149-169,

Vidler, Anthony. "Homes for Cyborgs," In Not at Home: Suppression of Domesticity in Modern Art and Architecture, 161-78. Edited by Christopher Reed. London: Thames \& Hudson, 1996.

Wigley, Mark. "Prosthetic Theory: The Disciplining of Architecture." Assemblage 15 (1991), 7-29.

Winance, Myriam. "Trying out the Wheelchair: The Mutual Shaping of People and Devices through Adjustment." Science, Technology and Human Values, 31, no. 1 (January 2006): 52-72.

Woods, Brian and Nick Watson. "In Pursuit of Standardization: The British Ministry of Health's Model 8F Wheelchair, 1948-1962." Technology and Culture 45, no. 3 (July, 2004): 540-51.

- - N"No Wheelchairs Beyond this Point: A Historical Examination of Wheelchair Access in the Twentieth Century in Britain and America." Social Policy and Society 4, no. 1 (January 2005): 97-105.

"A Short History of Powered Wheelchairs," Assistive Technology 15, no. 2

(Winter 2003): 164-80. http://www.ncbi.nl.nih.gov/pubmed/15137733. 
Woods, B., D., N. Watson, and D. MacKenzie. A Historical Sociology of the Wheelchair. Full Report of Research Activities and Results, Economic and Social Research Council, 2004. http://www.esrc.ac.uk.

\section{Filmography}

\section{Feature Films}

Aaltra (2004). Directed and produced by Gustave de Kervern and Benôit Delépine, DVD: New York: Film Movement, 2006.

Body of War (2007), Directed by Ellen Spiro and Phil Donahue, Mobius/Phil Donahue Enterprises.

Born on the Fourth of July (1989). Directed by Oliver Stone. DVD: Burbank, CA:

Universal Pictures, 2012.

Come as You Are (also called Hasta la Vista) (Belgium, 2011). Directed by Geoffrey Enthoven. Kinepolis.

Coming Home. Hal Ashby, director, 1978. DVD: Beverly Hills, CA: Twentieth Century Fox Home Video.

Darius Goes West: The Roll of His Life (2007). Directed by Logan Smalley. Athens, GA: Darius Goes West.

Interrupted Melody (1955). Directed by Curtis Berhardt. DVD: Burbank, CA: Warner Bros. Entertainment 2009. 
The Intouchables. (France, 2011). Directed by Olivier Nakache and Eric Toledano. Quad Productions.

Lucky Star (1929). Directed by Frank Borzage, director. Craze Digital Movies, Daily Motion. http://www.dailymotion.com/video/xq8gq5 lucky-star shortfilms. Posted April 19, 2012, accessed April 7, 2014.

The Men (1954), Fred Zinnemann, director, Stanley Kramer. Stanley Kramer/United Artists.

Murderball (2004). Directed by Henry Alex Rubin, Dana Adam Shapiro, directors. DVD. New York: Velocity/Thinkfilm, 2005.

Musical Chairs (2012). Directed by Susan Seidelman, Dream Dance Co.

Rear Window (1954) Directed by Alfred Hitchcock. VHS: Burbank, CA: MCA/Universal Home Video, 1984.

Sympathy for Delicious (2010) Directed by Mark Ruffalo. DVD: Los Angeles: Maya Films, 2010.

The Waterdance (1992). Directed by Neal Jimenez and Michael Steinberg. VHS: Burbank, CA: Columbia Tristar Home Video, 1992.

West of Zanzibar. (1928) Directed by Tod Browning, DVD: Burbank, CA: Turner Entertainment, 2012.

Whatever Happened to Baby Jane (1962). Directed by Robert Aldrich. Warner Bros.

\section{Video Clips, Shorts, Television}

Awards and Athletics at Annual Meeting, Employment of the Handicapped "Honor the Handicapped," MCA/Universal, vol. 39, release 36, 05/02/1966. National Archives identifier 2050956.

“BMW Presents Men and Machine with David Weir.” March 21, 2012. Accessed December 21, 2013. http://www.youtube.com/watch?v=x7NKsiBqZ1Uhttp://www.Youtube.com /watch?v=x7NKsiBqZ1U

Evan Kemp interview. Disability Rights Leadership Archives. Motion Pictures 942D, \#142. Bancroft Library, University of California, Berkeley. 
Fatty and Mabel at the San Diego Exposition. (1915). Directed by Fatty Arbuckle. Keystone Films. 14 minutes. b/w, silent. http://www.youtube.com/watch?v=l8cebyi-s1k, accessed April 7, 2014.

"Full of Words." Axis Dance Co Choreography by Marc Brew, 2011. http://www.yhoutube.com/watch?v=AaXn62CEhQk, Posted Oct. 26, 2011, accessed May 2, 2014.

The Good for Nothing, (Also called His New Profession) (1914). Directed by Charlie Chaplin. Mack Sennett (Keystone Film). 16 minutes, b/w, silent.

http://ia600304.us.archive.org/21/items/CC 1. Accessed April 7, 2014.

Rolling (2007). Directed by Gretchen Berland, fourwheeldrive productions. http://www.thirteen.org/rolling/thefilm/.

What's My Score? U.S. Department of Veterans Affairs, 1946. Records of the Department of Veterans Affairs, 1946, Natl Archives identifier 1367. Moving Images Relating to Veterans, 1945-1975.

\section{Appendix}

William Peace, anthropologist/activist and writer of the blog Bad Cripple, posted this in response to a talk he previewed, which was based on the first chapter of this thesis and presented at a workshop for the Future of Disability Studies, Columbia University, New York, NY, on October 25, 2013.

\section{THURSDAY, OCTOBER 24, 2013}

An Ode to My Wheelchair

Penny Wolfson, author of Moonrise, is writing about the history of the wheelchair. I find her work fascinating. Remarkably, no definitive book about the history of the wheelchair exists. Wolfson's research is historically oriented. I find the photographs of early wheelchairs Wolfson has found fascinating. It is not the wheelchair that I am interested in. Rather I wonder what did the person think of their wheelchair. Did they consider the wheelchair as an empowering device? The early wheelchairs I assume were made one by one with a specific person in mind. One image and person sticks out as particularly interesting. Stephan Farffler circa 1655, a German watchmaker made the first self propelled wheelchair. 


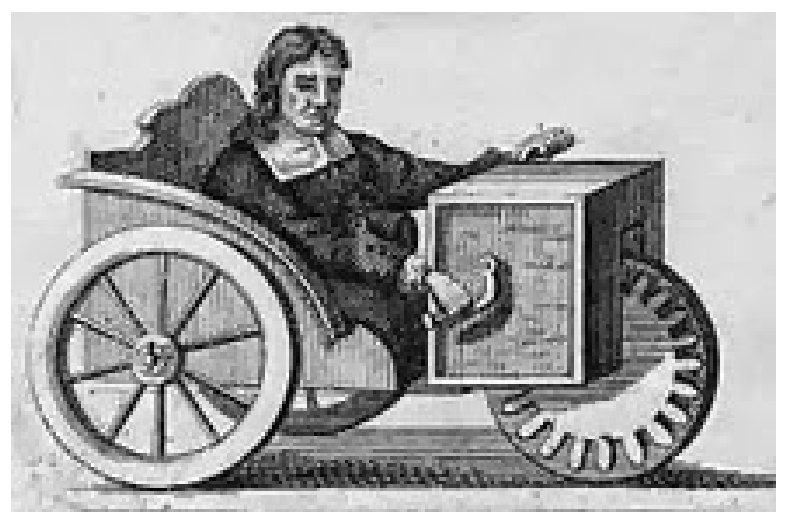

Using a little imagination and adding contemporary materials the above photograph could easily be reconfigured to be a modern day handcycle. Imagine the box in front is transparent. I see no reason a watchmaker could not have a set of complex gears inside the box. Streamline the seat, lower everything to the ground and I can readily imagine my handcycle.

Today, wheelchairs are mass produced and the vast majority are poorly designed. For the last two years I have been looking for a light weight wheelchair and have failed to find something I like and can afford. I am discouraged but hopeful. I think we are on the cusp of developing radically new and improved wheelchairs. I was supposed to be in New York tomorrow acting as a respondent to Wolfson who is presenting her research at Columbia. Below is my reply to her presentation. It might be an awkward read as I react directly to Wolfson's work. But I still think it is worth a read. My focus is on the rigid frame wheelchair and why I am optimistic about the future. I am very interested in what some old time crips can add to the development of rigid frame wheelchair in California circa 1980.

In September 2010 I found a huge wound on my hip. It appeared suddenly. For the first and only time in my post spinal cord injury life I had a severe, grossly infected wound. Such wounds can and do result in death. I was lucky to have survived. I spent four weeks in the hospital before I was medically stable. I was tethered to a wound vacuum for 6 months. I did not sit up for 10 months. I was bed bound for more than a year. It took another year to recover from spending so much time in bed. This experience altered my life. After meeting with Penny Wolfson and discussing her project about the history of the wheelchair memories of my year in bed flooded back. One thought dominated: how did I survive a year without using my wheelchair?

As I write these words my life is normal--or what passes for normal when you are paralyzed. My black labrador Kate is by my side and her body is leaning against my wheel. This is a far cry from a ritual she established with me when I was bed bound. Every morning when I woke she greeted me with great enthusiasm. Tail waging, 
excitement coursing through every fiber of her body she let me pet her head. She then would look at me and turn her head and stare at my wheelchair. Her head would go back and forth several times. The message was not subtle: she wanted me to get up and into my wheelchair so we could play. Sadly, I disappointed her every morning. This ritual made me miss my wheelchair. Despite being paralyzed for over 30 year it was not until 2010 that I realized my wheelchair was an extension of my concept of self. I use self here in a Goffmanesque framework. I was not the only being that was miserable. In many ways my dog and I were in mourning. The pain felt was visceral. I missed my wheelchair. I missed the power it gave me to be independent. I missed the feel of upholstery against my back. I missed pushing against the tires and the intimate knowledge I could discern with a single touch. I missed the speed with which I could move. I missed the dirt I collected during the day on the wheelchair frame. Kate missed my tires and the smells they picked up that are utterly fascinating.

Few paralyzed people have written about the relationship between their body and wheelchair. In John Hockenberry's memoir Moving Violations he wrote about how he felt empowered by his wheelchair on a gorgeous early morning day when crossing the Brooklyn Bridge. Simi Linton in her memoir My Body Politic wrote about her cherry red power wheelchair she named Rufus. Alice Shepperd of Axis dance company contends her wheelchair is an extension of her spine. For me, Wolfson's photographs reinforce the human capacity to imagine and adapt. When I see the photographs Wolfson has amassed my soul is warmed. I am part of a vibrant history few know about. I feel less alone knowing others have adapted. I am just one of a cadre of strong willed individuals that has been empowered by a wheelchair. My overwhelmingly positive assessment of wheelchair use is well out of the norm. For most people, wheelchairs are a poor substitute for bipedal locomotion. A wheelchair is a thing, a product, an inanimate object. Worse yet, people associate a wheelchair with inability and physical incapacity. Symbolically wheelchair use is a sign of weakness, disability, and more than once I have heard others describe it as a portable social isolation device. This is in part why I do my best to combine scholarship and activism. Too many lives have been lost or needlessly compromised because of mere physical difference. Frankly, I love my wheelchair--every piece of it. It is a part of me, akin to my leg or arm. I cannot envision life without it. It is a vibrant positive part of who I am. When it breaks, I am devastated--how could such an integral part of me fail. Such mechanical failures are very rare, most easily fixed. Such thoughts remind me of how I feel when I am sick. How dare my body malfunction.

My obvious and intense feelings for my wheelchair reveals a divide exists between those who use a wheelchair and those that do not. This cultural gulf is the size of the Grand Canyon. I firmly believe there is a disability culture as unique and fascinating as any other subcultural group. Not all crippled people are members--some are not happy nor do they embrace disability culture. The reasons for this are many and varied starting with the overwhelming stigma associated with disability and wheelchair use. Some of us see through this cultural bias--we understand it for what 
it really is--bigotry plain and simple.

I hereby and publicly acknowledge my love for my fire engine red wheelchair with its plain black upholstery, one brake, four wheels, worn black duct tape, excellent hubs, and superb ride. How does a paralyzed person explain the connection with their wheelchair? More to the point, how does one put soul into the care and development of a wheelchair? I for one believe we need to perceive the human wheelchair relationship as a unique form of symbiosis. I am not suggesting as transhumanists would that we merge technology and the human body. Rather I would urge people to forcefully reject the symbolic associations routinely made about wheelchair use. When good design meets disability the results are remarkable--beautiful even. But good design very rarely meets disability. In fact I would argue bad design and disability is the norm. For many years I have wondered why can't disability be fashionable? Why are so many products produced for people with a disability ugly design disasters? The answer to these questions are as simple as they are complex. People with a disability existence is not valued. The problem is not technological but rather social.

The photograph Wolfson showed of Stephen Farffler's wheelchair circa 1655 is a perfect example of empowerment and excellent design. I see that photograph and I am filled with questions about Farffler's life and ability to adapt. The wheelchair he invented and used was a precursor to modern handcycles used by many paralyzed people today. Farffler was centuries ahead of his time and yet is largely unknown because we do not teach or value the history of disability.

Wolfson's photographs also reaffirmed my intense dislike for Everest and Jennings, the foremost wheelchair manufacturer from the 1930s to 1980. Harry Jennings invented the first folding wheelchair for his friend Herbert Everest, a paraplegic. Unlike all other wheelchairs manufactured at the time, E\&J models were made of tubular metal. The wheelchairs they made folded and were designed to fit into the trunk of a car. This revolutionary design enabled Everest and Jennings to go out together during an era when people with a disability were simply not seen in public. The audacity and creativity of E\&J original design was tarnished by greed. For fifty years the company enjoyed a monopoly on the wheelchair industry and rigged wheelchair prices. In the late 1970s the Department of Justice busted the E\&J monopoly via an anti trust law suit. This is when I entered the picture as a paralyzed man in 1978. I owned a number of E\&J wheelchairs when I was first paralyzed. The wheelchairs produced by E\&J had not been substantially modified since 1930 . These wheelchairs were ugly and antiquated. They broke down on a regular basis.

With no options paralyzed people adapted. Innovation did not come from corporations but rather a critical, though very small, mass of people in California. Between the late 1970s and mid 1980s wheelchair design and construction were revolutionized. The rigid frame wheelchair was invented. These wheelchairs were manufactured one at a time. The rigid frame developed a cult like following. They were revolutionary in that the design was simple and made for rugged use. Early 
testing of the rigid frame often involved dropping the frame off the roof of a building or throwing it out of the back of a car going $60 \mathrm{mph}$. The frames did not break. Ideas were borrowed from aviation, motorcycle, and bicycle industry. What really set the rigid frame wheelchair apart was the fact they were made with a heart. That is they were designed with the user in mind. And that user was an active man or woman. A person that was going to have a typical life.

Paralyzed people were at the forefront of development. The wheelchairs were cheap--in 1980 they sold for $\$ 500$ at most. Dozens of companies popped up on the west Coast. Most went out of business. The business model utilized was terrible. Many wheelchairs were sold at a loss. Dozens if not hundreds were given away. The man that made my wheelchair frame 30 years ago had a unique business model. A person was expected to buy not one but two wheelchairs. One wheelchair would be held in reserve by the company--ready to ship at a moments notice. At a prescribed time of year the wheelchair would also be refurbished. New paint, bearings, upholstery, and tires installed. This concept failed and the company went out of business.

The rigid frame wheelchair caught on quick even though initially all health insurance companies refused to pay for them. Paralyzed people knew they were life altering and somehow came up with the money. Through the wheelchair basketball community young men such as myself spread the word. In less than five years orders started to flood into the companies that made rigid frame wheelchairs. They were not equipped to handle the scale of orders received. One company, Quadra, approached E\&J. They were willing to make a deal with the devil. In 1979 E\&J annual sales of wheelchairs amounted to $\$ 100$ million. They had the ability to handle the manufacturing of rigid frame wheelchairs. Quadra approached E\&J and a meeting was held. Jeff Minnebraker and Brad Boegel brought a number of rigid frame wheelchairs to E\&J. They were enthused and explained in great detail why the rigid frame was a revolutionary design. At the time use of aeospace technology was well out of the norm. The use of quick release axles had never been used on a wheelchair. These men expected E\&J would be as excited as they were. E\&J executives literally laughed at them. The attitude at E\&J was paternalistic. Two paralyzed men could not possibly come up with a better design than the largest wheelchair maker in the world. No offer was made and E\&J continued making substandard products. Within five years of this meeting E\&J would go out of business.

E\&J failed because they did not value contemporary design nor did they satisfy the needs of their consumers. They also failed because they were firmly committed to the medical model of disability. When the first rigid frame wheelchairs were manufactured a significant cultural cultural shift took place at the same time. The first users of these wheelchairs utterly rejected to work with durable medical goods companies. Rigid frame wheelchairs were sold at bike shops up and down the west coast. Only one wheelchair dealer, Abbey Medical in Fresno, would sell rigid frame wheelchairs. Fresno's proximity to Berkeley, the home of the disability rights 
movement, was an important variable. Only one person on the east coast sold rigid frame wheelchairs. It was clear to all active wheelchair users the rigid frame design would very quickly replace folding wheelchairs. Marilyn Hamilton, a paraplegic, realized the business potential of the rigid frame wheelchair. She bought Quadra and other makers of rigid frame wheelchairs. She called her company Motion Designs and made the first mass produced rigid frame wheelchairs called quickies. Hamilton was a shrewd business woman who professionalized the wheelchair industry. That is they worked outside the medical model of disability and were wildly successful. She sold her company to the giant multinational corporation known today as Sun Rise Medical. Quickies continue to be sold to this day but have a terrible reputation. In fact Sunrise Medical is the modern day equivalent of E\&J.

In looking at the evolution of the wheelchair in general as Wolfson has done and the rigid frame wheelchair as I have it is my impression that empowering design, truly revolutionary change, requires a complex series of events to take place at the same time. I am particularly hopeful because a unique generation of wheelchair users are coming of age. I refer to these young men and women as post ADA cripples. This is the first generation of crippled people that have had close to typical life expectations and they will demand wheelchairs that match their lifestyle just as I did back in 1978. From a technical standpoint, we are at a cross roads as well. The introduction of light weight but strong carbon fiber materials are being used for the first time by wheelchair companies. One such design from Sweden, the Panthera X, weighs in at less than 10 pounds. It is the lightest wheelchair ever manufactured. It is also the most expensive manual wheelchair manufactured (cost exceeds $\$ 10,000$ ). It is my hope innovative designs such as the Panthera $\mathrm{X}$ is a sign of what is to come.

My concern is socio-economic: are we as a society willing to invest in people with a disability? That is are we willing to provide people with a disability the very best and well designed empowering devices? I also worry have we replaced one disability stereotype with another? Previously we have associated wheelchair use with physical infirmity and the elderly. Now I wonder do we associate wheelchair use with sporty young people. I would argue we need to offer a wide range of choices for people that use a wheelchair. Just as we have a dizzy array of choices for chairs we purchase for our homes I see no reason we cannot offer the same unlimited number of choices for people that need to use a wheelchair. I even have a name for this concept--chairwear. Sadly, I am not that clever. Chairwear is an idea suggested by Graham Pullin that I think has great potential.

Posted by William Peace at 3:15 AM

William Peace

An anthropologist by trade (PhD 1992 Columbia University), I am interested in disability rights and activism. 


\section{ILLUSTRATIONS}

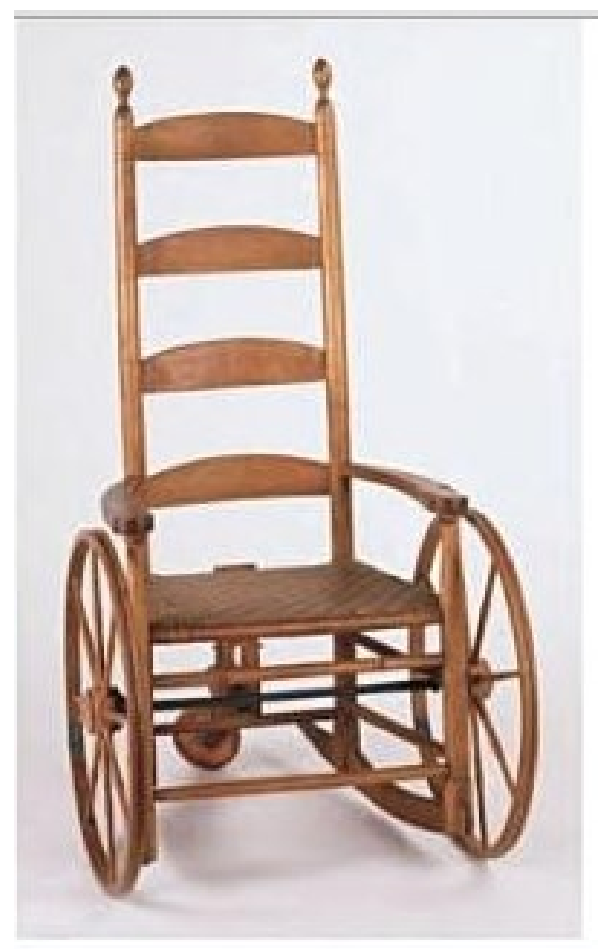

Figure 1. Rocking Armchair Adapted to a Wheelchair, 1810-30. Maker unknown, Watervliet/New Lebanon, NY. Birch, maple, beech, ash splint, chestnut, walnut, brass, iron, steel. 47 1/2” x 26” x 31 3/4 “. Collection of Shaker Museum/Mount Lebanon, New Lebanon, NY, 1957. 8417.1, Photo by Alan LaValle. 


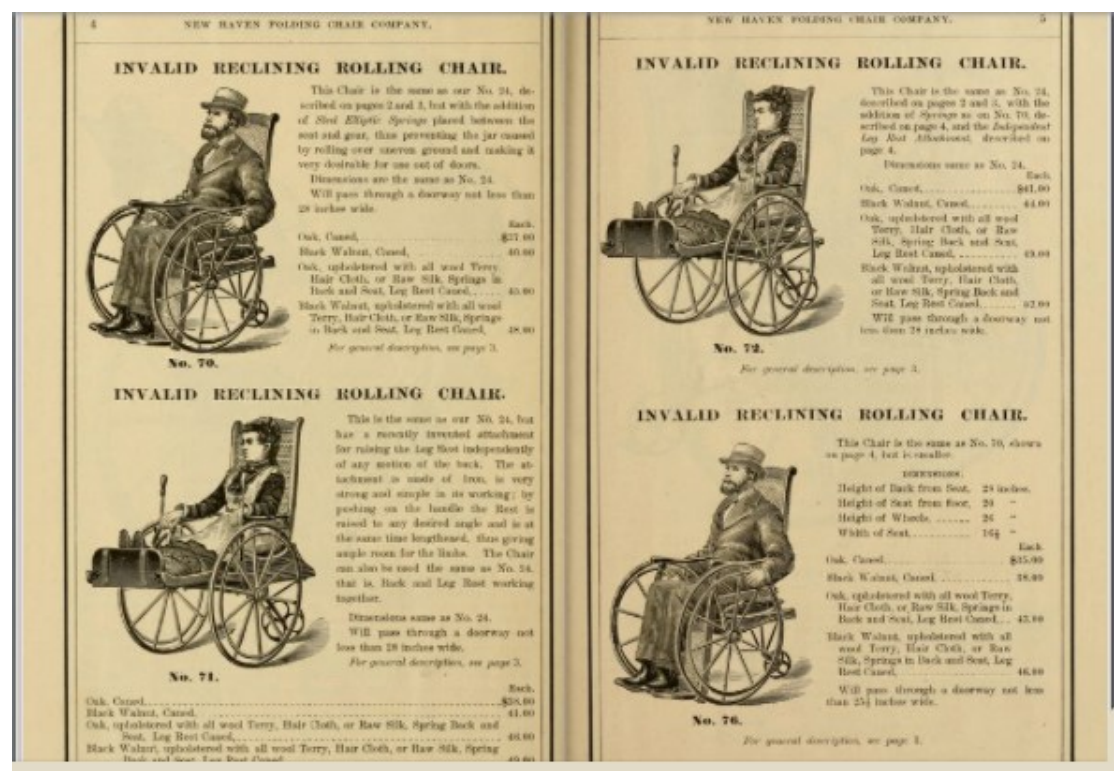

Figure 2. Seventeenth Annual Illustrated Catalogue and Price List of Folding Chairs and Invalid Rolling Chairs (New Haven, CT: The Company 1879), 4-5. 


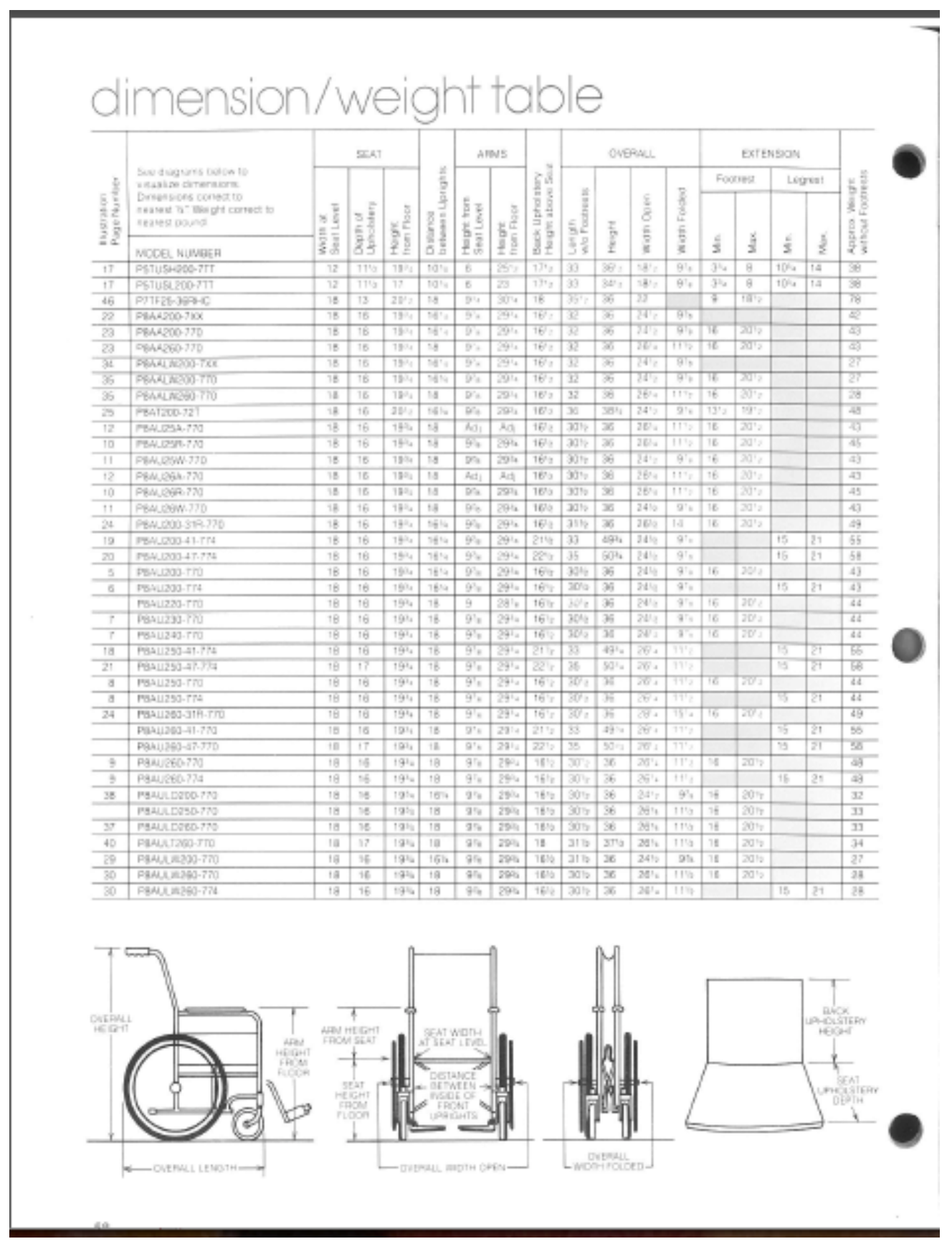

Figure 3. "Dimension/Weight Table, Premier catalog, Everest and Jennings, April 1972, 58. 


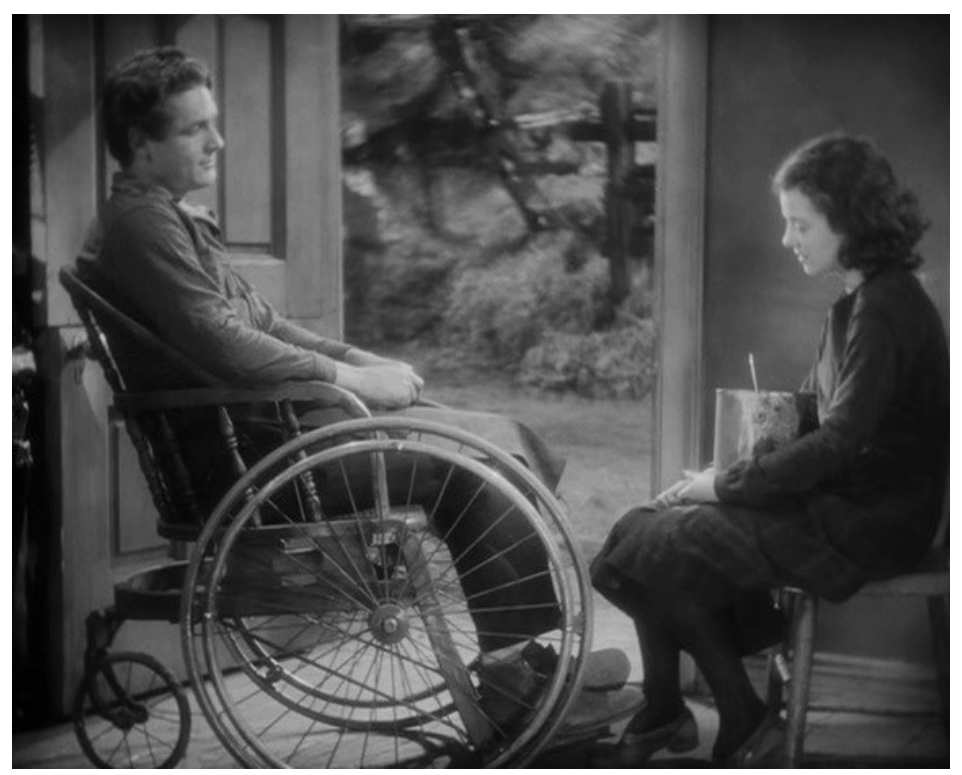

Figure 4. Screen shot from Lucky Star (1929), with Charles Farrell and Janet Gaynor, directed by Frank Borzage. Fox Fillm.

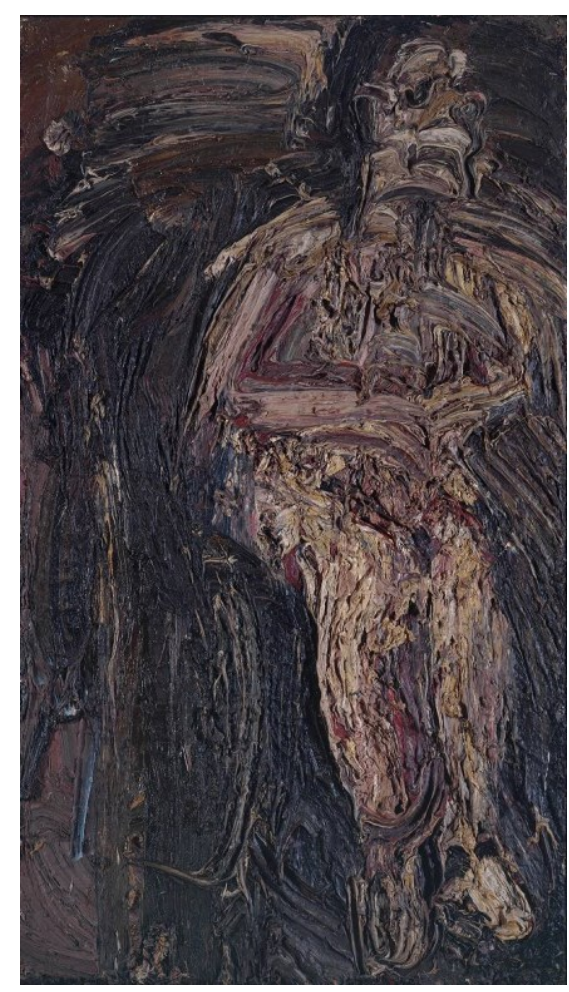

Figure 5. Man in a Wheelchair, Leon Kossoff, 1959-62. Oil paint on wood, support: 2134 x $1232 \mathrm{~mm}$, frame: 2290 x 1385 x 75 mm, Tate Gallery, London, T00564. 


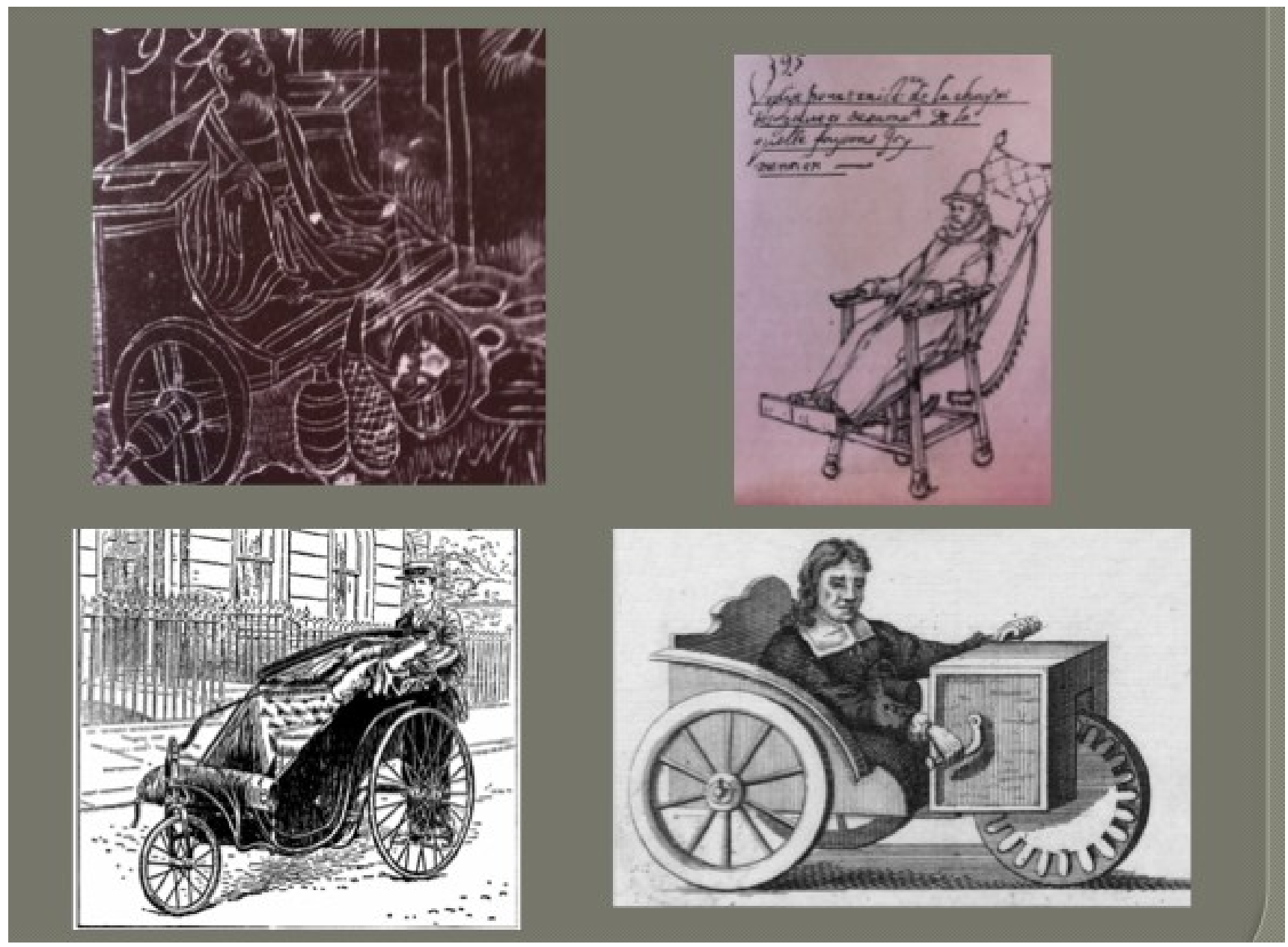

Figure 6. Wheelchairs: clockwise, from top left, Sarcophagus, $6^{\text {th }}$ century A.D., China; King Philip of Spain's gout chair, 1595; Stephen Farffler's hand-operated wheelchair, ca. 1655; and a Bath chair, England, 18 ${ }^{\text {th }}$ 19th century. First three from Herman Kamenetz, The Wheelchair Book: Mobility for the Disabled, Springfield, IL: Charles C. Thomas, 1969, chap. 1; last, Wikipedia, entry "Bath chair," http://en.wikipedia.org. 


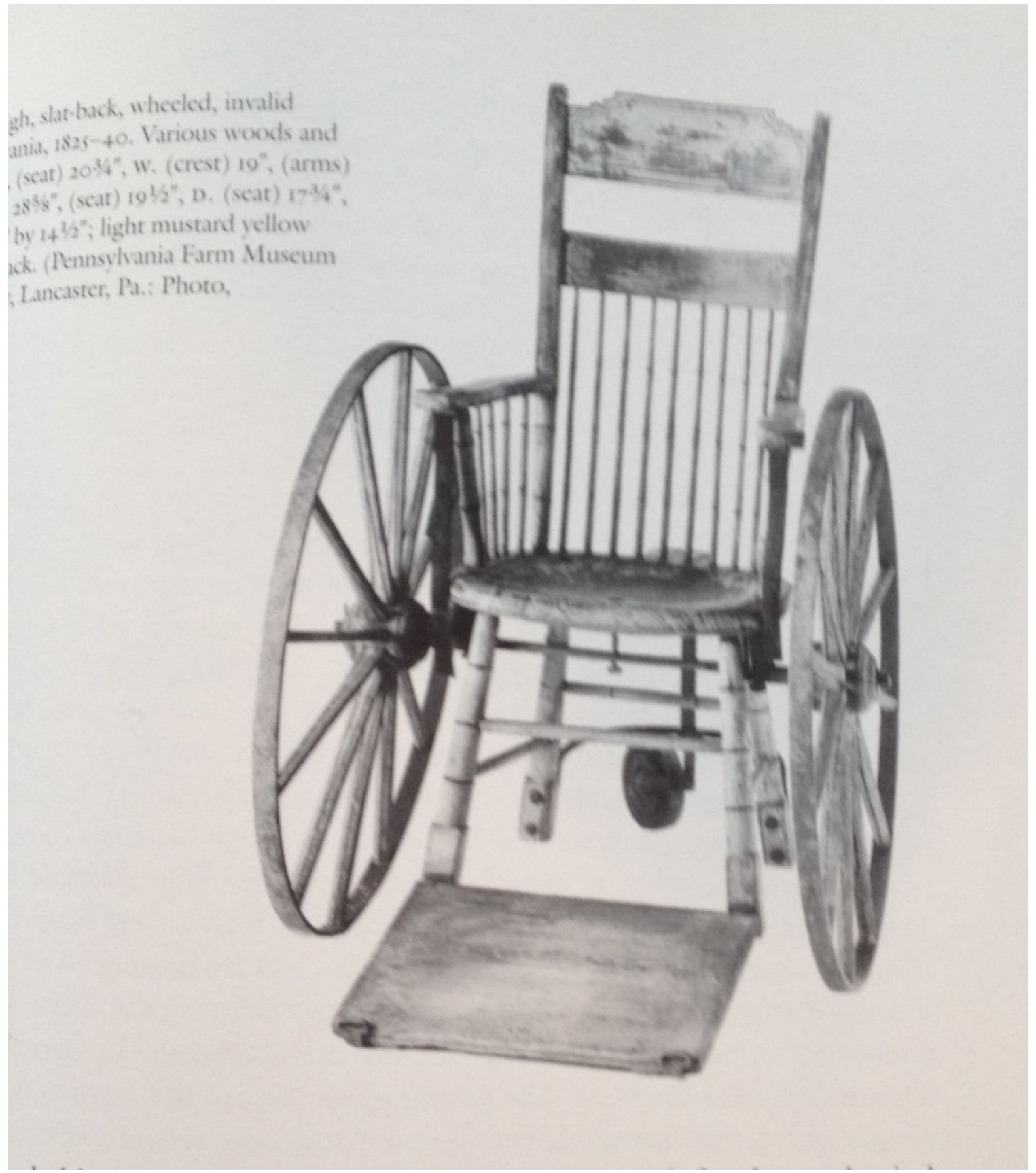

Figure 7. Wheeled invalid chair, 1825-40; various woods and iron; light mustard yellow ground with black. Pennsylvania Farm Museum of Landis Valley Lancaster, PA, photo, Winterthur. In Nancy Goyne Evans, American Windsor Furniture, Specialized Seating (New York: Hudson Hills, 1997), 91. 
T. B. MINNISS

Invalia Carriage.

No. 2.708

Patented May 10, 1853
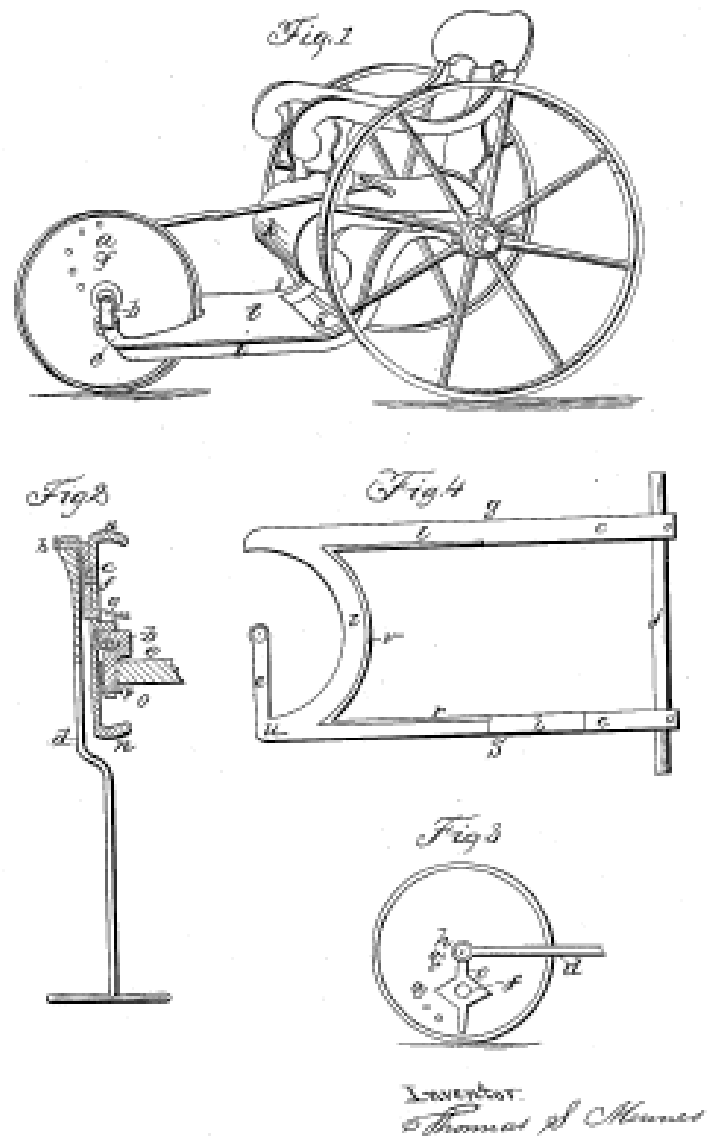

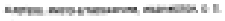

Figure 8. Patent drawing for locomotive invalid chair, Thomas Minniss, U.S. Patent 9708, May 10, 1853. 


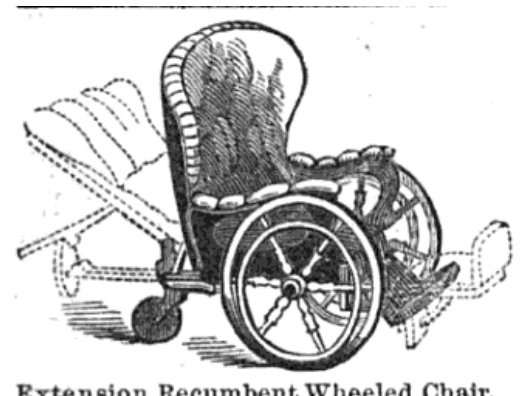

\section{H. THOMPSON, Patent Chair}

MANUFACTURER,

TU EAST BROADWAY,

NEW YORK,

Formerly KING SON, of Broadway.

Extension Recumbent Wheeled Chair.

Speculum Chair,

Chairs for Invalids,

Office, Library, Parlor,

Barber, Rocking,

Bed, Commode, etc., etc.

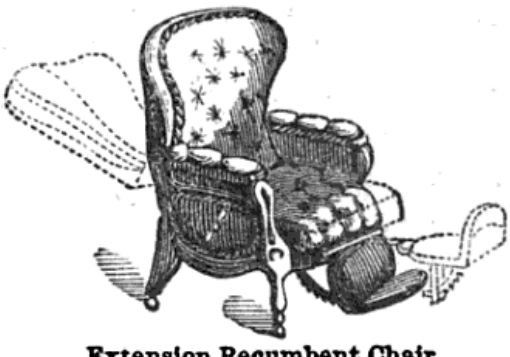

Extension Recumbent Chair.

Figure 9. Advertisement for H. Thompson patent chairs, 1869, in The Medical Register of New York, New Jersey, and Connecticut, New York: Bradstreet and Sons, 1869, 333.

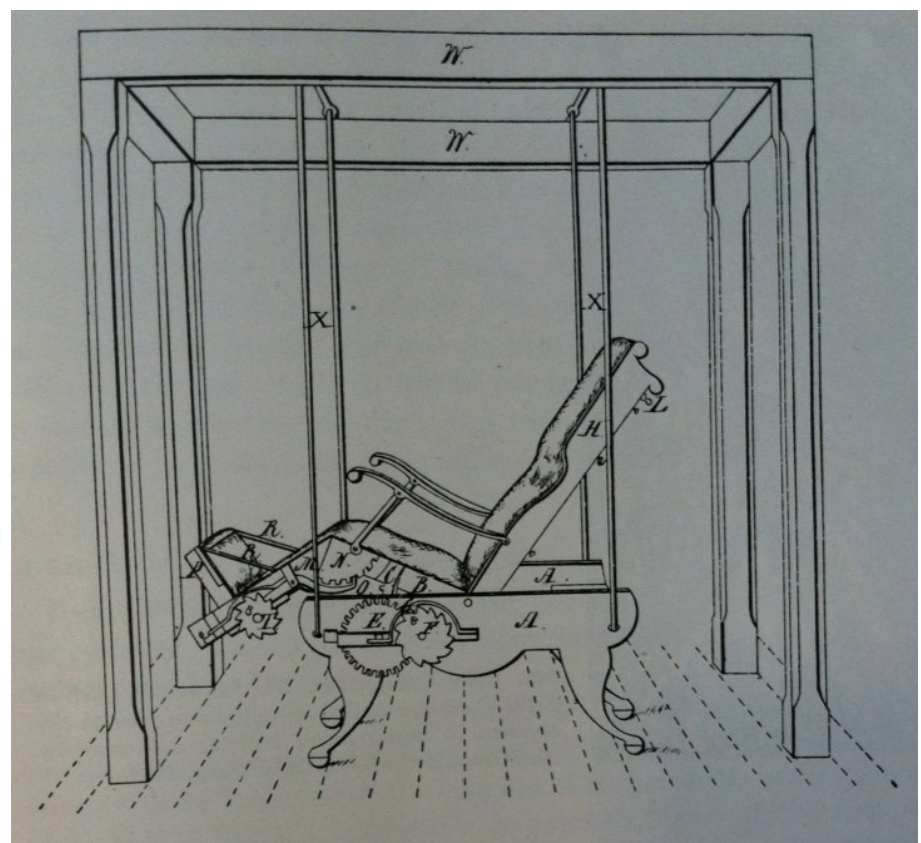

Figure 10. Nineteenth-century invalid chair or variety couch, 1838, in Sigfried Giedeon, Mechanization Takes Command, New York: Oxford University Press, 1948, 411. 


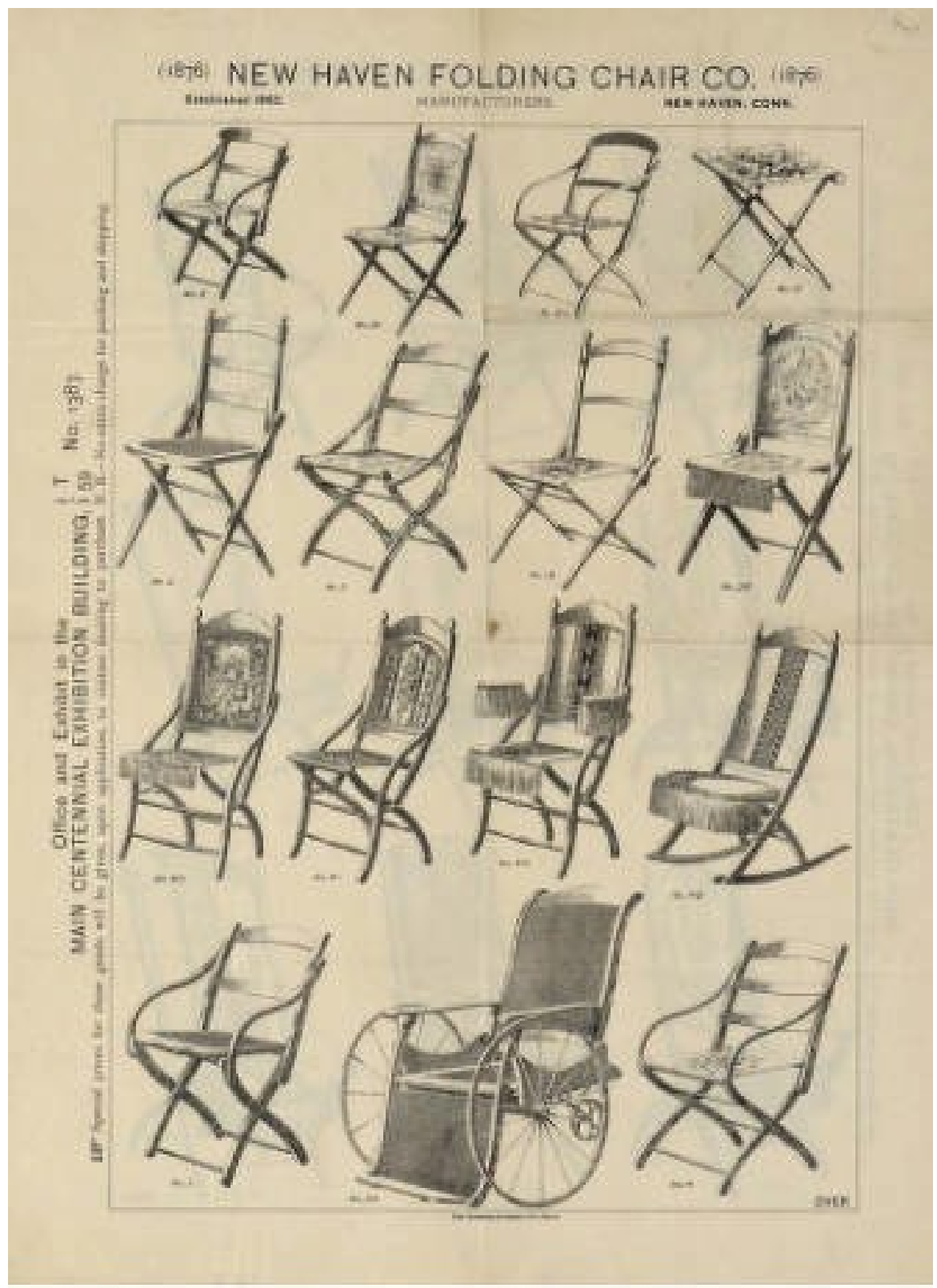

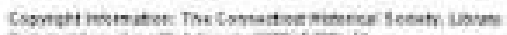

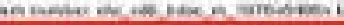

Figure 11. Broadside for the 1876 Centennial, New Haven Folding Chair Co., 1879,

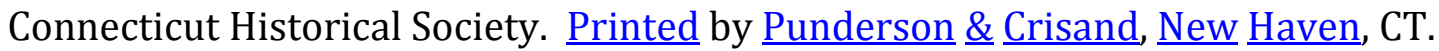
Broadsides Medium 1876, Call \#N5486n. http://www.cthistoryonline.org. 


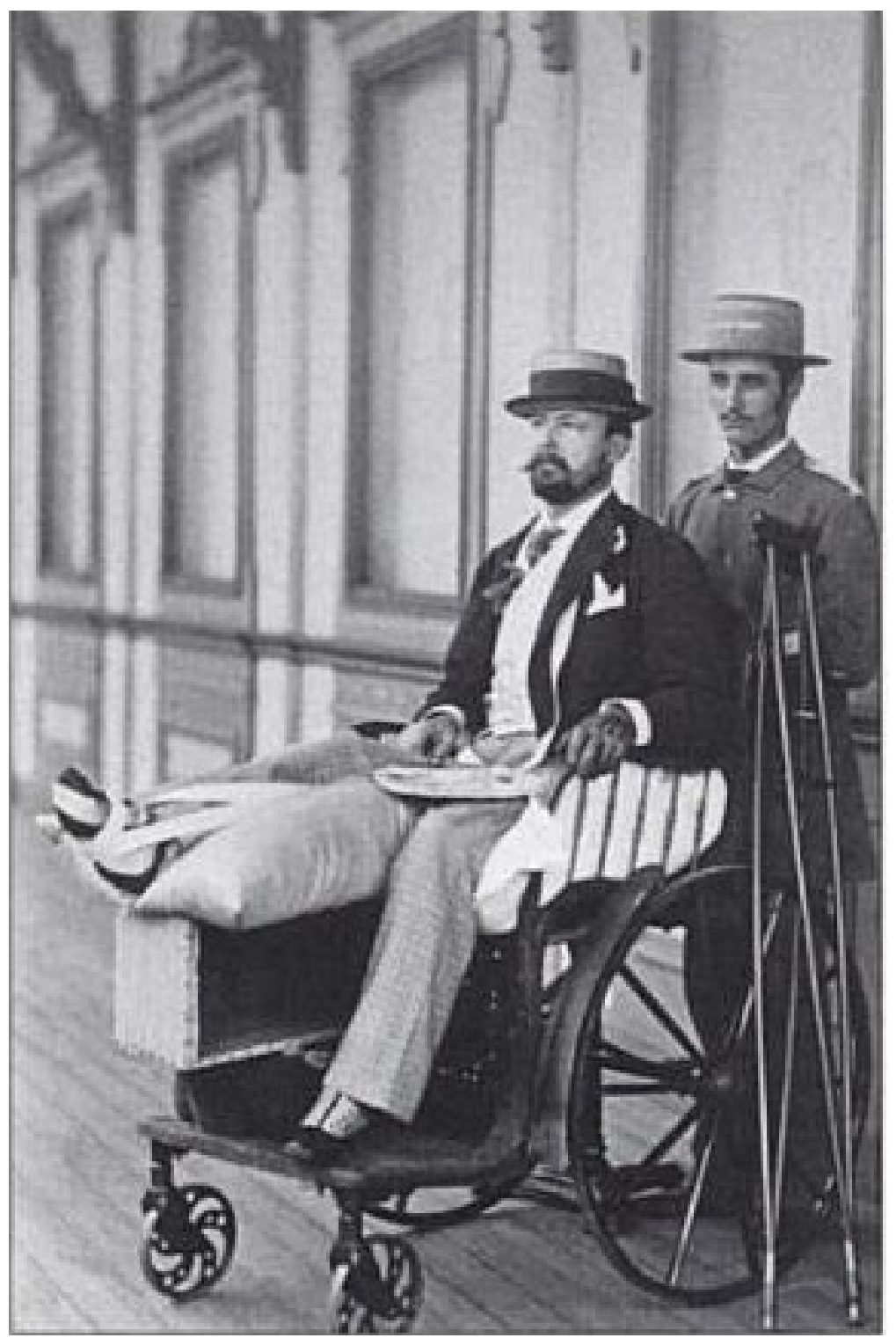

Figure 12. Rolling Chair at the 1876 Centennial, designed by Herbert Smith, in Philadelphia's 1876 Centennial Exhibition, Linda P. Gross and Theresa R. Snyder, Charleston, SC: Arcadia, 2005, 22. 


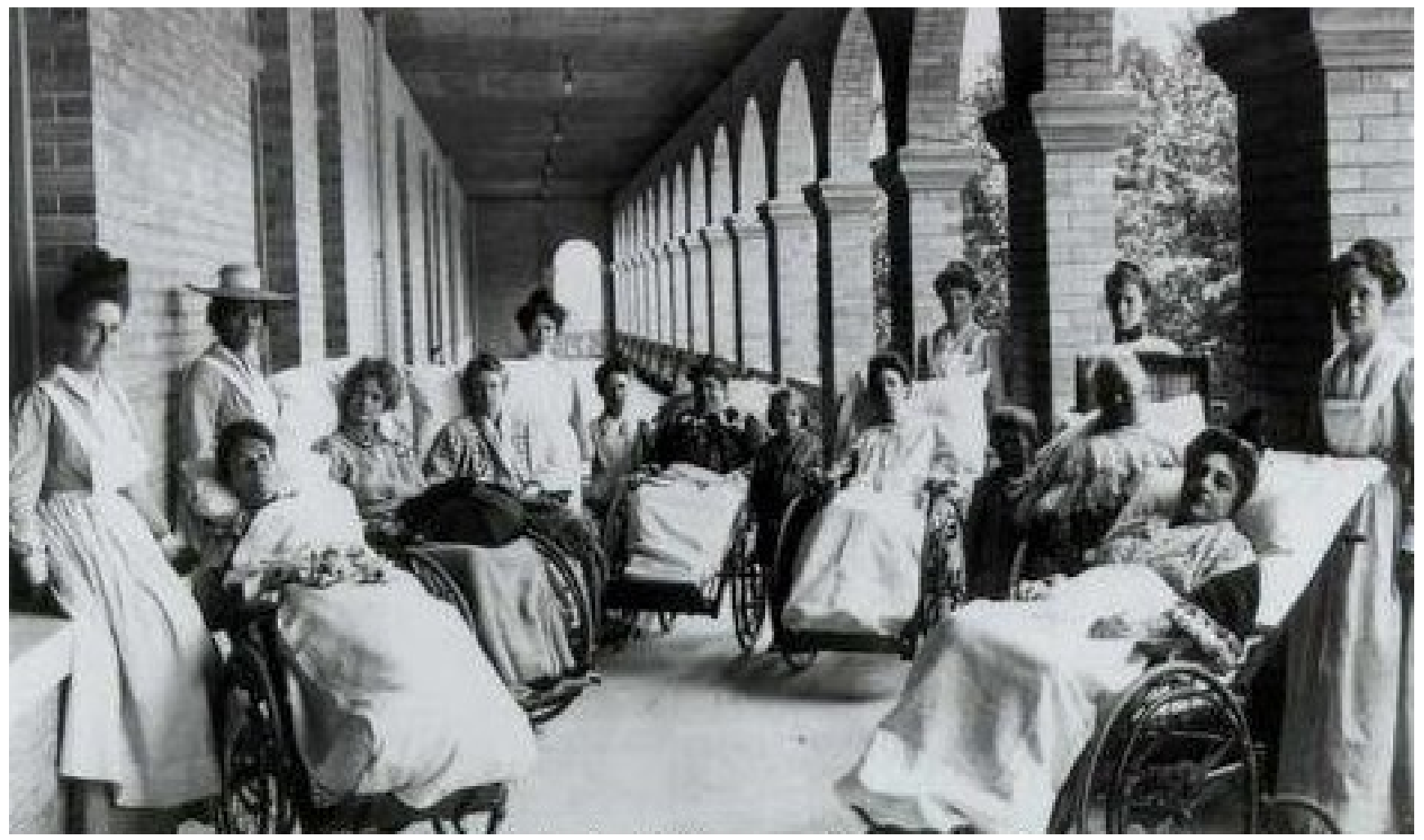

Figure 13. Women in Sanitarium, 1890, Bentley Historical Library, University of Michigan, Disability History Museum Library Collection, http://www.disabilitymuseum.org. 


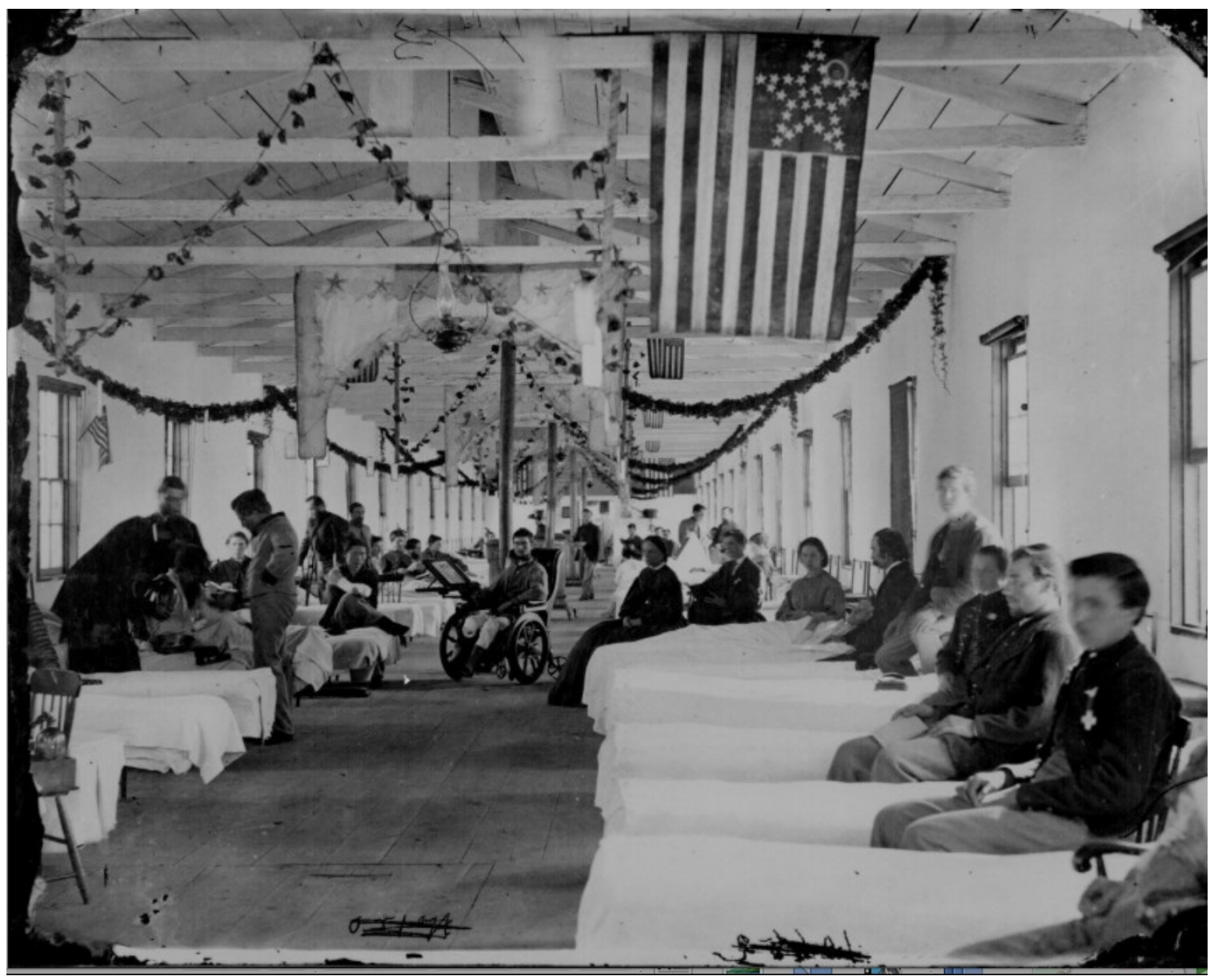

Figure 14. Armory Square Hospital, Mathew Brady, 1863-65, albumen silver print from glass negative, Metropolitan Museum of Art, New York, Harris Brisbane Dick Fund, 1933, accession number 33.65.306. 

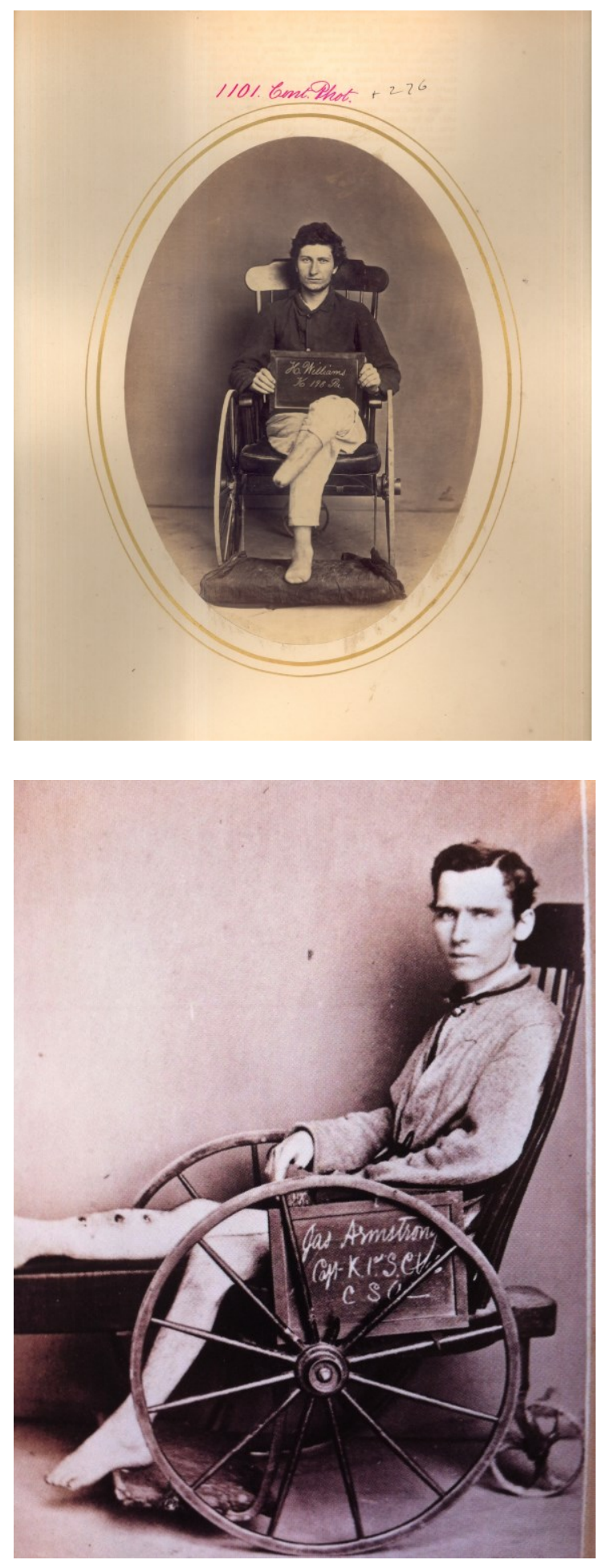

Figure 15. Two Civil War Soldiers in wheelchairs, Top, Jas Armstrong, and bottom, Hiram Williams, Plates 1 and 80, Shooting Soldiers: Civil War Medical Photography, R.B. Bontecou, Plates 1 (Armstrong) and 80 (Williams). 


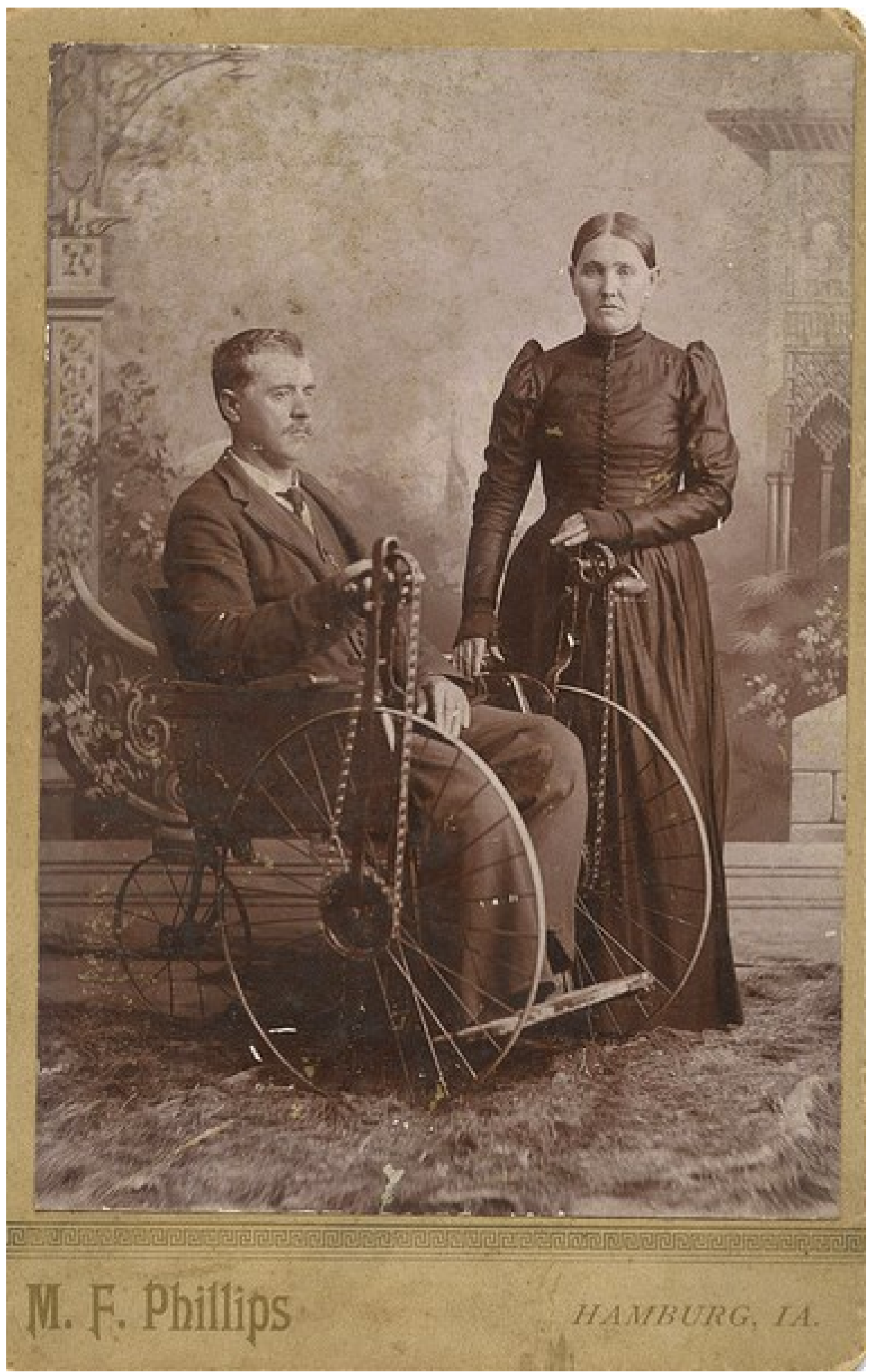

Figure 16. Colonel Elijah Parkhurst and his wife, ca. 1890, in his locomotive chair, M.F. Phillips, photographer, Hamburg, LA, http://www.flickr.com/photos/neatocoolville/6359654641/. 

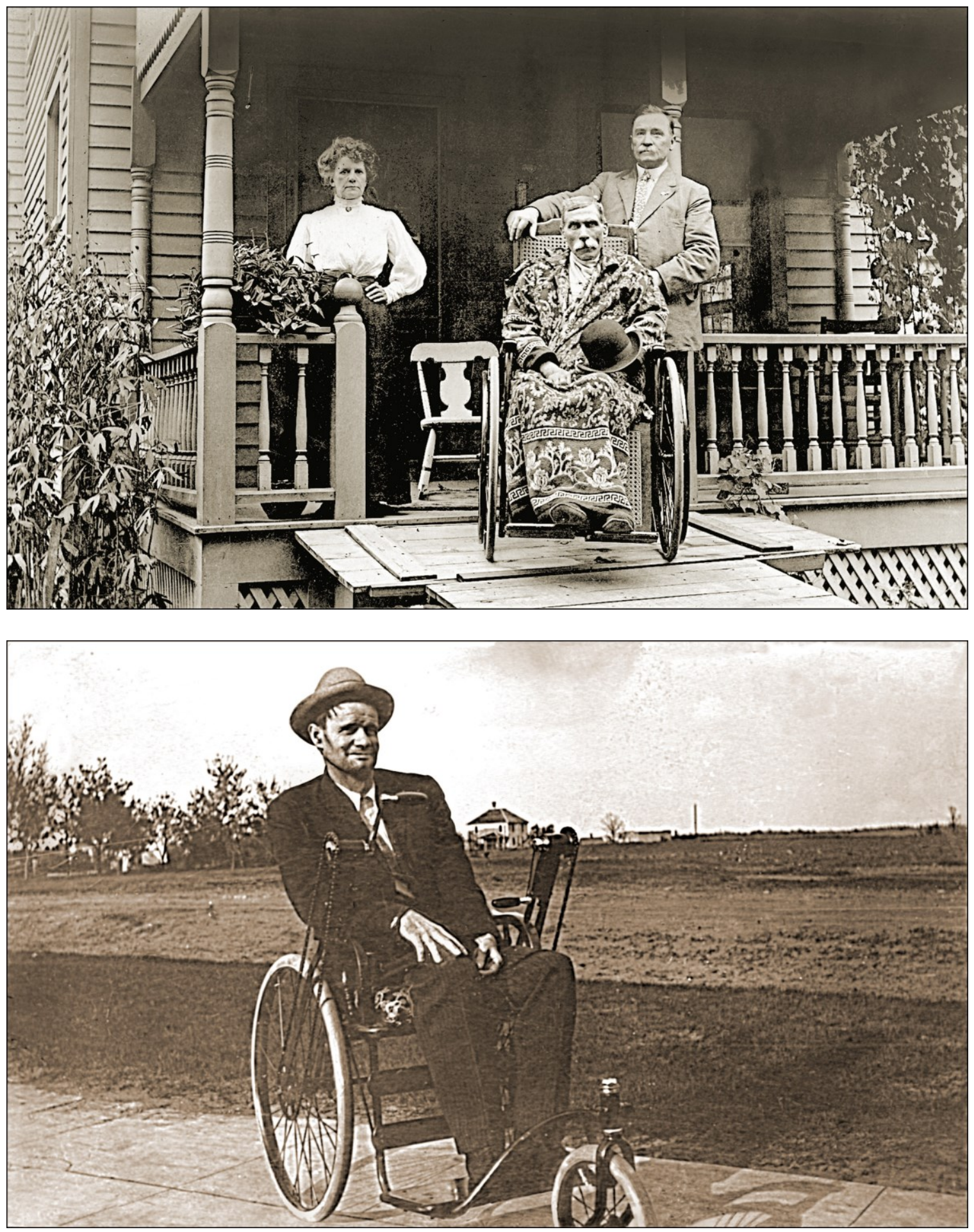

Figure 17. Nineteenth-century photographs of outdoor wheelchair use: Man on a porch in a wheelchair (Shutterstock image ID 1418725); and vintage photo of man in wheelchair (Shutterstock image ID: 230521). 


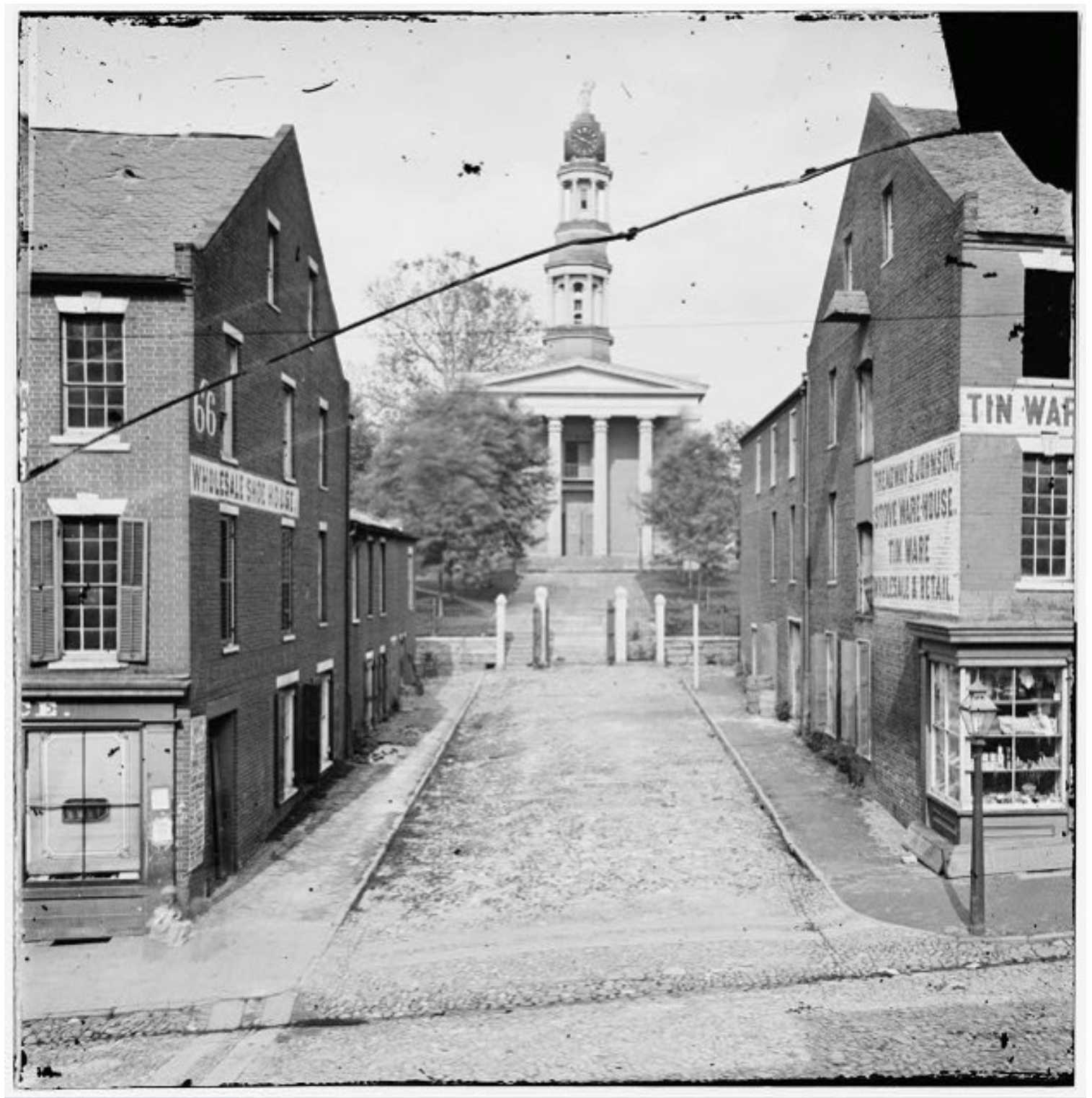

Figure 18. Petersburg, VA, Courthouse, photographer unknown, late spring 1865, Library of Congress, LC-B811-3293. 


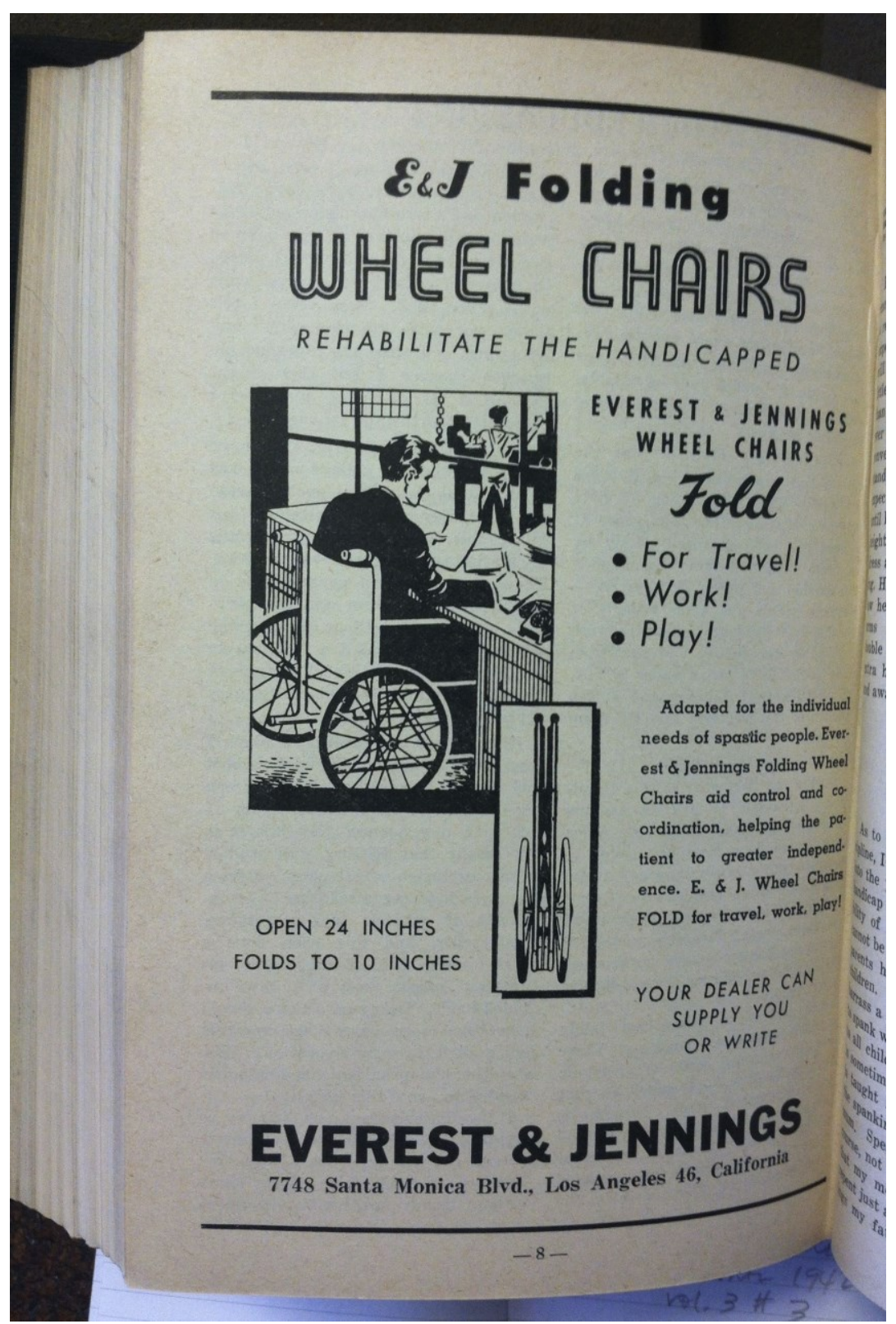

Figure 19. Advertisement for Everest and Jennings foldable wheelchair, in Spastic Review 8, no. 9 (September 1947), 11. 


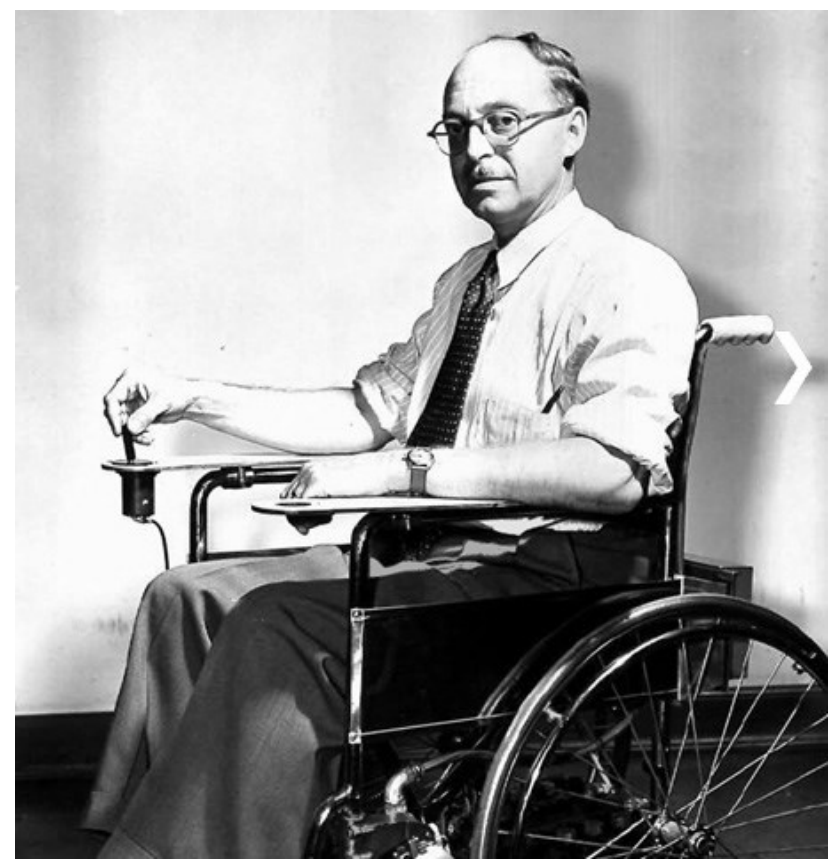

Figure 20. George Klein in the electric wheelchair he invented with the Canadian National Research Council, 1953, in Richard Bourgeois-Doyle, George J. Klein:

The Great Inventor (Ottawa: NRC, 2004), 162.

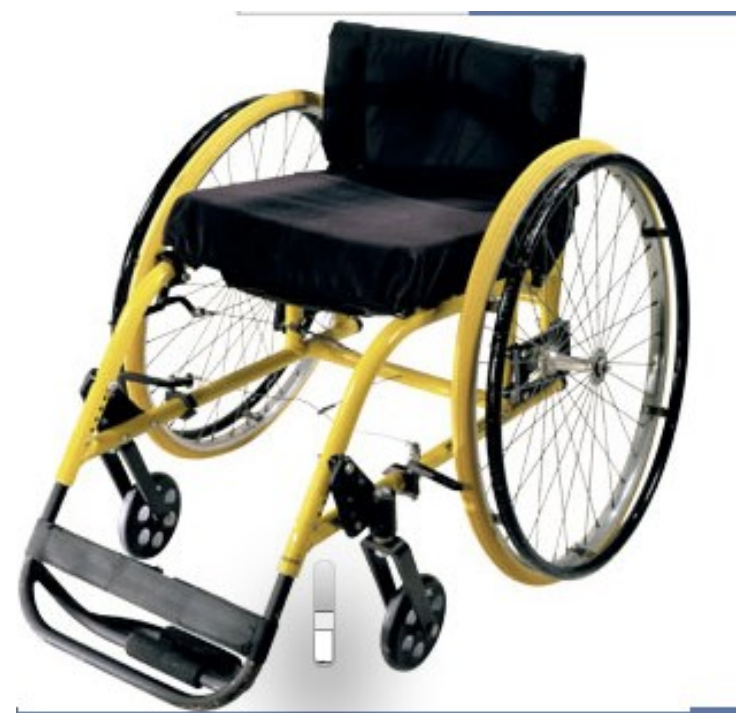

Figure 21. The Quickie, Marilyn Hamilton's tennis wheelchair, 1983. National Museum of American History, Smithsonian Institution, Washington, DC, online exhibition "Breaking Records/Breaking Barriers," history.si.edu/sports/exhibit/removers/wheelchair. 


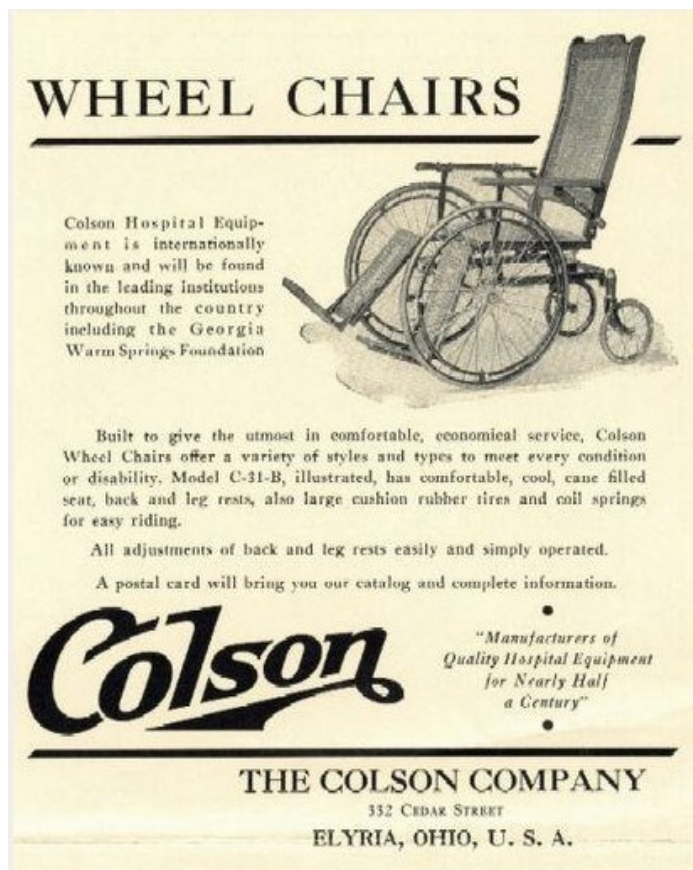

Figure 22. Colson company wheelchair, April 1933, Roosevelt Warm Springs Institute for Rehabilitation Archives, Disability History Museum, http://www.disabilitymuseum.org.

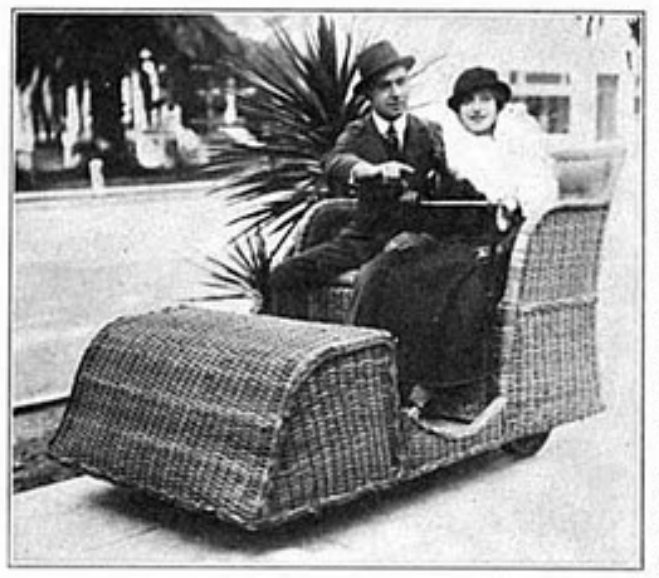

The real, easy, classy, comfortable, luxurious way to see and thoroughly enjoy the Exposition is in an Osborn Electriquette, which supplants the antiquated push-chair and jinrikisha. The only passenger conveyance permitted on the grounds.

The simplicity of operation renders experience unnecessary. A child can drive it. It's great fun.

Stations at each entrance gate, all prominent points, and "Neptune's Wonderland" on the "Isthmus."

EXPOSITION MOTOR CHAIR COMPANY, San Diego Exposition

Figure 23. Advertisement for The Electriquette, 1915, reproduced in Spring 2013 newsletter, The Committee of One Hundred (Balboa Park, San Diego), http://www.c100.org. 


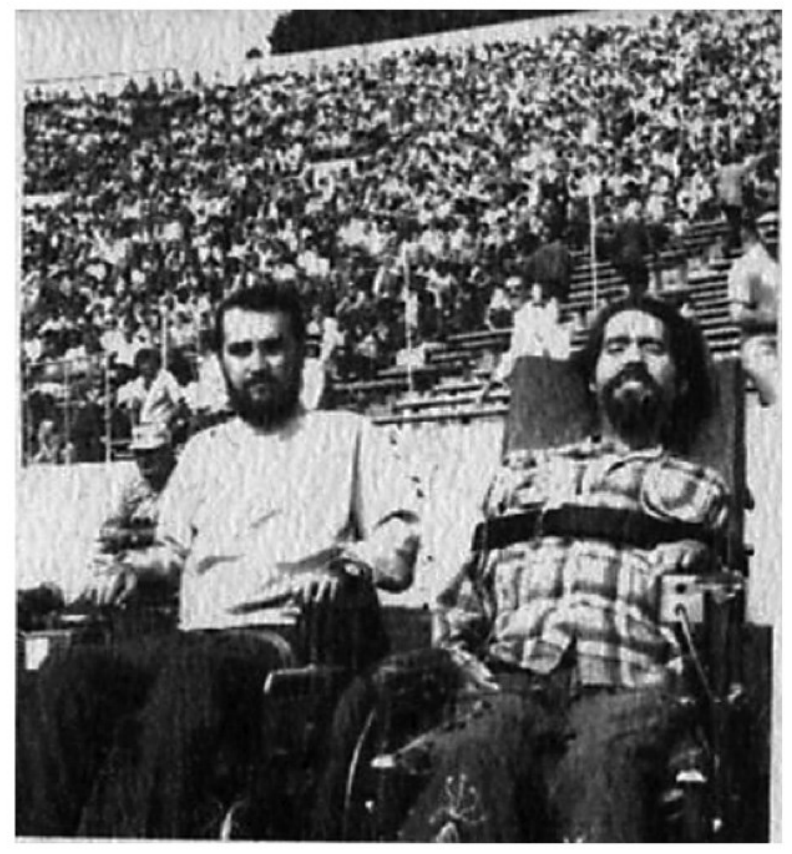

Figure 24. The Rolling Quads at Berkeley, mid 1960s. "The Rolling Quads," by Rebecca Klumpp, Disability Bible, posted April 18, 2013, accessed May 7, 2014, http://www.disabilitybible.com.

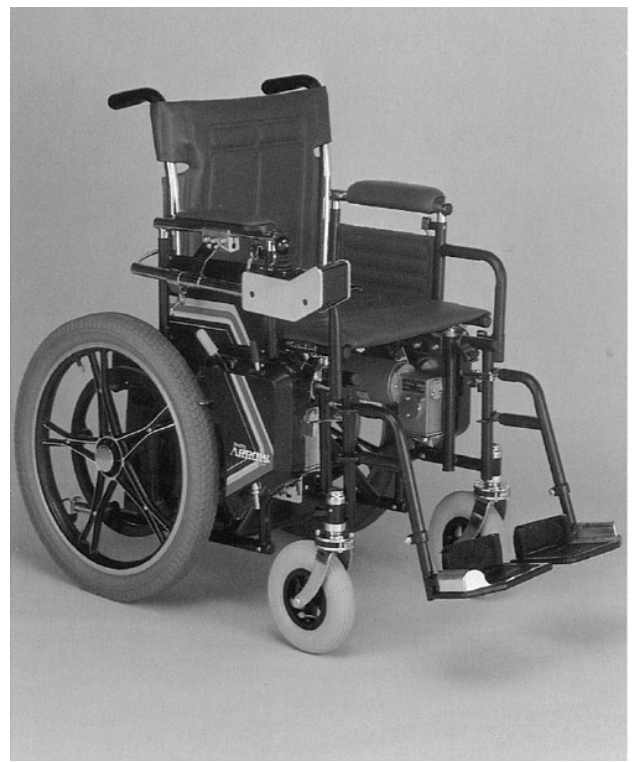

Figure 25. Power wheelchair, Rolls Arrow by Invacare, 1984, NMAH Trade Literature Collection, Smithsonian Institution, Washington, DC. 


\section{Lightning. Pure andSimple.}

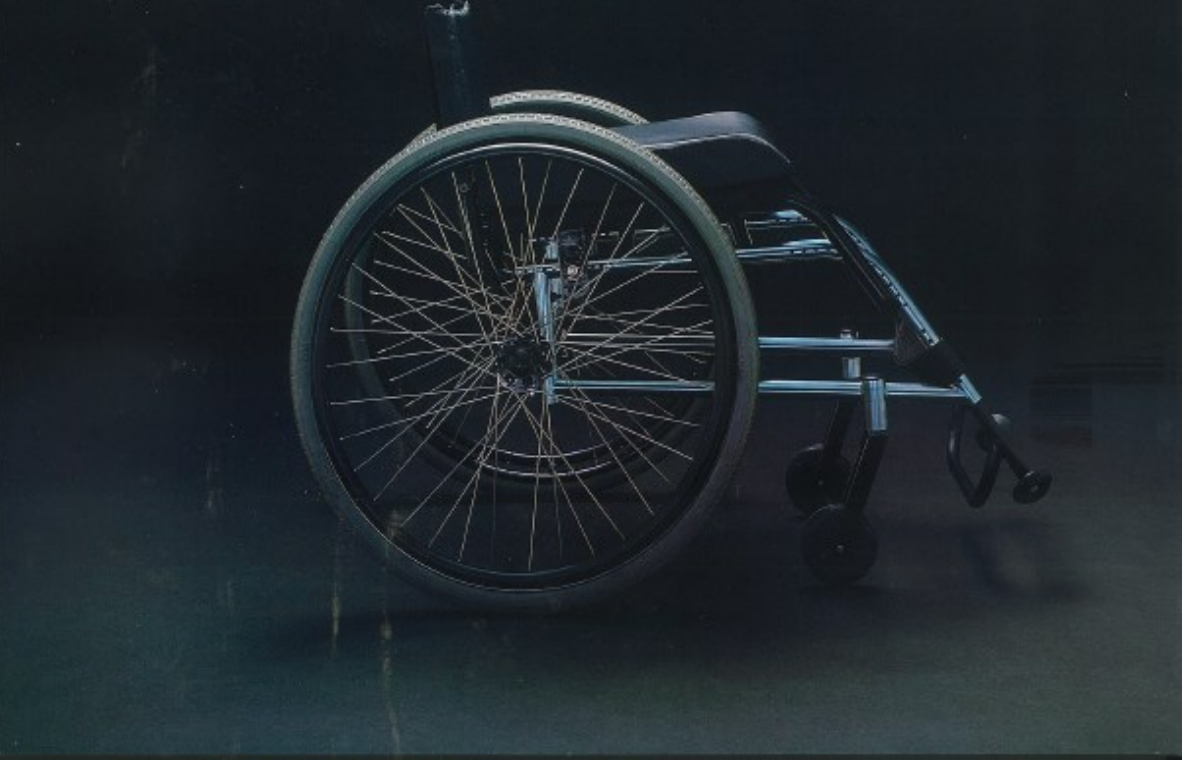

Figure 26. Everest and Jennings "Lightning" chair, 1983, catalog NMAH Trade Literature Collection, Smithsonian Institution, Washington, DC.

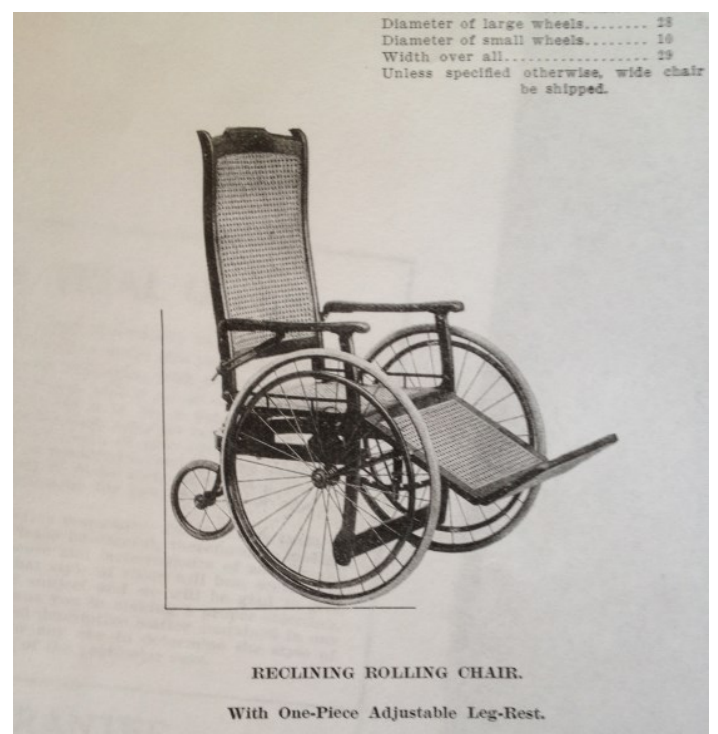

Figure 27. Wheelchair pictured in Gordon's Invalid Chairs catalog, ca. 1900-1910, NMAH Trade Literature collection, Smithsonian Institution, Washington, DC, 32. 

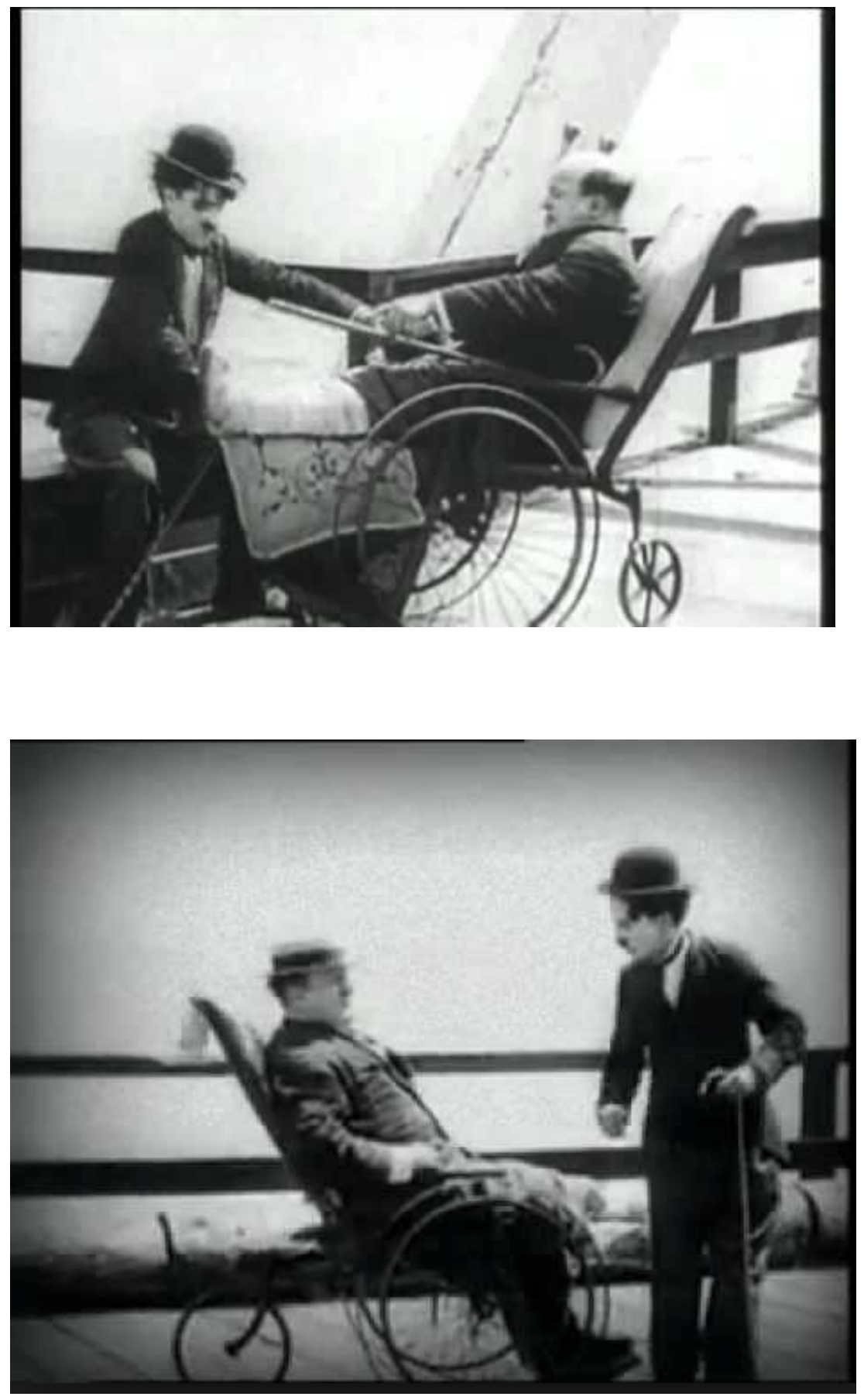

Figure 28. Screen shots, The Good for Nothing (1914), Charlie Chaplin and Jess Dandy, Keystone Films,

https://archive.org/details/CC_1914_08_31_TheGoodforNothing. 


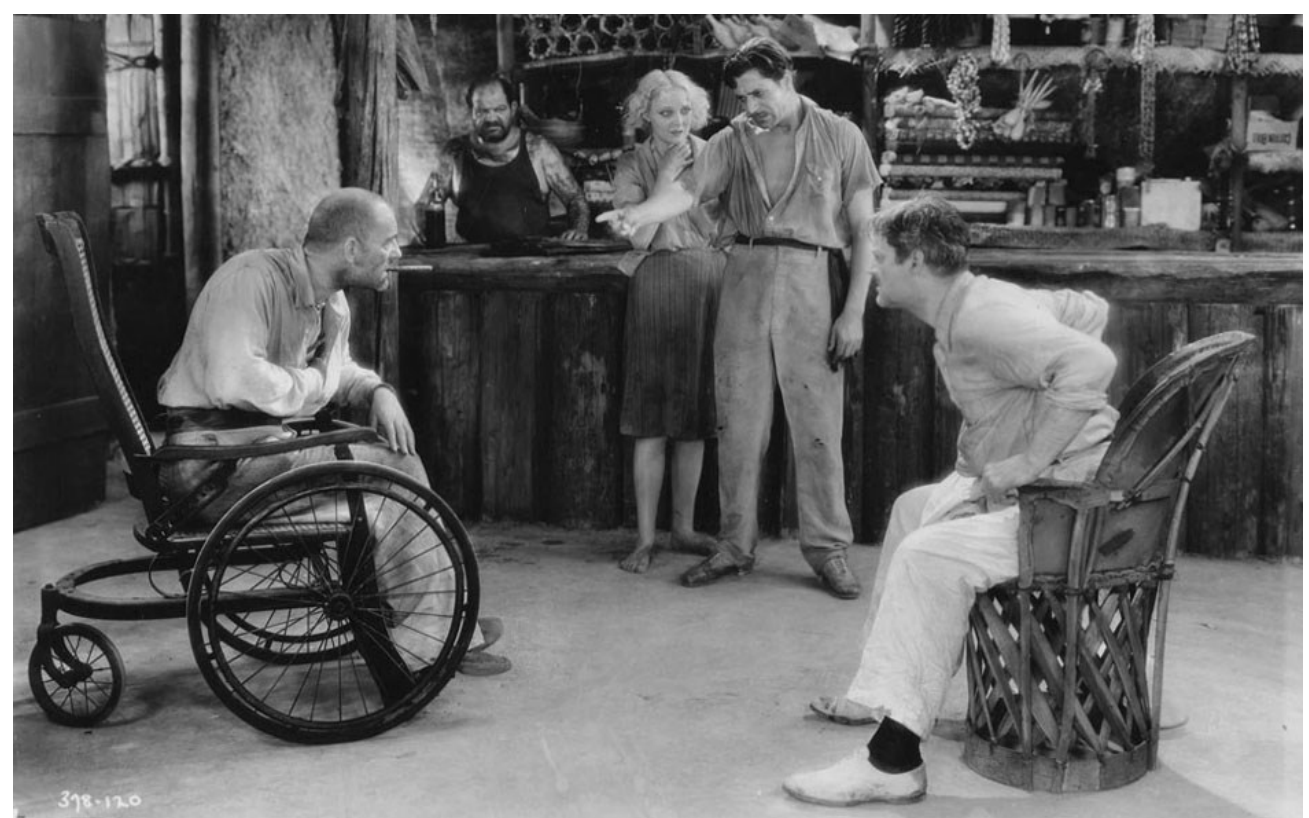

Figure 29. Publicity still from West of Zanzibar (1928). Lon Chaney is in the wheelchair, Lionel Barrymore in chair on right. Standing, Warner Baxter and Mary Nolan. http://www.eastmanhouse.org/museum/publications/annualreport/2010/media/7-1.jpg.

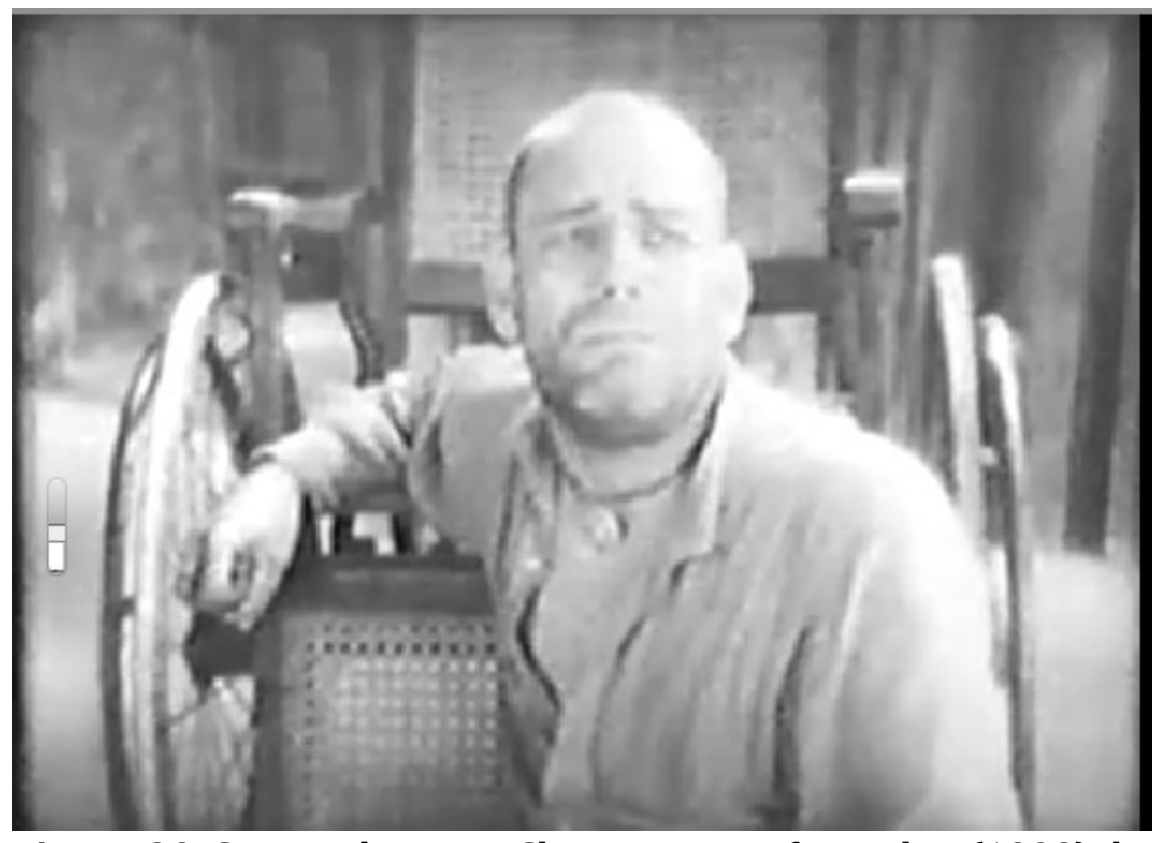

Figure 30. Screen shot, Lon Chaney, West of Zanzibar (1928) directed by Tod Browning, 1928, Metro Goldwyn Mayer. 


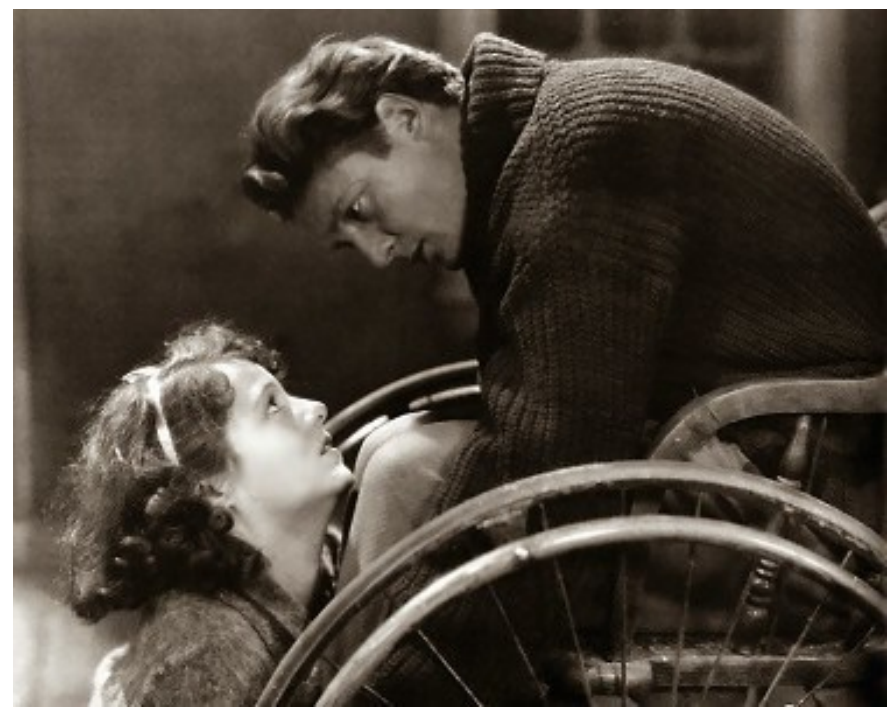

Figure 31. Screen shot Lucky Star (1929), Janet Gaynor and

Charles Farrell, directed by Frank Borzage, Fox Film, "Golden Silents," http://www.goldensilents.com/stars/luckystar1.jp.

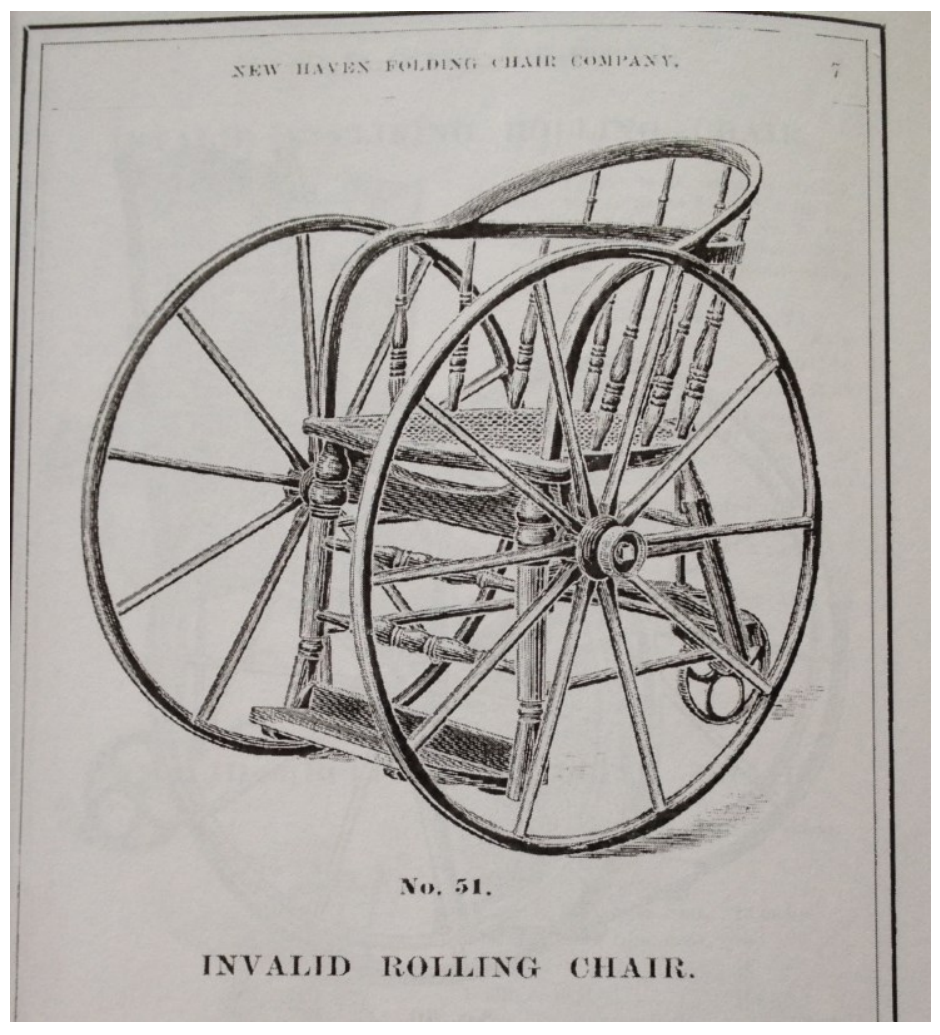

Figure 32. Seventeenth Annual Illustrated New Haven Folding Chair Catalogue ad Price List of Folding Chairs and Invalid Rolling Chairs (New Haven: The Company) 1879, 7. 


\section{DIMENSIONS.}

Height of back from seat......201/2 inches.

Height of seat from floor........21

Height of seat from foot-board.. $17 \%$

Height of arms from seat....... $9 \%$

Depth of seat................18

Width of seat between arms.... $18 \% / 4$

Diameter of front wheels......28

Diameter of rear wheel.........10

Width over all..............29

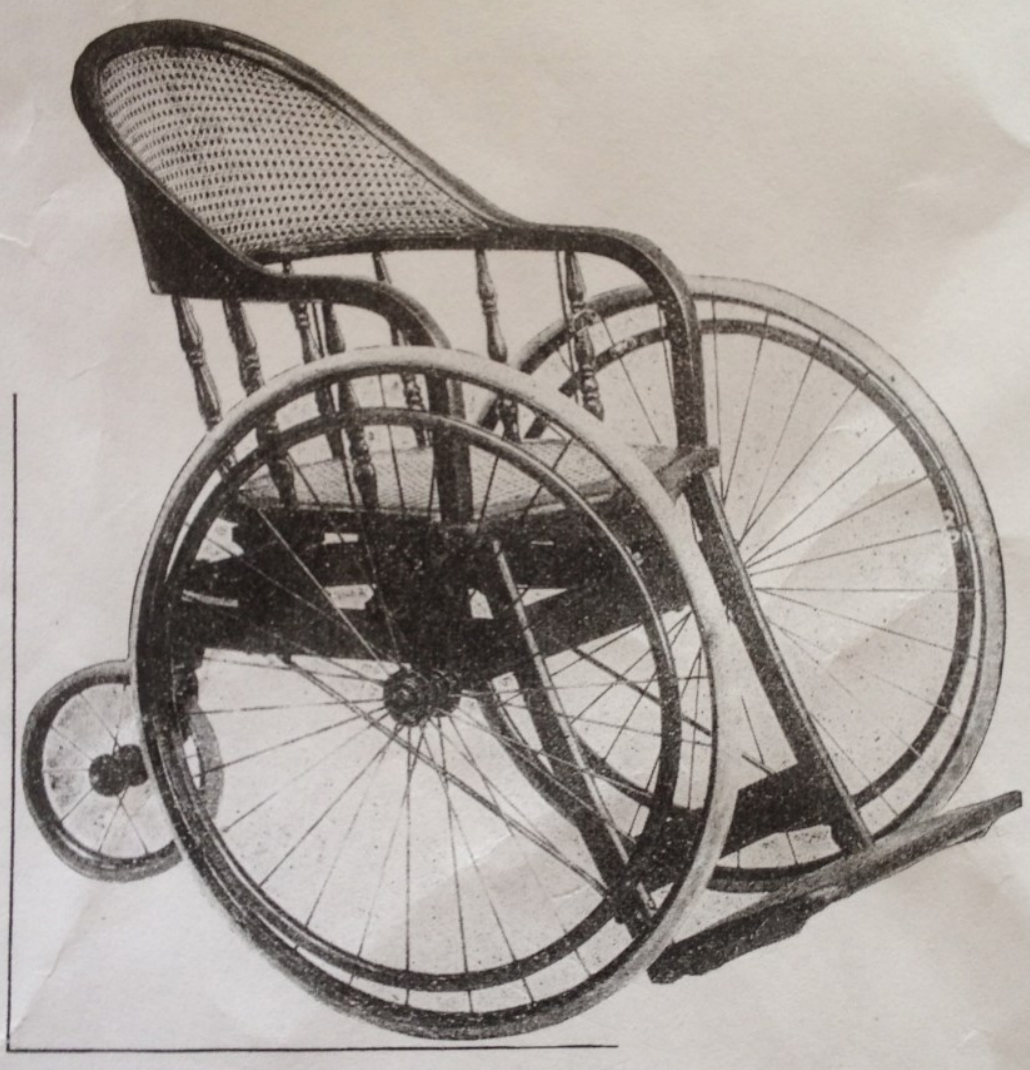

FIXED ROLLING CHAIR.

With Bow Frame, no Springs, and One Rear Swivel Wheel.

Figure 33. Wheelchair pictured in Gordons' Invalid Chairs catalog, c. 1900-1910, NMAH Trade Literature Collection, Smithsonian Institution, Washington, DC, 42. 

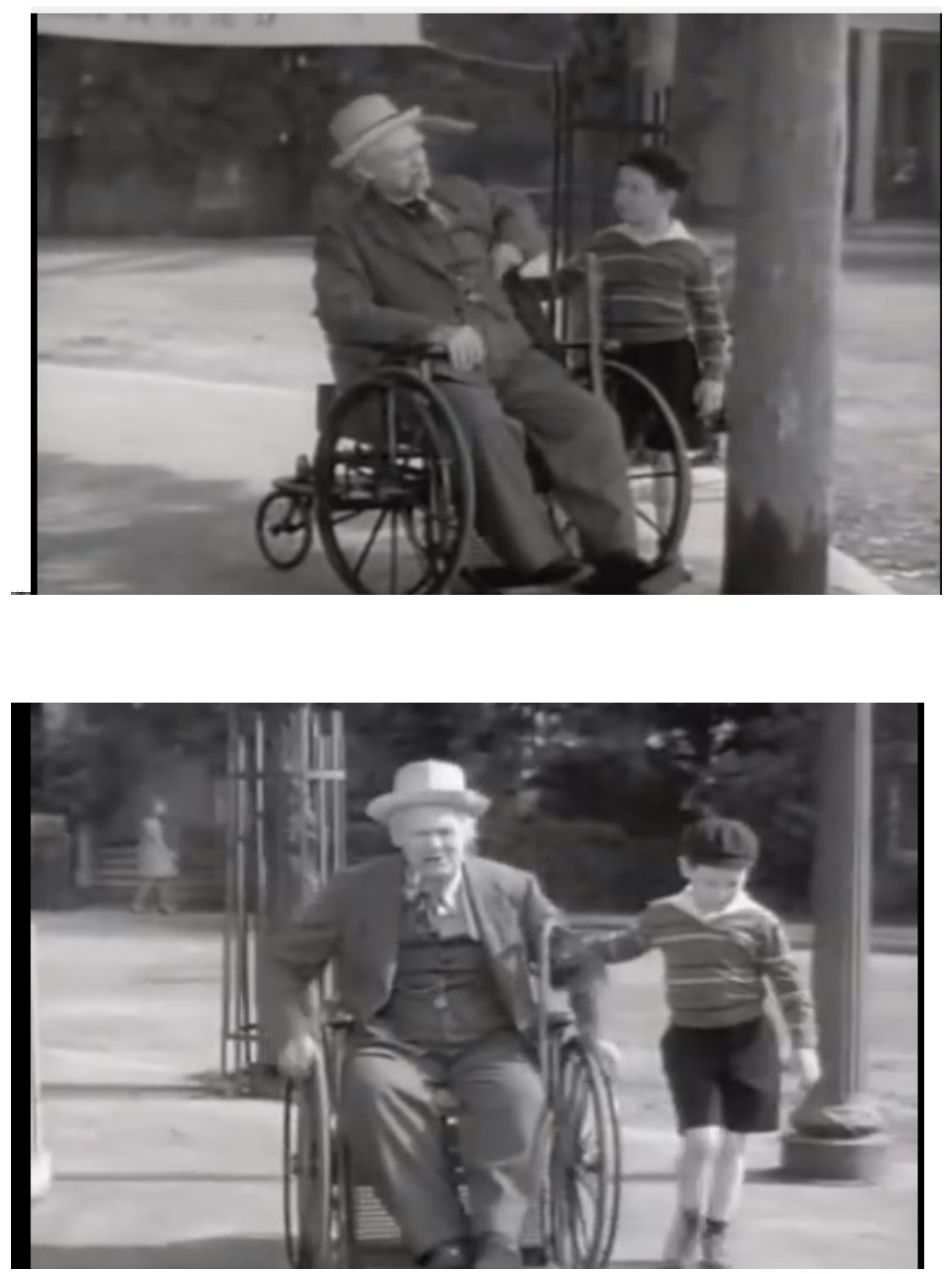

Figure 34. Screen shots, On Borrowed Time (1939), Lionel Barrymore and Bobs Watson directed by Harold S. Bucquet, Metro Goldwyn Mayer. 
$A$ LL of the newest and most desirable features A are to be found in these folding chairs. The seats and back are padded with loam rubber and ubular steel frame is exceptionally strong and irid. Foot boards fold for ease in enterisg and gid. loot bords fold tor eas in an in

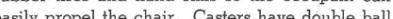

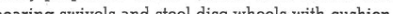
ther ubler solished chrome plated hish on all melal parts or lark blue.

Two styles are available-one with the large vheels in front recommended for use indoors for

and the other with the

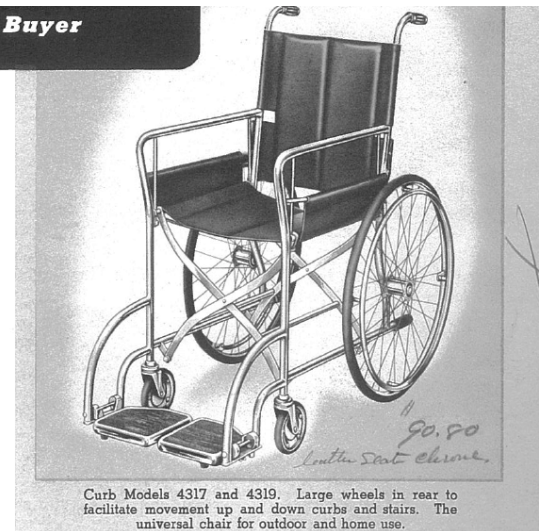

Figure 35. A typical folding wheelchair from the period, Colson catalog, 1948, NMAH Trade Literature Collection, Smithsonian Institution, Washington, DC.

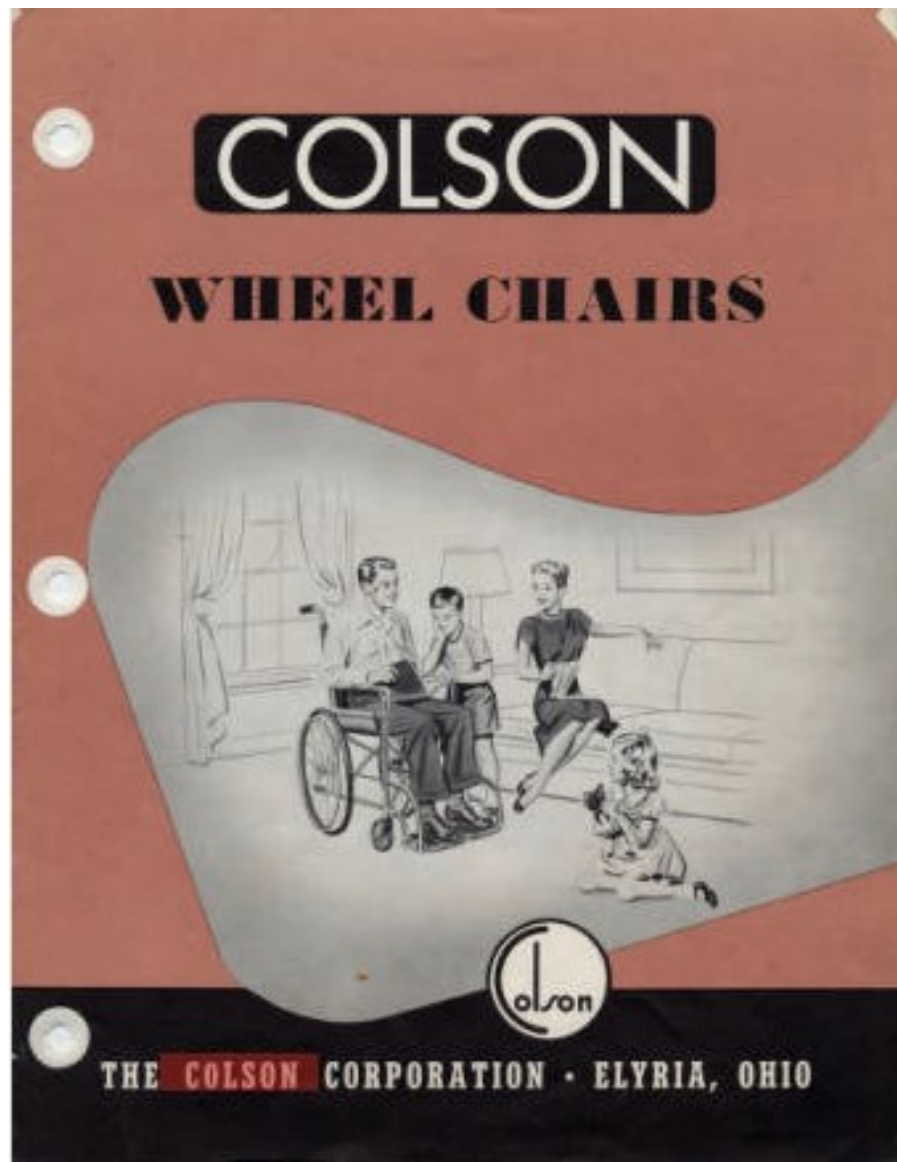

Figure 36. Cover of Colson catalog, 1948, Colson

Corporation Collection, 1982.058, www.ohiomemory.org. 


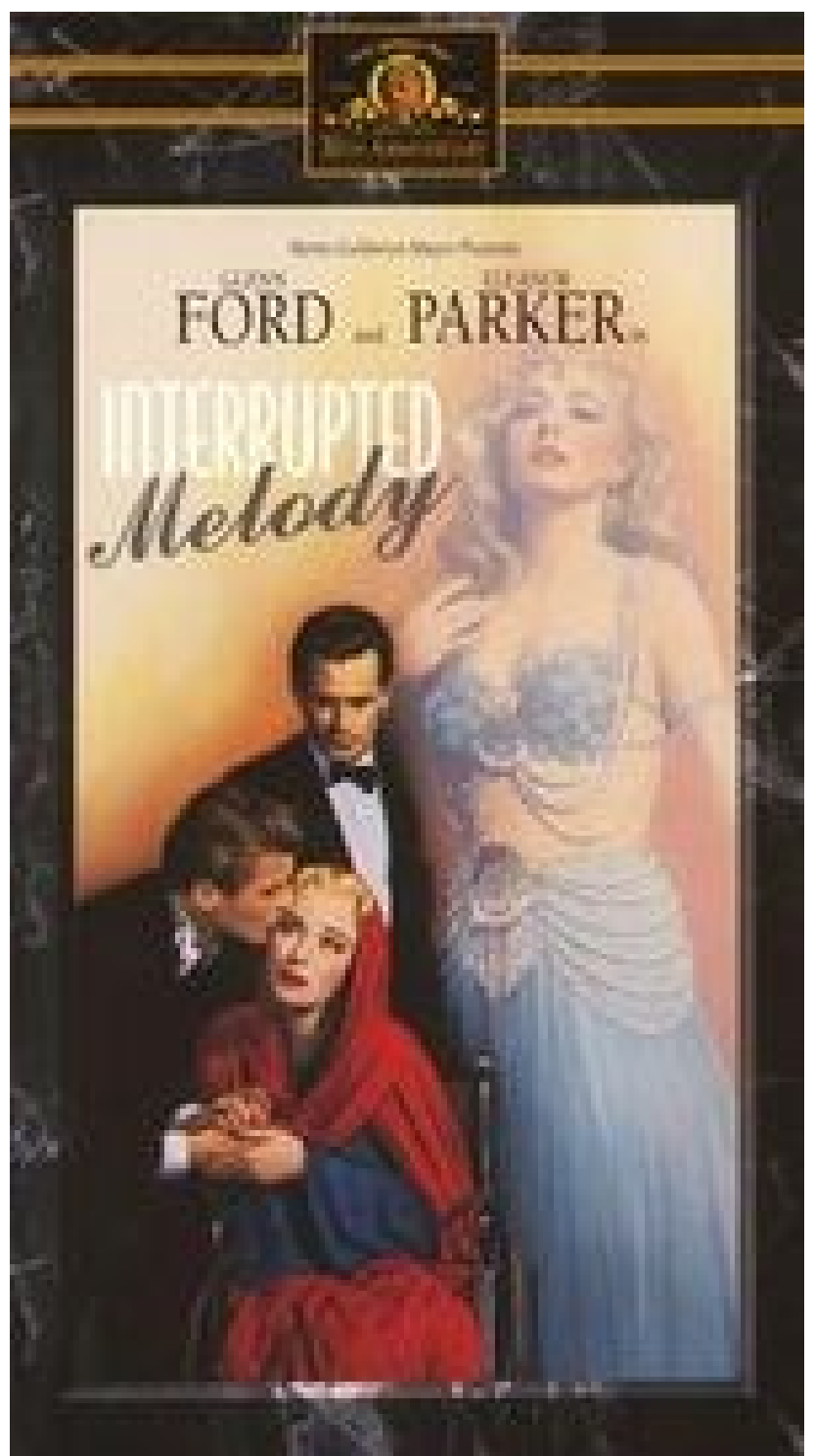

Figure 37. Poster for Interrupted Melody (1955)

Eleanor Parker and Glenn Ford, directed by Curtis Bernhardt, Metro Goldwyn Mayer, http://www.rottentomatoes.com. 

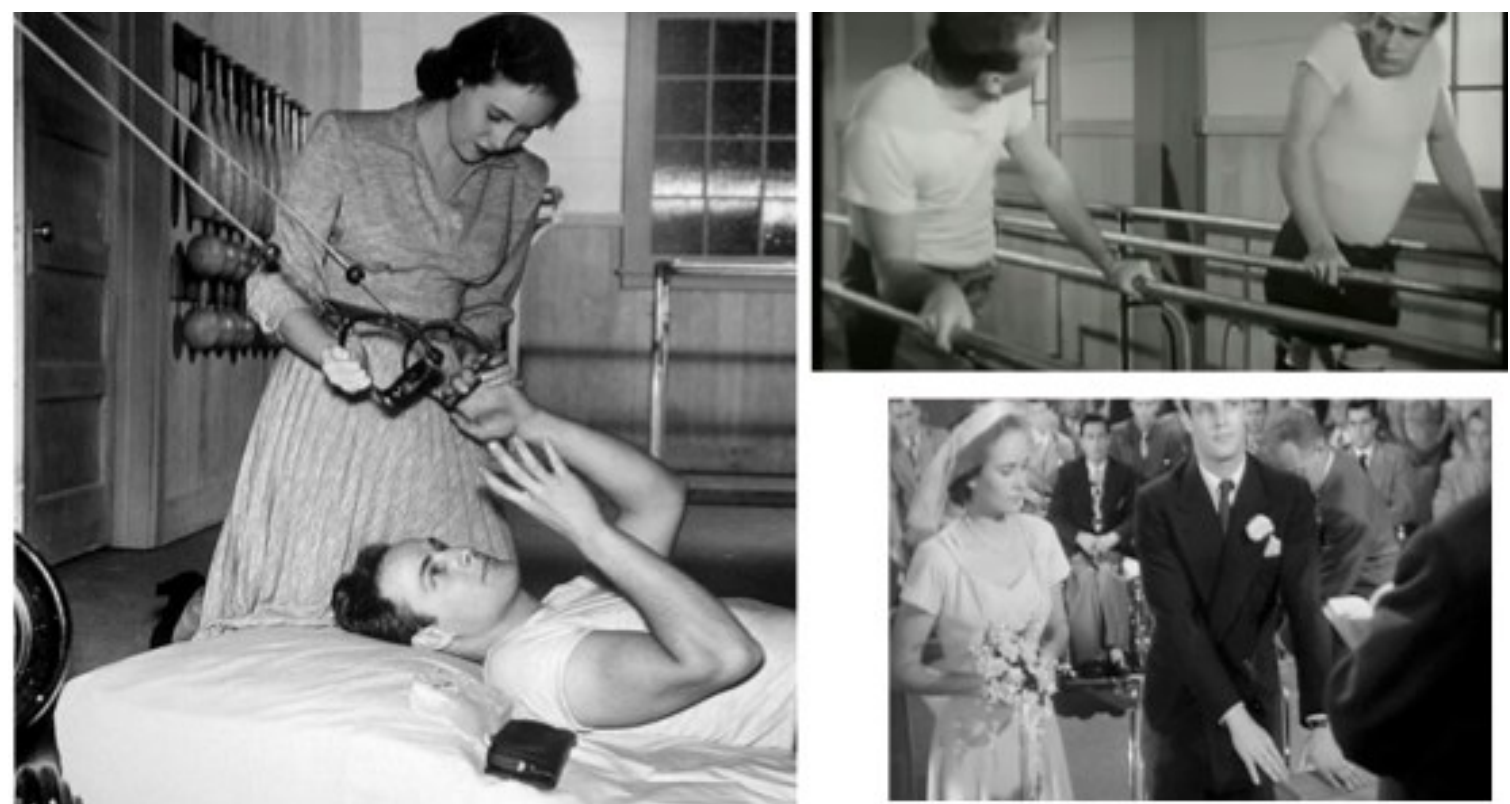

Figure 38. Screen shots from The Men (1950), with Marlon Brando and Teresa Wright, directed by Fred Zinnemann, Stanley Kramer/United Artists.

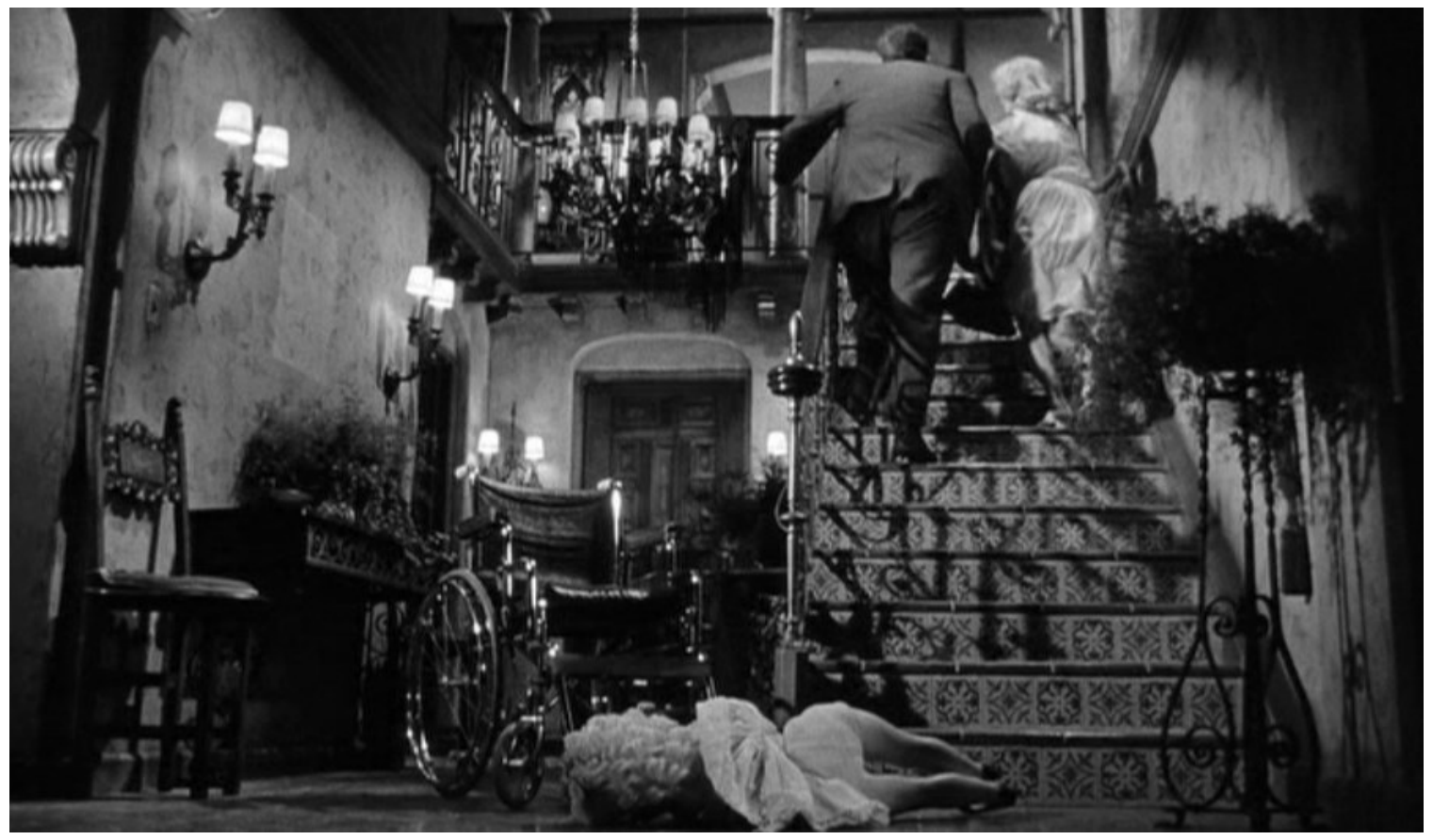

Figure 39. Screen shot from Whatever Happened to Baby Jane? (1962), Bette Davis and Victor Buono, directed by Robert Aldrich, Warner Brothers. 


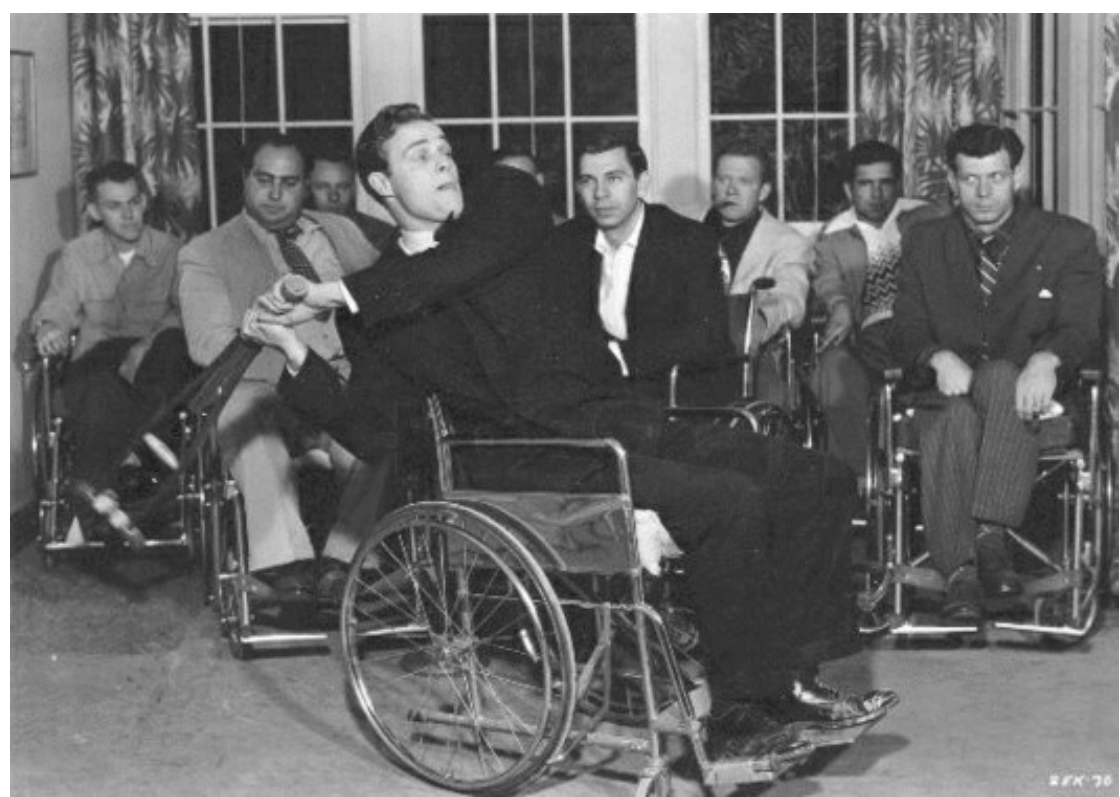

Figure 40. Screen shot, The Men (1950), Marlon Brando, directed by Fred Zinnemann, Stanley Kramer/United Artists.
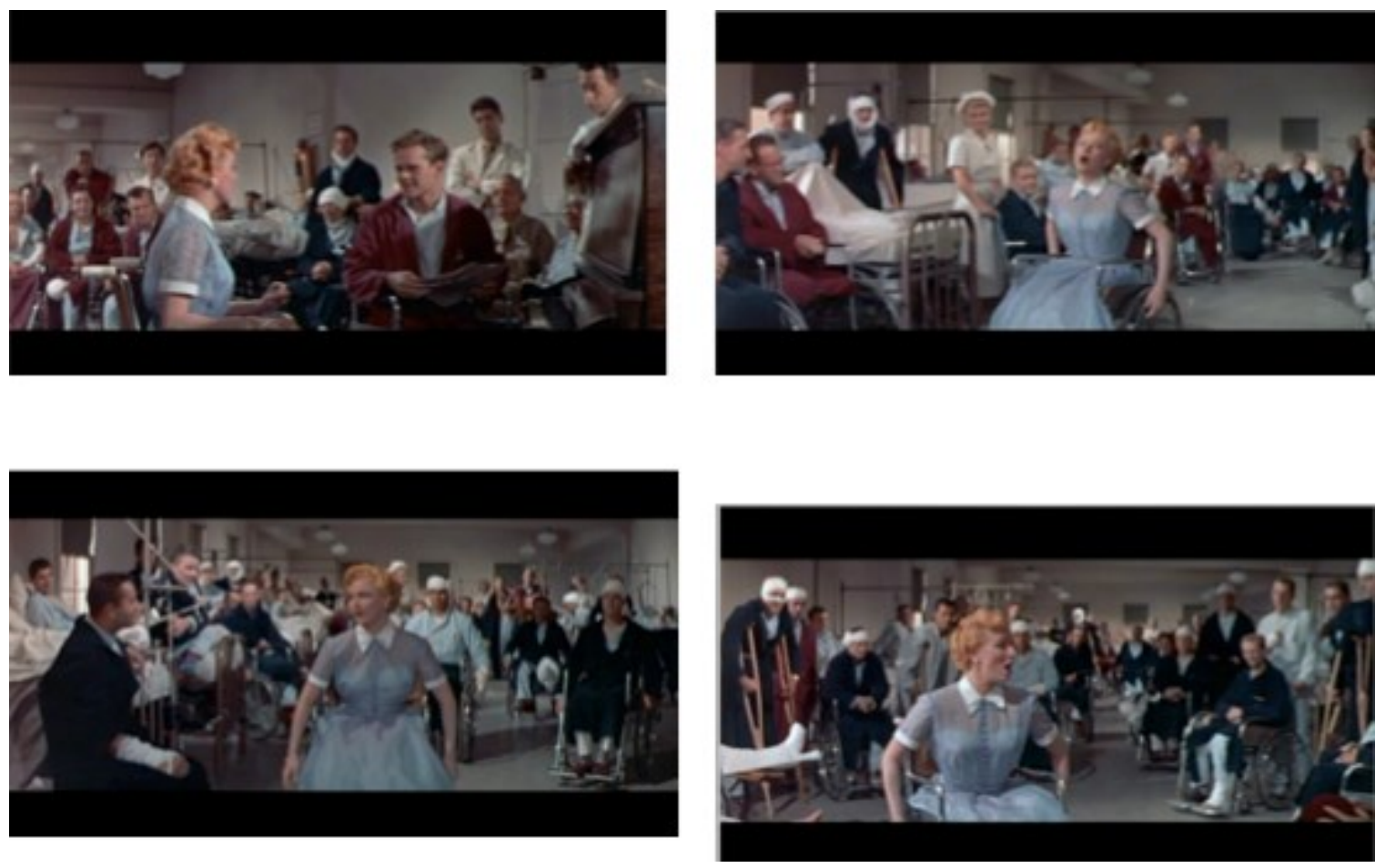

Figure 41. Screen shots, Interrupted Melody (1945), Eleanor Parker, directed by Curtis Bernhardt, Metro Goldwyn Mayer. 

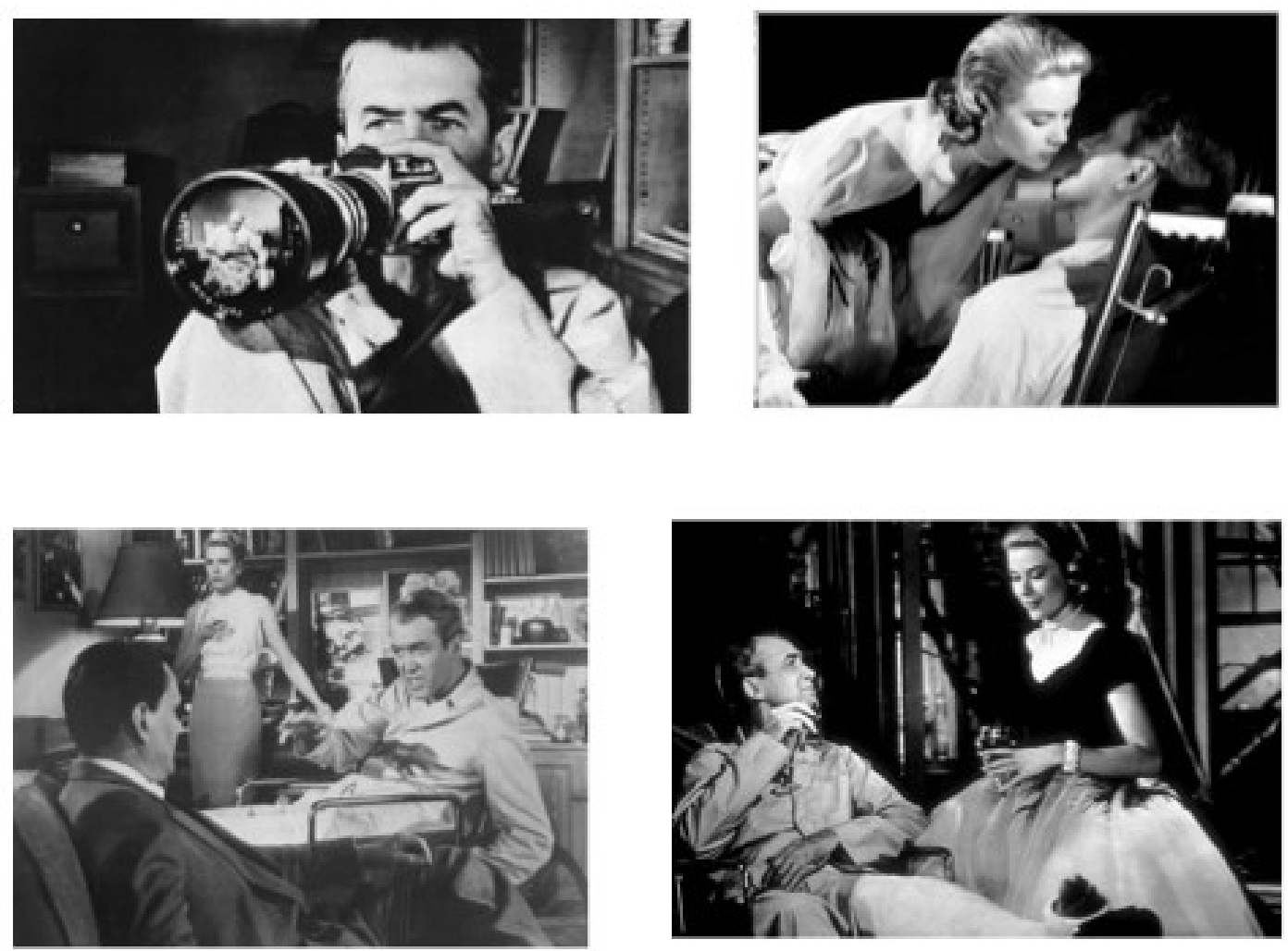

Figure 42. Screen shots, Rear Window (1954), James Stewart and Grace Kelly, directed by Alfred Hitchcock, Paramount. 


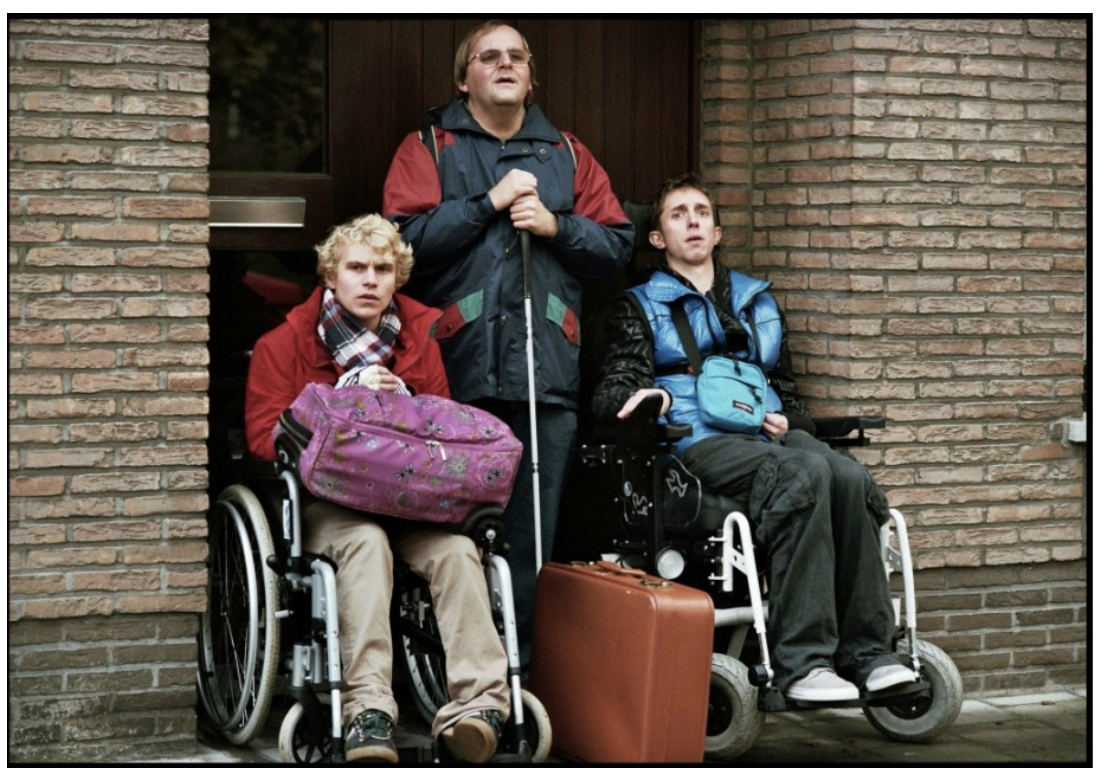

Figure 43. Screen shot, Come as You Are (Belgium, 2011), from left, Gilles De Shrijver, Tom Audenaert, and Robrecht Vanden Thoren, directed by Geoffrey Enthoven, Kinepolis Film.

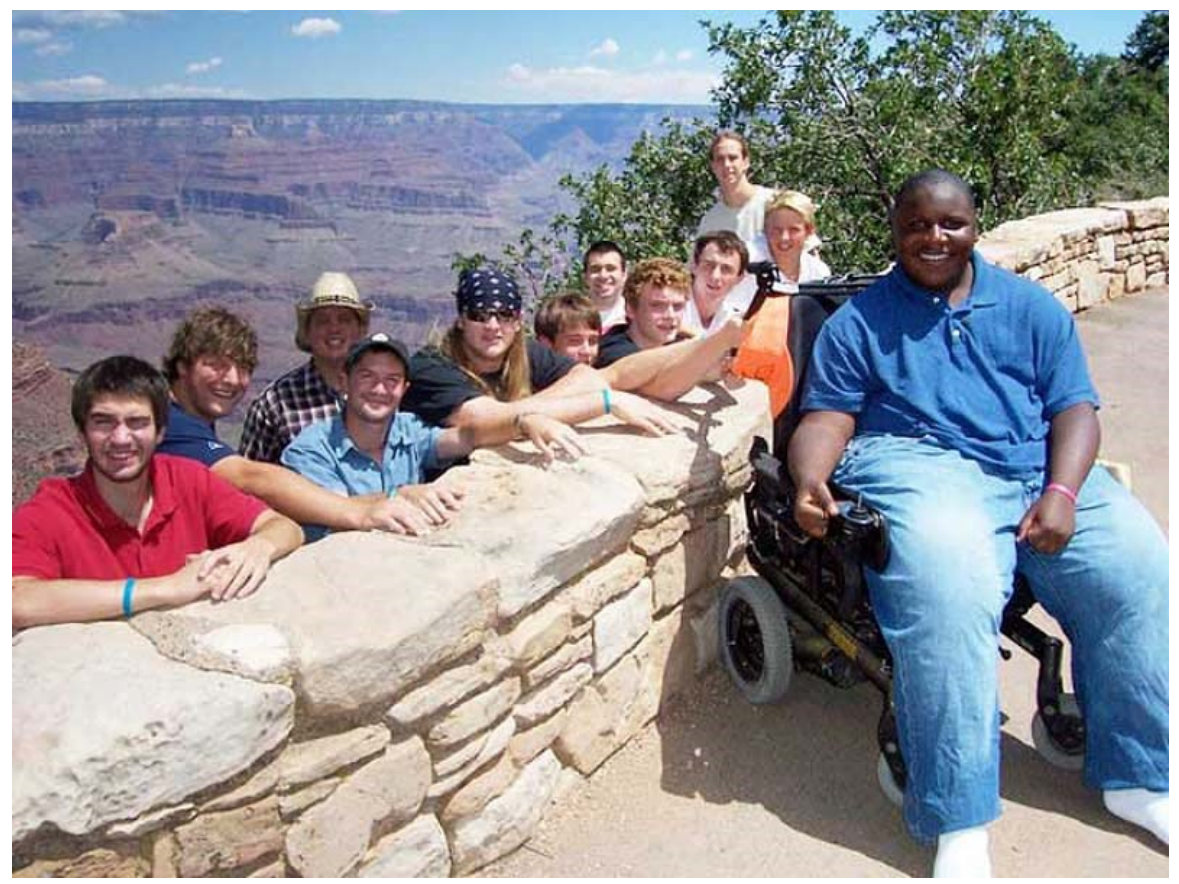

Figure 44. Darius Weems and his friends at the Grand Canyon. Darius Goes West: The Roll of His Life (2007), directed by Logan Smalley. http://gussiedup.files.wordpress.com/2010, accessed April 7, 2014. 


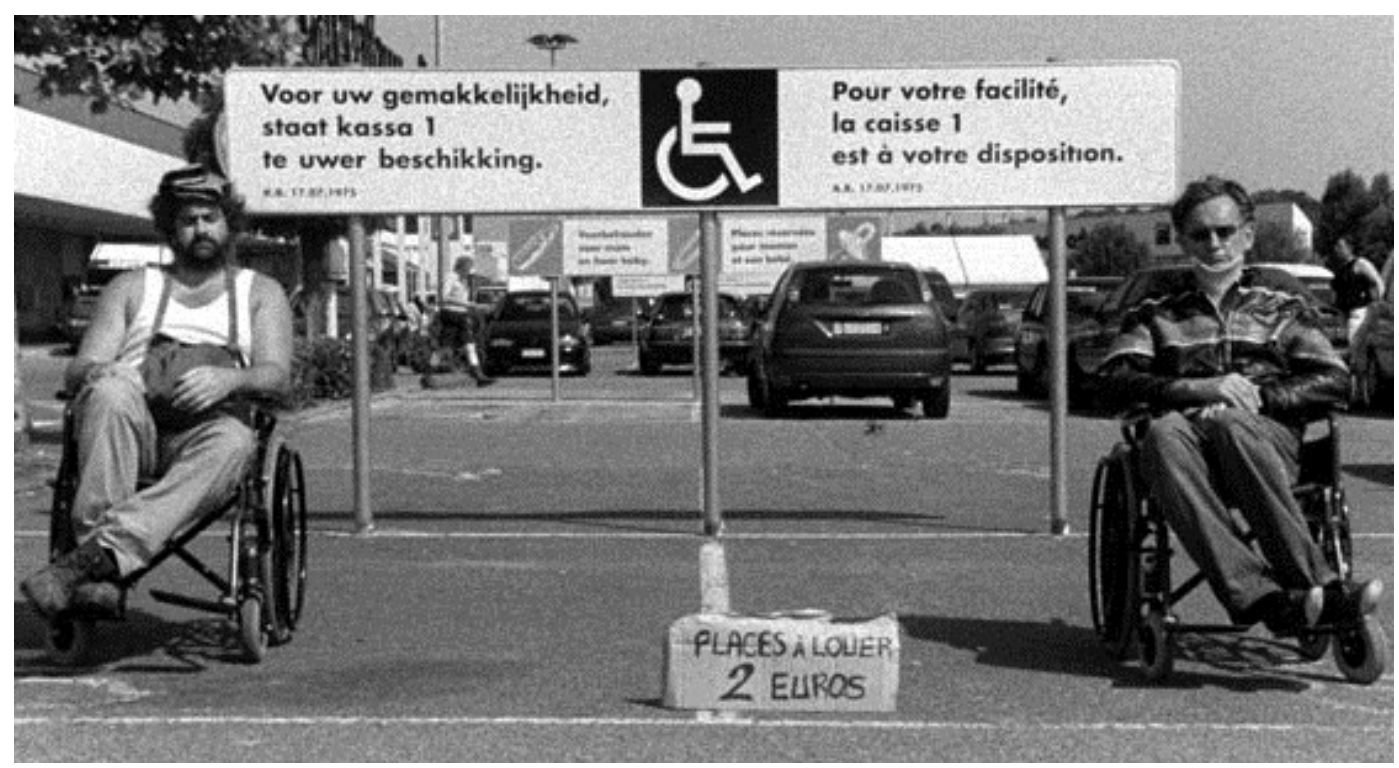

Figure 45. Screen shot, Aaltra (Belgium, 2004), Gustave de Kevern, Benôit Delépine, actors and directors, Film Movement.

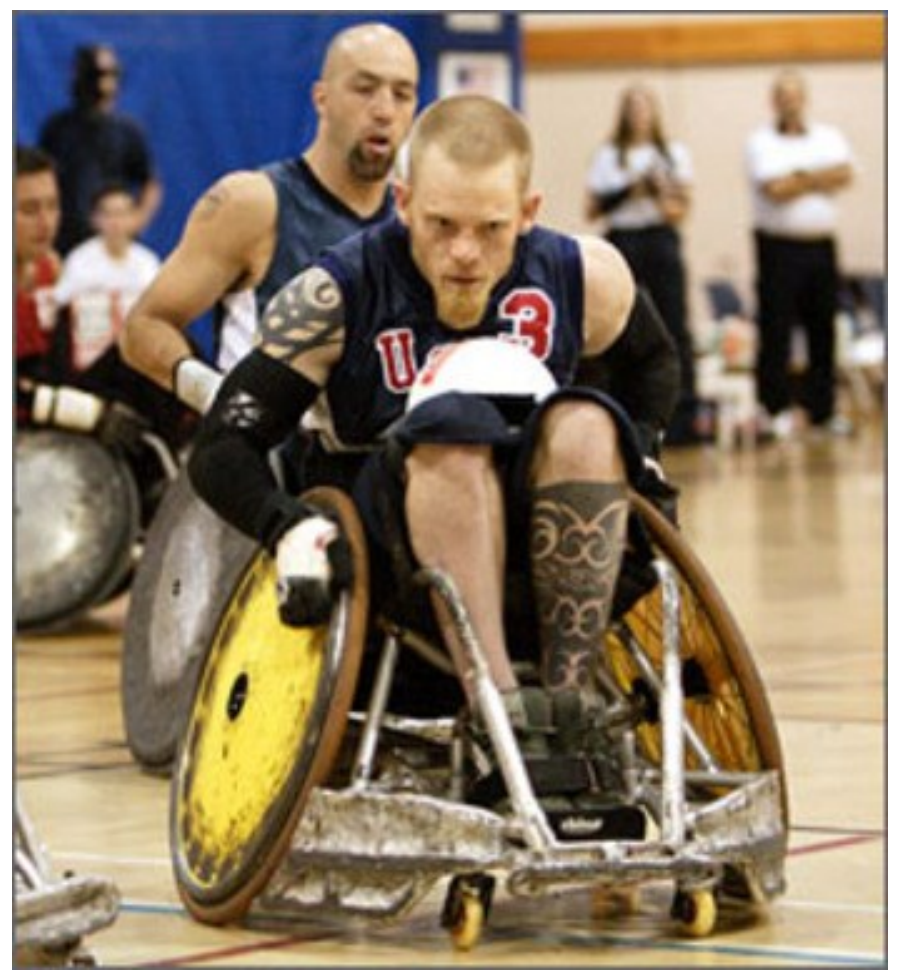

Figure 46. Screen shot, Murderball (2005), Mark Zupan, Directed by Henry Alex Rubin, Dana Adam Shapiro, Paramount/MTV Film. 


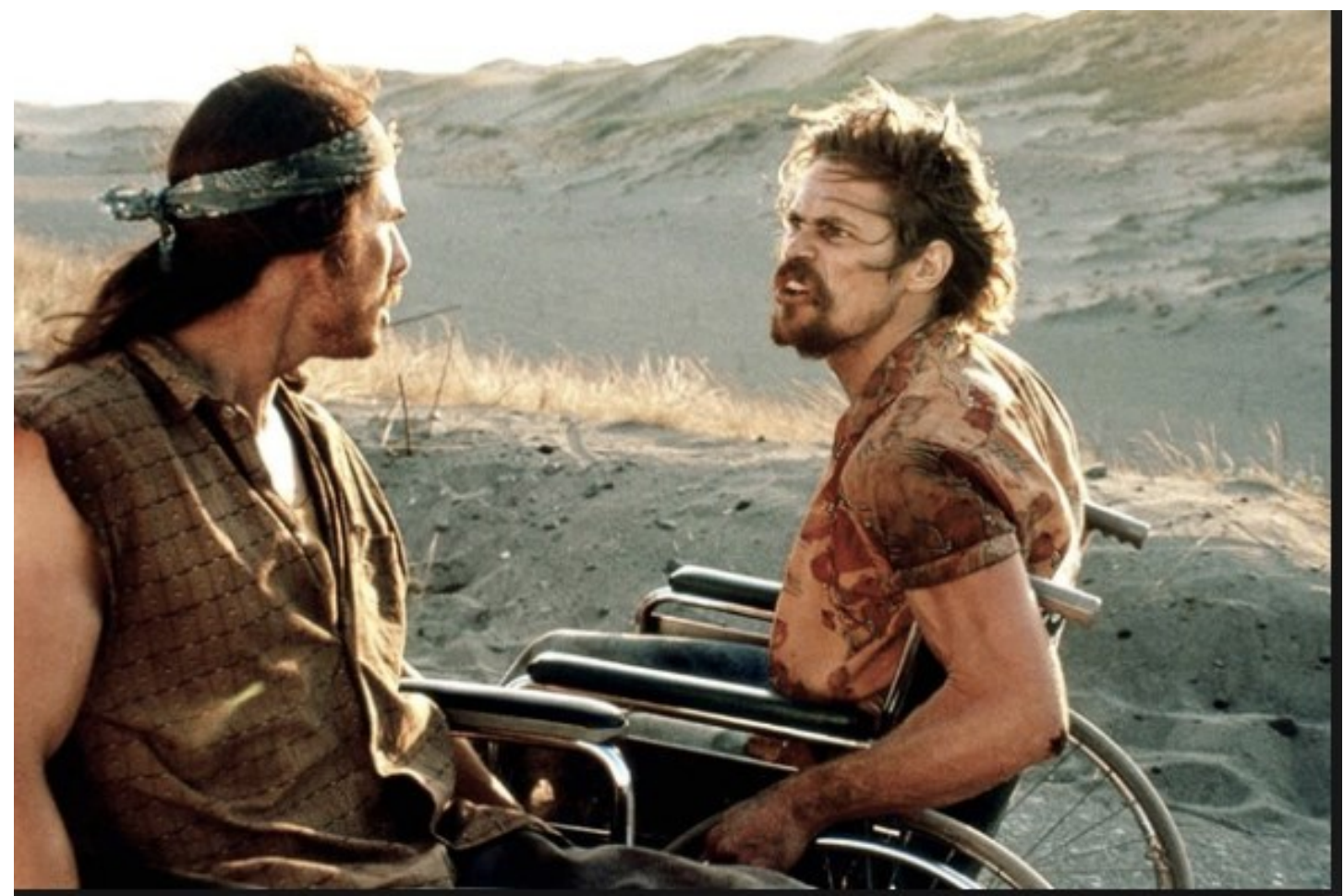

Figure 47. Screen shot, Born on the Fourth of July (1989). Tom Cruise and Willem Dafoe, directed by Oliver Stone, Universal Pictures.

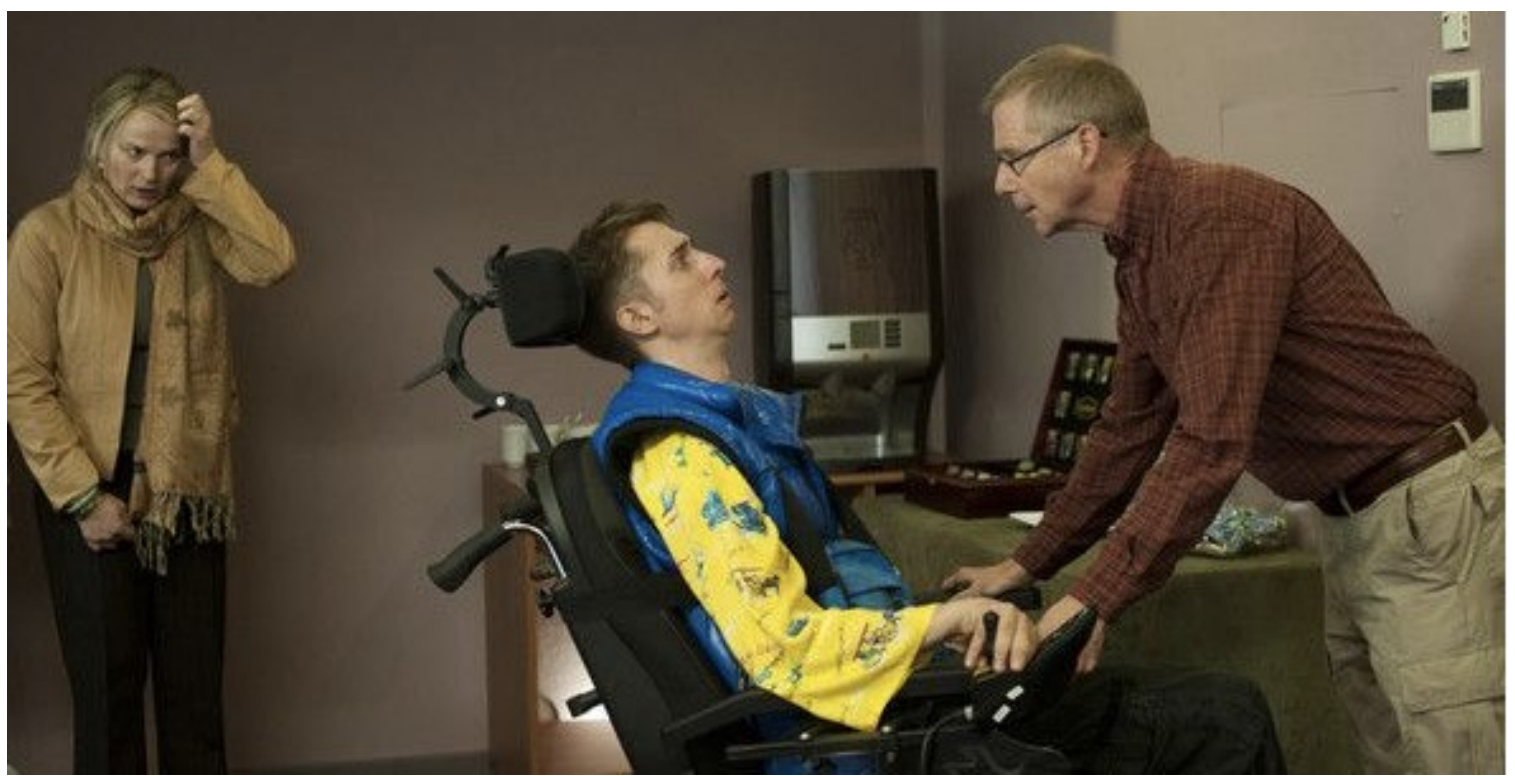

Figure 48. Screen shot, Come as You Are (Belgium, 2011), Robrecht Vanden Thoren as Philip and Karl Vingenhoets as his father, directed by Geoffrey Enthoven, Kinepolis Film. 


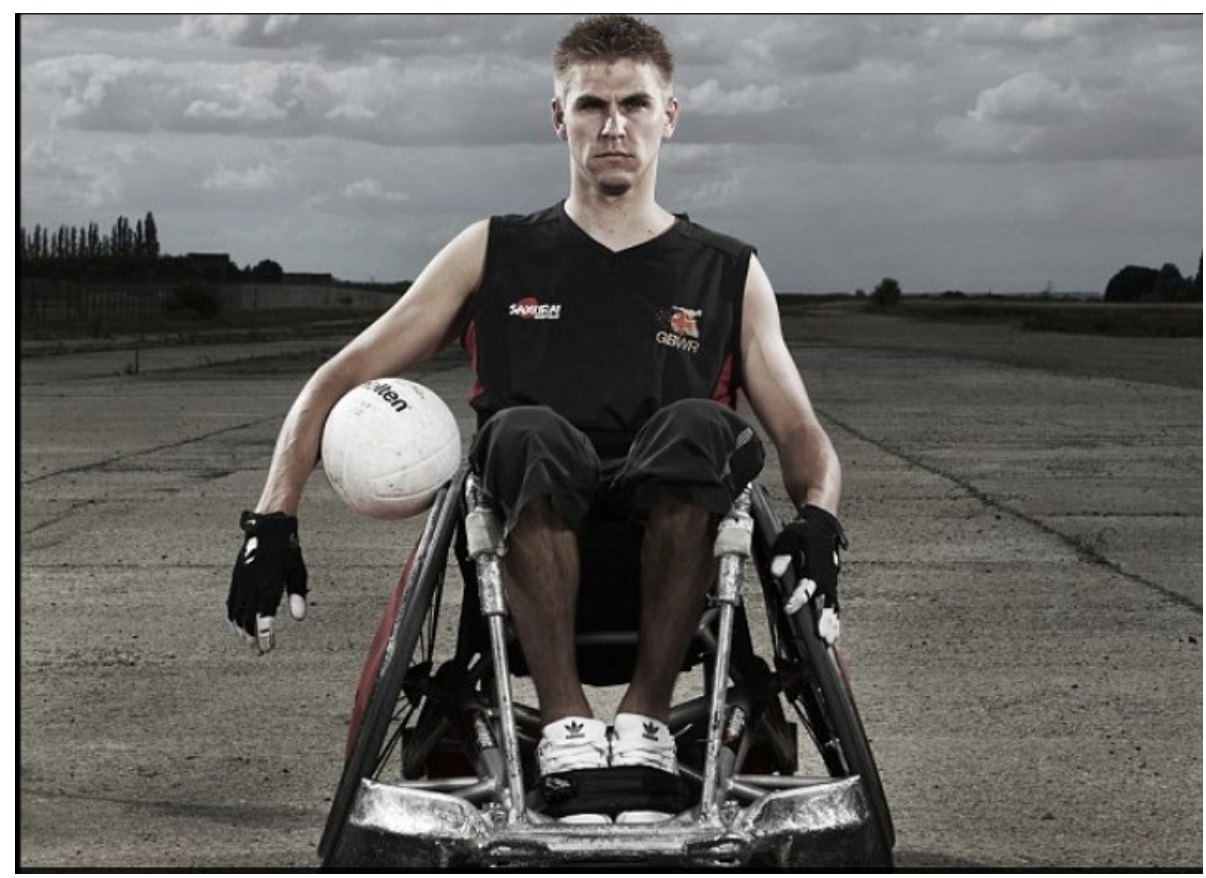

Figure 49. Paralympian Steve Brown, Daily Mail Online, posted September 8, 2012, accessed May 7, 2014, http://www.dailymail.co.uk.

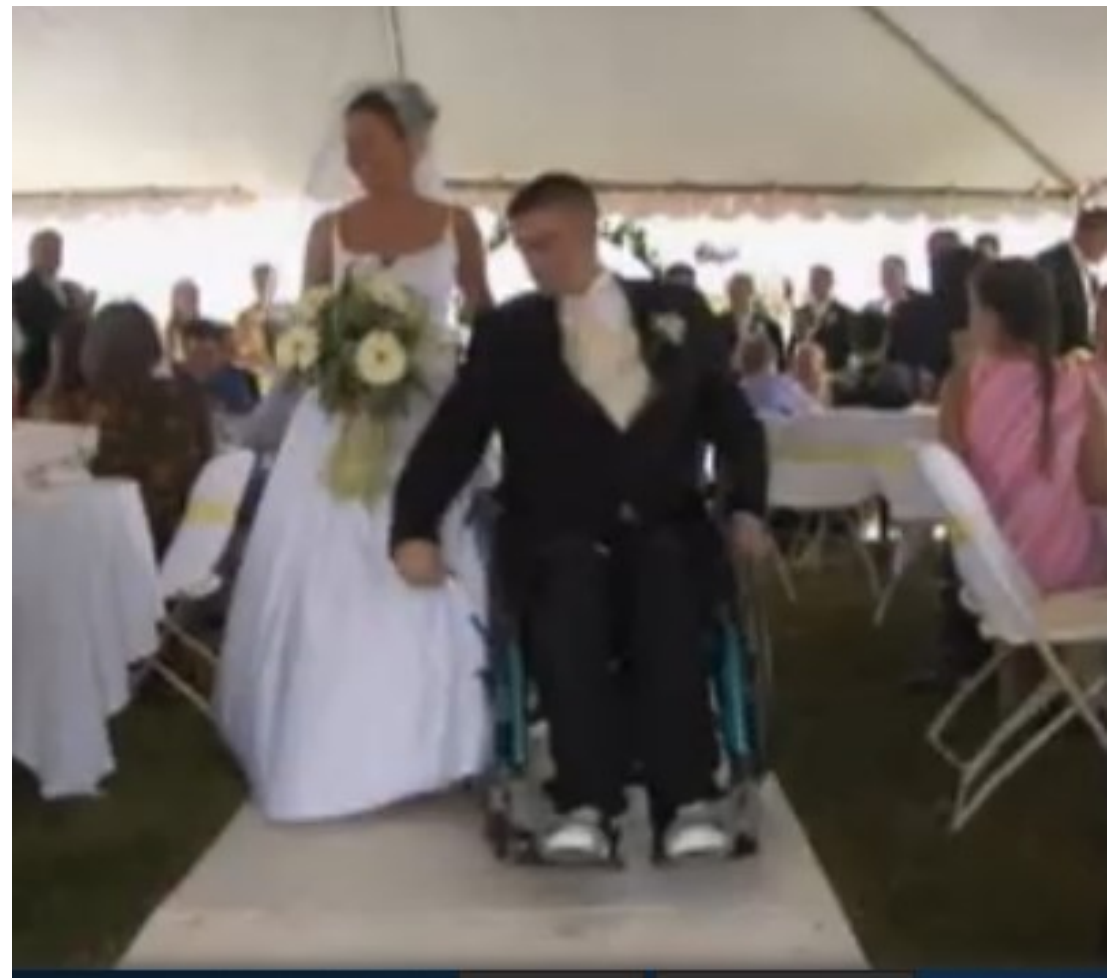

Figure 50. Screen shot, Body of War (2007), Tomas Young and wife, directed by Ellen Spiro and Phil Donahue, Mobius/Phil Donahue Enterprises. 


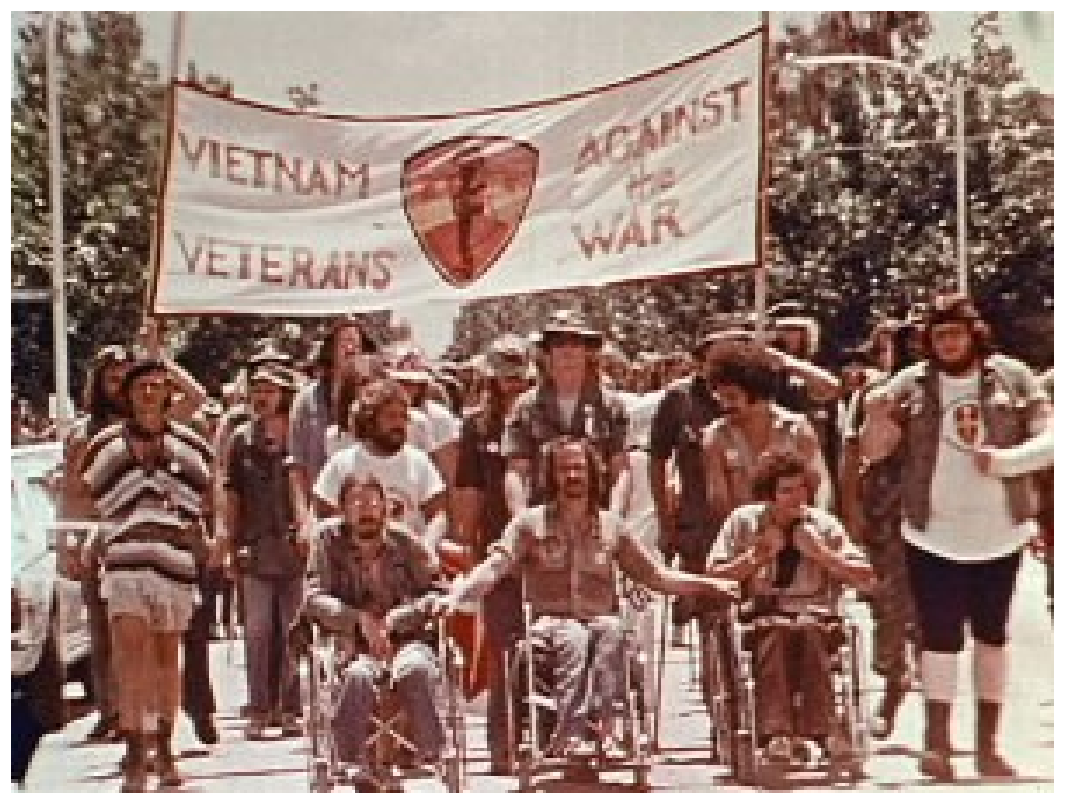

Figure 51. Screen shot, Operation Last Patrol (1972, Ron Kovic

(center), directed by Catherine Leroy and Frank Cavestani, Cinema Libre.

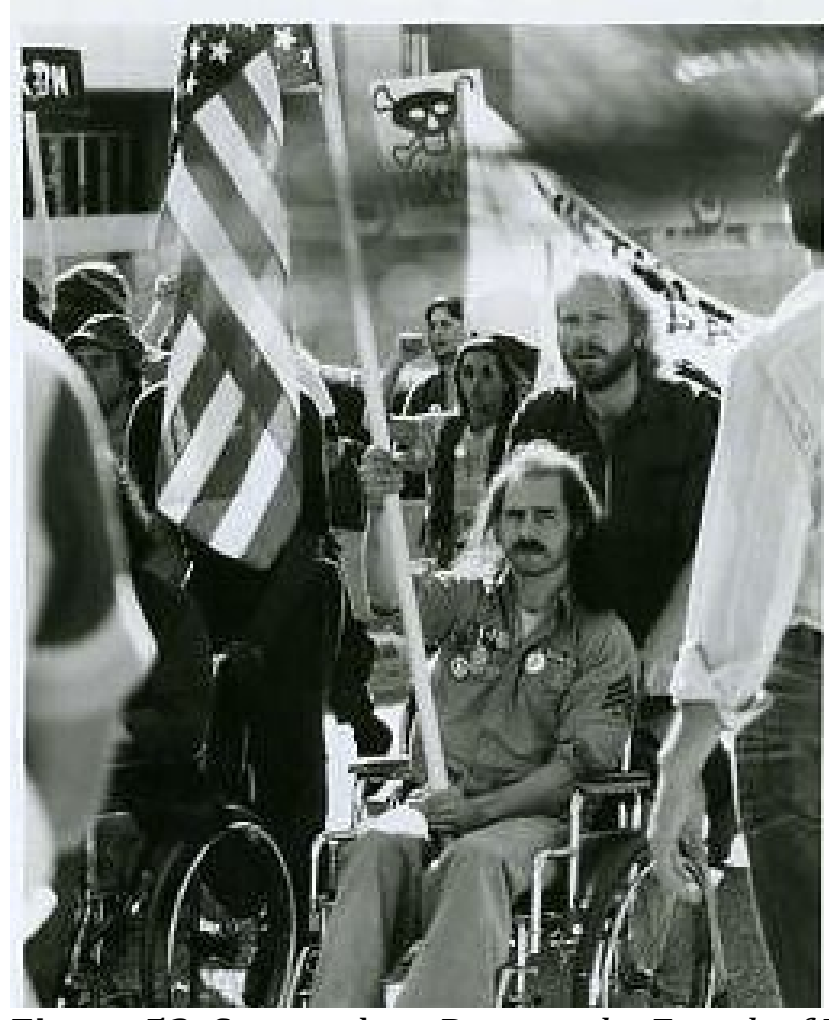

Figure 52. Screen shot, Born on the Fourth of July (1989), Tom Cruise, directed by Oliver Stone, Universal Pictures. 


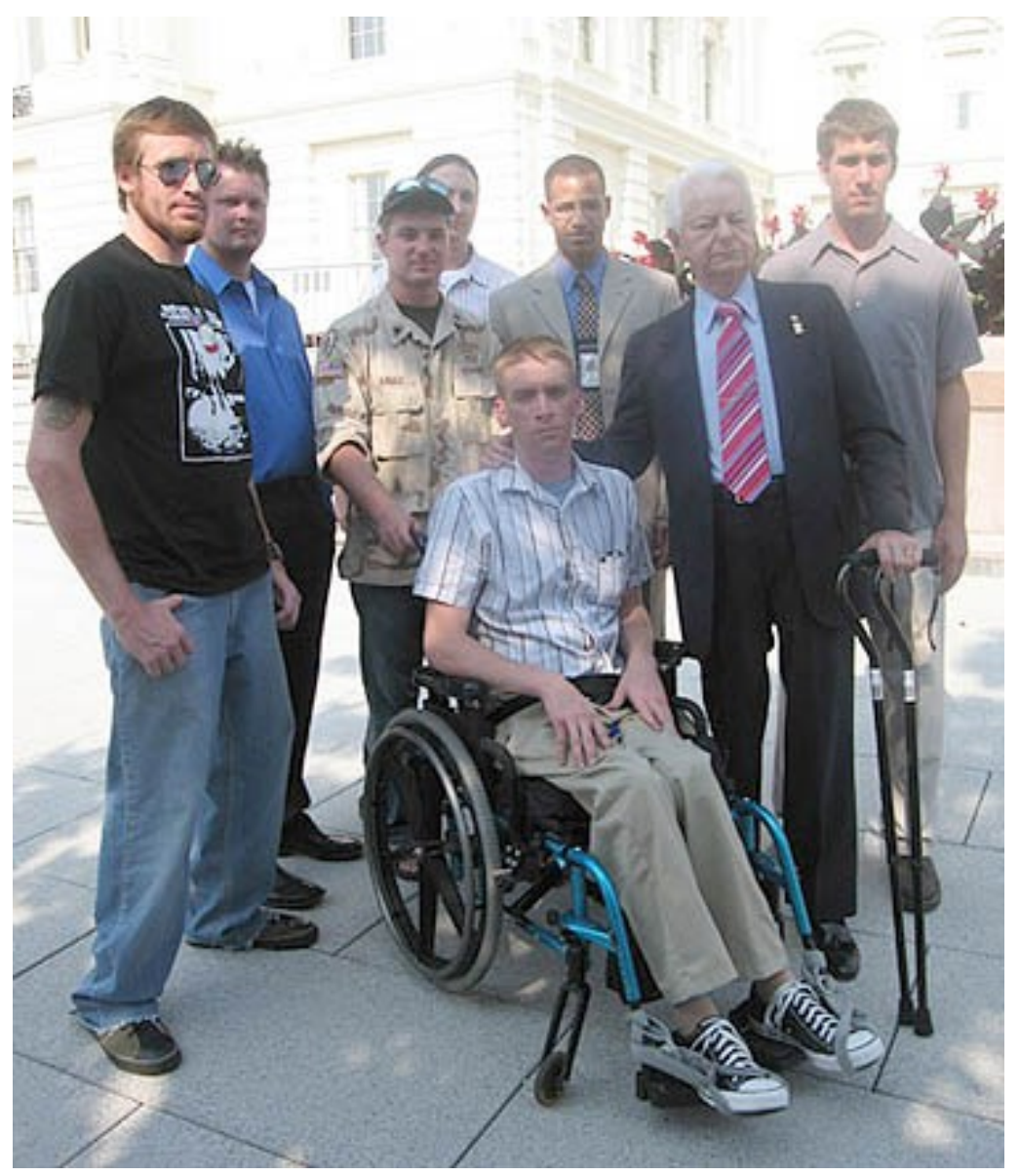

Figure 53. Tomas Young and Senator Robert Byrd, with others, in Washington, DC, "Phil Donahue's 'Body of War,"” Hamptons.com, posted October 22, 2007, accessed May 7, 2014, www.hamptons.com. 